OECDpublishing

STRUCTURAL

ADJUSTMENT,

MASS LAY-OFFS

AND EMPLOYMENT

REALLOCATION

OECD SCIENCE, TECHNOLOGY AND INDUSTRY

POLICY PAPERS

May 2019 No. 72 
The document was approved and declassified by written procedure by the Committee on Industry, Innovation and Entrepreneurship on 24 December 2018 and prepared for publication by the OECD Secretariat.

This report has been prepared by Filipe Silva (OECD/STI/SPD), Carlo Menon (OECD/STI/SPD), Paolo Falco (OECD/ELS/SAE) and Duncan MacDonald (OECD/ELS/SAE).

Note to Delegations:

This document is also available on O.N.E under the reference code:

DSTI/CIIE(2018)2/FINAL

This document, as well as any data and any map included herein, are without prejudice to the status of or sovereignty over any territory, to the delimitation of international frontiers and boundaries and to the name of any territory, city or area.

(C) OECD 2019

You can copy, download or print OECD content for your own use, and you can include excerpts from OECD publications, databases and multimedia products in your own documents, presentations, blogs, websites and teaching materials, provided that suitable acknowledgment of OECD as source and copyright owner is given. All requests for commercial use and translation rights should be submitted to rights@oecd.org. 


\section{Structural adjustment, mass lay-offs and employment reallocation}

\section{ABSTRACT}

This report investigates the factors associated with the intensity of "mass lay-offs" across countries and industries, controlling for the dynamics of overall employment. The results suggest that some important drivers of structural transformation (e.g. digitalisation and globalisation) are not as clearly linked to mass lay-offs as one might expect, once their impact on overall job destruction is accounted for. The report also investigates the reemployability prospects of workers in sectors at high risk of mass lay-offs. Finally, the paper draws implications for different areas of policymaking, from labour market policy to industrial policy and also trade policy.

Acknowledgements: The contribution of Timothy DeStefano, Laurent Moussiegt and Cenk Yildiran to the analysis is gratefully acknowledged. The authors are also grateful to CIIE national delegates for their inputs and to Stijn Broecke, Chiara Criscuolo, Koen de Backer, Nick Johnstone, Mark Keese, Dirk Pilat, and Shruti Singh for comments on earlier versions of the draft. Angela Gosmann and Jennifer Lee contributed with editorial support. 


\section{Table of contents}

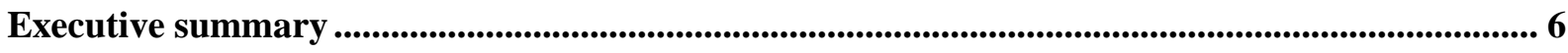

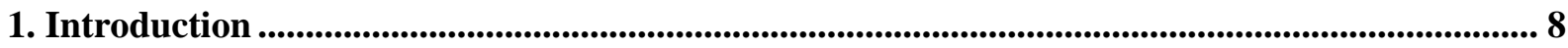

2. Mass lay-offs in the economic literature................................................................................................... 11

3. Empirical analysis of mass lay-offs .......................................................................................................... 13

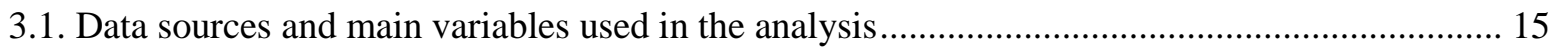

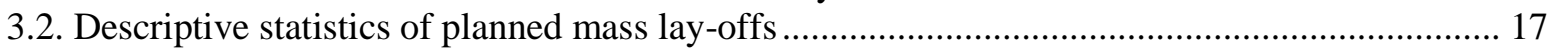

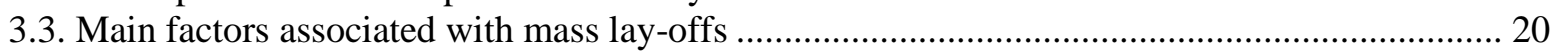

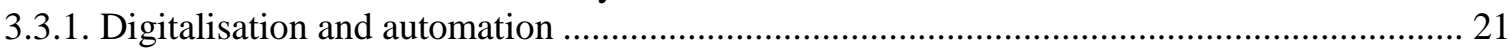

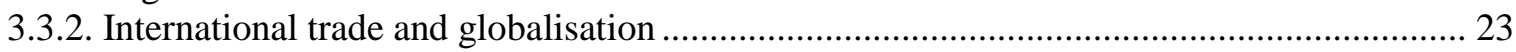

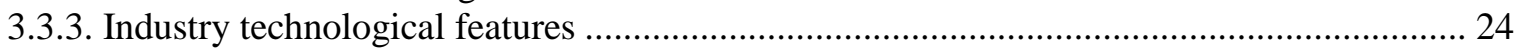

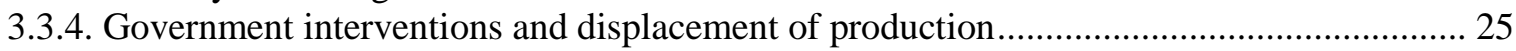

3.3.5. Employment protection legislation and trade union density ................................................ 26

3.4. The re-employability of workers moving out of different sectors ............................................. 27

3.4.1. How quickly do displaced workers find a new job?....................................................... 27

3.4.2. How big is the skills distance between workers at high-risk of mass layoff and those in other

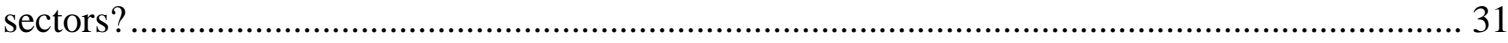

3.5. Location, location, location: which regions are most affected by ML and why? ..................... 34

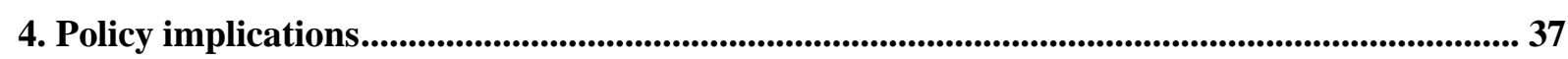

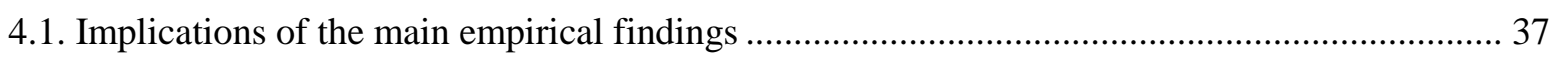

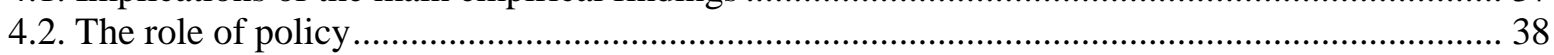

4.2.1. Helping firms: rescue and restructuring interventions, and other support policies .............. 39

4.2.2. Helping workers: training, active labour market policies and social protection ................... 40

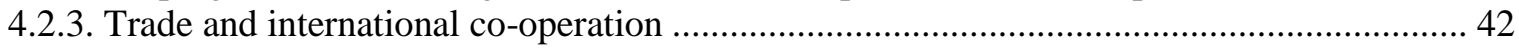

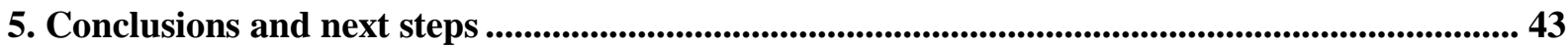

Notes ....................................................................................................................................................................................... 45

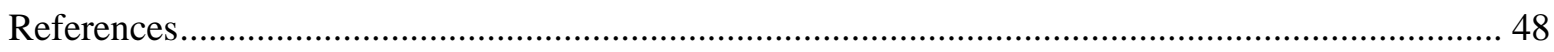

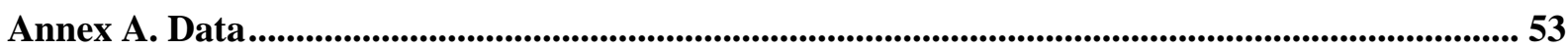

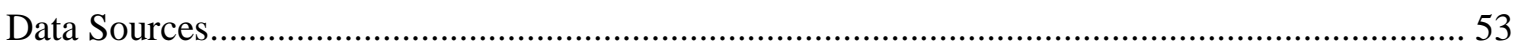

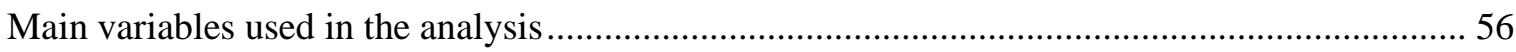

Annex B. Unemployment duration analysis: econometric model ....................................................... 62

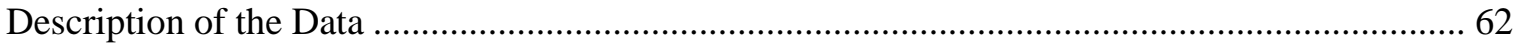

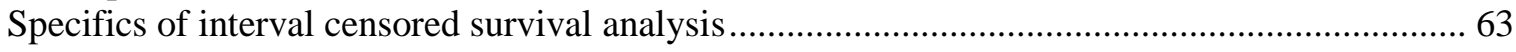

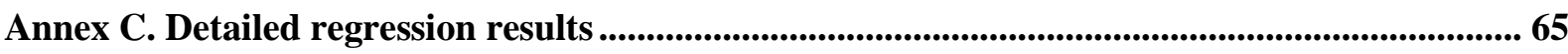

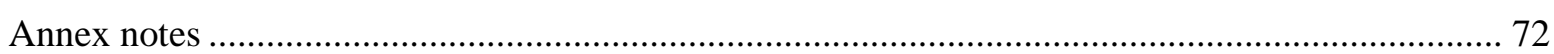




\section{Tables}

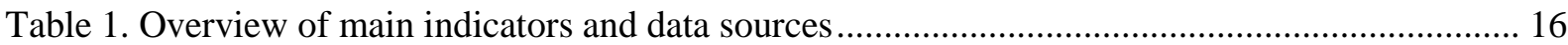

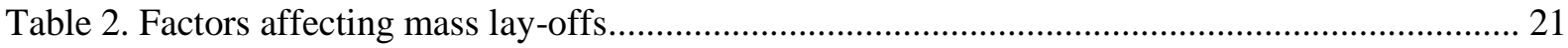

Table 3. Taxonomy for policies affecting mass lay-offs ........................................................................ 38

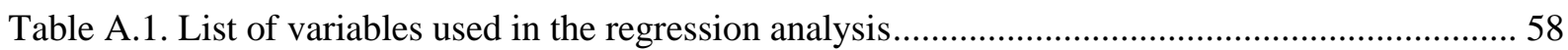

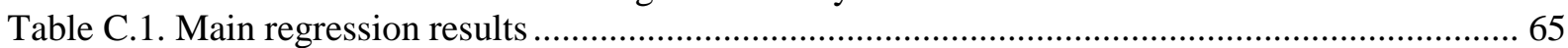

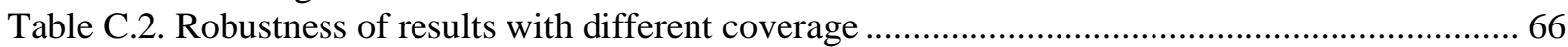

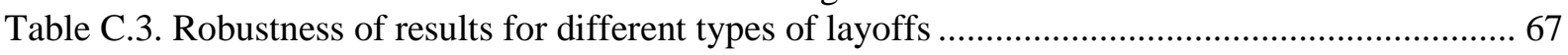

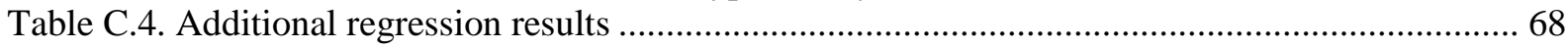

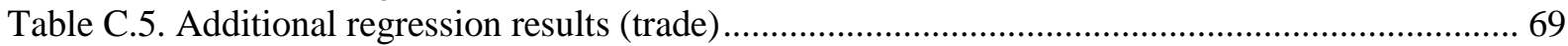

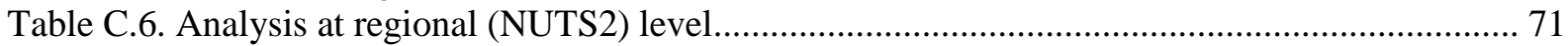

\section{Figures}

Figure 1. Mass lay-offs are one margin of adjustment of employment change.................................... 9

Figure 2. Number of employees affected by planned mass lay-off events (2002-16) .......................... 17

Figure 3. Share of employees affected by planned mass lay-off events by sector ................................ 18

Figure 4. The pace of labour adjustment across sectors .................................................................... 19

Figure 5. Workers in professional service industries are more likely to quickly re-join the workforce. 28

Figure 6. Re-employment potential vary more across economies than across sectors .......................... 29

Figure 7. The longer an individual remains unemployed, the less they earn in their next job .............. 30

Figure 8. Workers in sectors with high incidence of ML do not face long unemployment spells ........ 31

Figure 9. The gap between workers' competences and the skill requirements of jobs in other sectors varies

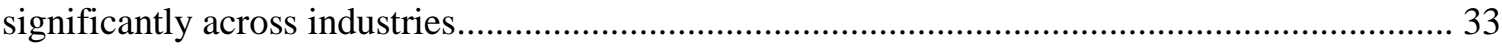

Figure 10. State aid spending by EU member countries: rescue and restructuring .............................. 39

Figure A.1. Number of relevant government interventions by type (2009-16) .................................. 55

Figure A.2. Number of relevant government interventions by sector $(2009-16)$................................ 56

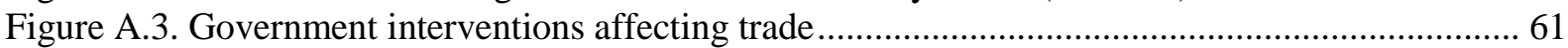

\section{Boxes}

Box 1. Adjusting to structural change through changes in employment composition .......................... 13

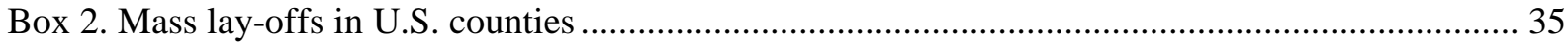




\section{Executive summary}

This report investigates the factors associated with the intensity of "mass lay-offs"1 across countries and industries. Mass lay-offs (ML) are only one of the ways through which firms can adjust to economic pressures. While they account for a relatively small fraction of all dismissals, mass-layoffs still affect a sizable number of workers and pose peculiar policy challenges. ${ }^{2}$ In particular, since they produce a high concentration of displaced workers often older and with more limited re-employability prospects - in a specific geographical area and in a short period, such events can produce major costs for individuals and society as a whole. Additional complexity in this policy area arises because of the possible distortionary effects of policy interventions at company or sector level.

The key contributions of the paper are the following. First, it provides an analysis of the incidence and determinants of ML, controlling for the dynamics of overall employment. This in turn allows for the identification of specific policy factors that are linked to the phenomenon. The results suggest that some important drivers of structural transformation (e.g. digitalisation and globalisation) are not as clearly linked to ML as one might expect, once their impact on overall job destruction is accounted for. Second, the report investigates the re-employability prospects of workers in sectors at high risk of ML. Third, the paper draws implications for different areas of policymaking, from labour market policy to industrial policy and - to some extent - trade policy as well.

While the concentration of ML within specific geographical areas poses a major challenge, the analysis highlights that the challenges faced by workers who are affected by masslayoffs are not dissimilar from the much larger share of displaced workers who do not undergo a ML episode. In fact, a number of sectors where ML events have prevailed in the recent past have grown and demonstrated to have the capacity to at least partly reabsorb displaced workers. This points to the conclusion that policy makers should place a balanced focus on the challenges faced by all displaced workers, rather than focusing disproportionately on MLs. This is in line with the idea that policy action should aim at protecting workers, rather than at protecting specific jobs in certain industries. The new OECD Jobs Strategy (OECD, 2018 $\left.{ }_{[1]}\right)$ provides a structured framework to design appropriate responses to these challenges. Nonetheless, it is important to recognise that certain categories of workers, especially older ones who experience displacement after a long tenure in a given job, face a high-risk of long-term unemployment and the prospect of significant earning drops when re-employed, should receive targeted support.

Turning to industrial policy, systematic support to declining sectors or companies may distort the optimal allocation of labour and hamper productivity in the long run. This may also result in welfare losses for the affected workers, to the extent that it would be possible for them to be employed in a more productive job. Policy interventions in this area are therefore more effective if they target directly the ultimate policy objective, i.e., the affected workers. Attempts to support workers indirectly by protecting their jobs - possibly via interventions targeting specific firms and industries - is generally a sub-optimal solution that should be avoided. If policymakers use such policies to smoothen the adjustment process (minimising the negative externalities of sudden ML) or to address cyclical and temporary downturns, a clear time horizon should be defined. Regional development policies could also be important in alleviating the socioeconomic costs of geographically concentrated MLs. 
Furthermore, the analysis shows that government interventions in support of domestic firms are not associated with fewer mass lay-offs. However, foreign government interventions that may affect global markets are linked to higher intensity of mass-layoffs. This underscores the importance of working towards co-ordinated responses to policy-induced market distortions that result in trade frictions and can lead to the displacement of workers in the economies of trade partners. Policymakers should consider working towards ensuring that trade can remain not only open, but also as free of distortions as possible. This is particularly relevant in the context of the recent discussions at the 2018 OECD Ministerial Council Meeting on renewing multilateralism to level the international playing field (OECD, 2018 $8_{[2]}$ ). 


\section{Introduction}

Economic forces constantly put pressure on industries to adjust and evolve over time. Coping with structural change often requires a reallocation (adjustment) of resources from the least productive (or shrinking) to the most productive (or expanding) areas of economic activity. This productivity-enhancing process results in major transformations of the labour market $\left(\mathrm{OECD}, 2017_{[3]}\right)$. In specific circumstances, labour adjustments tend to be concentrated in time and in space, and result in mass lay-offs (ML henceforth). While being only one of the possible channels through which structural adjustment takes place, ML are often perceived as the one that creates the highest social costs and that arguably poses the most acute policy challenges. The "lumpiness" of these events in both time and space is often exacerbated by weak re-employability prospects for the affected workers. For these reasons, ML events are a subject of lively public debate. ${ }^{3}$

However, little is known on the magnitude of the phenomenon across countries, on its drivers and associated economic factors, and on the employment trajectories of potentially affected workers. Having a better picture of these dynamics may inform the whole set of policies dealing with mass lay-offs, from active labour market policies to support measures for restructuring firms. This is important because substantial resources are being devoted to support measures for restructuring firms, even though the effectiveness of the provision of such resources is not yet fully understood.

The aim of this paper is to shed further light on the phenomenon, disentangling it from the general dynamics of employment change. This is done in two steps. First, the report explores the economic factors and megatrends (e.g. ICT, globalisation), national framework conditions (e.g., employment protection legislation), and idiosyncratic technological characteristics of industries that are associated with the incidence of ML, once the general employment trend and country- and sector-specific shocks are also taken into account. The second part of the analysis presents some preliminary findings of ongoing analysis aimed at assessing the skills endowment and re-employability prospects of workers at risk of mass lay-offs.

A ML event is defined in this paper as large number of dismissals in one company or production unit over a period in time that is shorter than one year. ${ }^{4}$ Other forms of labour adjustment include the use of temporary workers, part-time employment, outsourcing, and within-firm reallocation of labour to more productive business segments (in large firms). Mass-layoffs typically account for a relatively small share of all dismissals (OECD, $\left.2018_{[4]}\right) .5$

Each year, more than $20 \%$ of jobs (on average) are created or destroyed in OECD countries $\left(\mathrm{OECD}, 2018_{[4]}\right)$. While reallocation is key for productivity and part of the creative destruction process, high job turnover entails the displacement of workers and its associated costs. In terms of job destruction, also commonly referred to as job separations, it is important to distinguish voluntary from involuntary separations (see Figure 1). Job displacement affects between $1 \%$ and $7 \%$ of the workforce annually, but usually accounts for less than half of the total number of job separations that are predominantly voluntarily initiated by the worker $\left(\mathrm{OECD}, 2018_{[4]}\right) .{ }^{6}$ Data on planned mass lay-offs for seven European countries indicate that they represent less than $15 \%$ of all displacements. In the United States, data from the Bureau of Labour Statistics indicate that administratively registered mass lay-offs account for only about one fifth of all dismissals. As pointed out 
in $\left(\mathrm{OECD}, 2018_{[4]}\right)$, this suggests that displacement takes the form of medium scale layoffs.

Figure 1. Mass lay-offs are one margin of adjustment of employment change

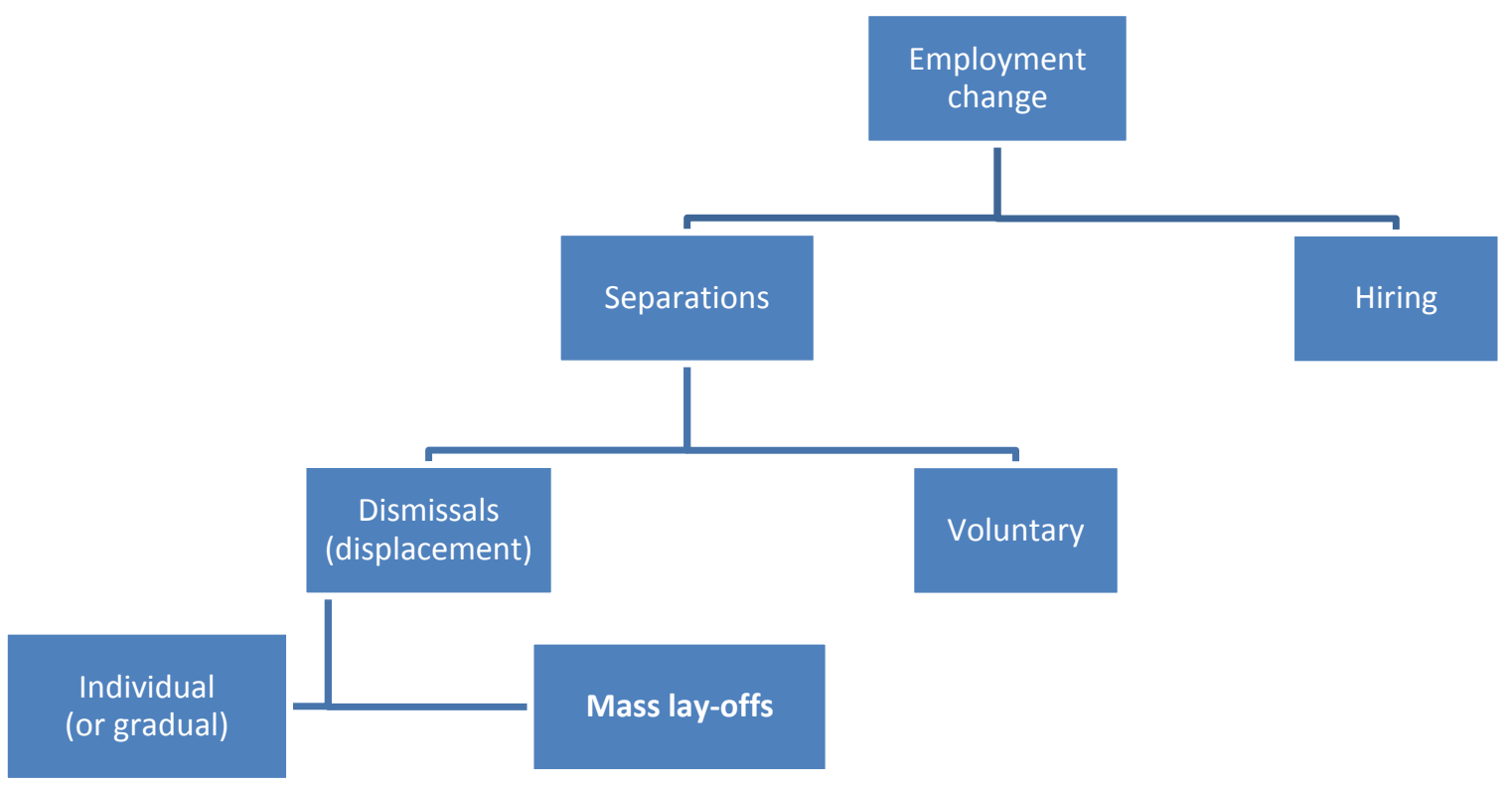

Source: Authors' elaboration. 
What drives mass layoffs? The results in this paper reveal that some key drivers of changes in employment across industries do not have significant additional impacts on the incidence of mass lay-offs. In particular, technology adoption (measured by ICT penetration) does not appear to drive mass lay-offs once its links with overall employment are taken into account. On the other hand, idiosyncratic technological features that allow sectors to adjust smoothly, labour market characteristics, and the reliance of domestic final demand on foreign value-added are amongst the factors that are associated with mass lay-offs. Moreover, the presence of policy-induced market distortions in a given sector increases the likelihood of mass lay-offs. The results also show that mass lay-offs tend to take place in manufacturing-intensive regions going through a process of de-industrialisation.

What are the re-employment prospects of the workers affected by mass-layoffs? Some evidence to answer this question is offered in the second part of the analysis. It reveals that specific sectors face special challenges, but, contrary to a commonly held view, the prospects of workers in sectors at high-risk of mass-layoff are not universally worse than those of dismissed workers in sectors where mass layoffs are less common.

This work is policy relevant and timely for a number of reasons. Several OECD countries are implementing a variety of support measures indirectly or directly aimed at avoiding localised mass lay-offs. For instance, in the European Union, "rescue and restructuring interventions" are considered to be compatible with the internal market rules if member states can "demonstrate that the failure of the beneficiary would be likely to involve serious social hardship", 7 e.g. because the unemployment rate of the affected region is above the national or European average. Over the period 2009-16, EU member countries spent EUR 5.9 billion in "rescue and restructure" state aid. National governments are also active in this domain - e.g. in February 2018 the Italian government announced the allocation of EUR 1.05 billion to manage the process of deindustrialisation, transition, and industrial crisis. $^{8}$

Different policy actions can affect the incidence and respond to the consequences of MLs. Striking the right balance between the different policy levers in order to promote a dynamic economy that allocates resources efficiently, while supporting workers and avoiding trade frictions, is a challenge. This report helps to advance the debate by shedding light on the determinants of mass layoffs - a peculiar channel of adjustment that often attracts the attention of policy makers - and by highlighting areas where future research will be necessary.

The report is structured as follows. Section 2 briefly summarises the literature on masslayoffs. Section 3 provides an overview of the empirical analysis of the incidence of mass lay-offs and of workers' re-employability prospects. Section 4 draws some key policy implications from the analysis. Section 5 concludes and identifies possible steps for future research. 


\section{Mass lay-offs in the economic literature}

Much less attention has been devoted to ML in the economic literature than in the policy debate. While several papers have investigated the effects of localised labour shocks - see e.g., (Blanchard and Katz, 1992 $2_{[5]}$ ); (Bound and Holzer, 2000[6] $)$ (Notowidigdo, 2011 $1_{[7]}$ ), few studies have focused specifically on ML. Foote, Grosz and Stevens $\left(2015_{[8]}\right)$ examine the long-run effects of ML on the local labour force across United States counties. In particular, the authors consider four main adjustment channels - in-migration, outmigration, retirement, and disability insurance enrolment - which are found to account for over half of the labour force reductions following a ML event. Gathmann, Helm and Schönberg $\left(2017_{[9]}\right)$ study spillover effects of ML in West Germany during 1981-2004 using German Security Records, to find that in regions where ML take place the employment rate four years later is $3.7 \%$ lower than a group of otherwise similar regions; the differential increase to $6.5 \%$ after 10 years. Welfare losses for displaced workers in the affected region include both wage losses and lower employment prospects; older workers are more affected due to lower geographic mobility.

Huynh et al. (2017 $[10])$ exploit the differences in Canadian firms' shutdown rates across and within industries and find that an increase in industry shutdown increases the probability of permanent layoffs and decreases earnings growth for workers at continuing firms. Utilities, clothing manufacturing, and motion picture and sound recording industries have the highest rate of shutdown. Jofre-Monseny, Sánchez-Vidal and Viladecans-Marsal (2018[11] $)$ examine the impacts of 45 large Spanish plant closures resulting from international relocations on local employment in the period 2001-06. Motor vehicles, trailers and semi-trailers industry, textile industry and machinery equipment industry are the most affected sectors. The authors estimate that for each job directly lost in the layoff, a net effect of only 0.6-0.7 jobs are actually lost in the region affected by the closure, because local incumbent plants expand employment by around 0.2 jobs, and new plants add about another 0.1 jobs. There are however no significant effects on employment of other industries nor on migration.

Some recent academic research suggests that the majority of workers affected by MLs are able to find re-employment, normally in the same sector - e.g. (Oesch and Baumann, 2015 [12]; Huttunen, Møen and Salvanes, 2011 [13]; Hane-Weijman, Eriksson and Henning, $\left.2018_{[14]}\right)$. One explanation might reside on the perception of future employers with regard to the worker's ability. Individual lay-offs might have a signalling effect about the ability of the individual workers, whereas the motives for the lay-off of a worker affected by a ML are not necessarily related to the ability of the individual worker but rather to the context of the firm or the sector. Older workers and those with lower levels of education are more likely to leave the work force or face long-term unemployment after a ML event (Oesch and Baumann, 2015 $5_{[12]}$; Huttunen, Møen and Salvanes, 2011 $\left.1_{[13]}\right)$.

Analysis by Huttunen, Møen and Salvanes $\left(2011_{[13]}\right)$ using Norwegian data indicates that re-employment is more likely in the same industry and notably in a different plant belonging to the same multi-plant firm (within firm reallocation). ${ }^{9}$ Even though displacement is found to increase the probability of leaving the labour force by $31 \%$, for those that remain the impact of displacement on earnings is relatively moderate but nonnegligible - about 3\% lower than non-displaced workers, after seven years. The analysis also indicates that workers moving across plants within the same firm do not experience any income loss. Workers that move to other industries are shown to earn less. 
In declining sectors, re-employment of workers affected by MLs might prove more challenging. This is a concern, given that the relevant skills have been found to be firmand industry-specific (Huttunen, Møen and Salvanes, 2011 ${ }_{[13]}$ ). The issue of the reemployability of dismissed workers in declining sectors is also not very frequently studied in the economic literature. Indeed, as stressed by some observers (e.g. WWG $\left(2016_{[15]}\right)$ ) there are relatively few studies assessing the impact of policy in the specific context of localised ML. The meta-analysis carried out by researchers at the What Works Centre for Local Economic Growth (WWG) finds only 11 studies reaching the minimum methodological standards set by the centre. These studies relate to both policies targeting workers (e.g., training or re-employment services) and support measures to particular industrial sectors or specific regions. Regarding the former, the WWG meta-analysis finds some cases that suggest that post-displacement retraining could be more effective than outplacement services offered before the lay-off and calls for further research to clarify the most adequate timing for intervention. The only study looking at area-specific support schemes finds a positive impact, but the programme was also very costly.

More recently, Andrews and Saia $\left(2017_{[16]}\right)$ exploit a panel of workers in 13 European countries over the period 1986-2008 and find that a number of country-level variables including higher spending on active labour market policies, structural reforms that stimulate labour demand, and regional mobility - are associated with better employment prospects of workers displaced by firm exit. However, the analysis does not take specific sectoral patterns into account, and nor does the study account for cases of mass lay-offs when the firm does not exit the market. Recent work by the OECD analyses policies aimed at fostering the re-employability of displaced workers (not necessarily as a result of masslayoffs), based on a series of country studies (OECD, 2018 $8_{[4]}$ ). This work finds that preventive measures and early interventions have an useful role in limiting the costs of job displacement. Finally, the new OECD Jobs Strategy (OECD, 2018 ${ }_{[1]}$ ) provides policy recommendations that could help labour markets cope with the rapidly changing economic environment. 


\section{Empirical analysis of mass lay-offs}

While the scarce empirical literature has focused mostly on understanding the implications of ML, this report sheds some light on the economic factors that help explaining the prevalence of ML in some sectors. Using data on ML events across European Union (E.U.) economies, this section presents a detailed portrait of ML across countries and sectors and identifies a set of drivers of structural adjustment through ML.

This analysis is complemented by additional insights on the extent of geographical concentration of MLs using data from the United States (see Section 3.5), as well as on changes in employment composition as an alternative form of adjustment based on Japanese data (Box 1).

\section{Box 1. Adjusting to structural change through changes in employment composition}

One of the ways Japanese firms have adjusted structurally is to change their reliance away from regular permanent workers towards non-regular workers on fixed contracts. The main types of non-regular workers in Japan are part-time and haken employees. Part-time workers are hired directly by a company, while haken workers are indirectly hired through employment agencies. Non-regular employees are paid considerably less than regular workers and have more flexible contracts (Asao, 2011 $1_{[17]}$ ). Structural adjustment through employee composition could allow firms to restructure and increase competitiveness without facing the economic and social costs of firing workers, thereby reducing shocks to local communities. Nevertheless, greater reliance on non-regular contracts may have social implications for the workforce due to weaker job stability.

Average employment classification, 2001-14

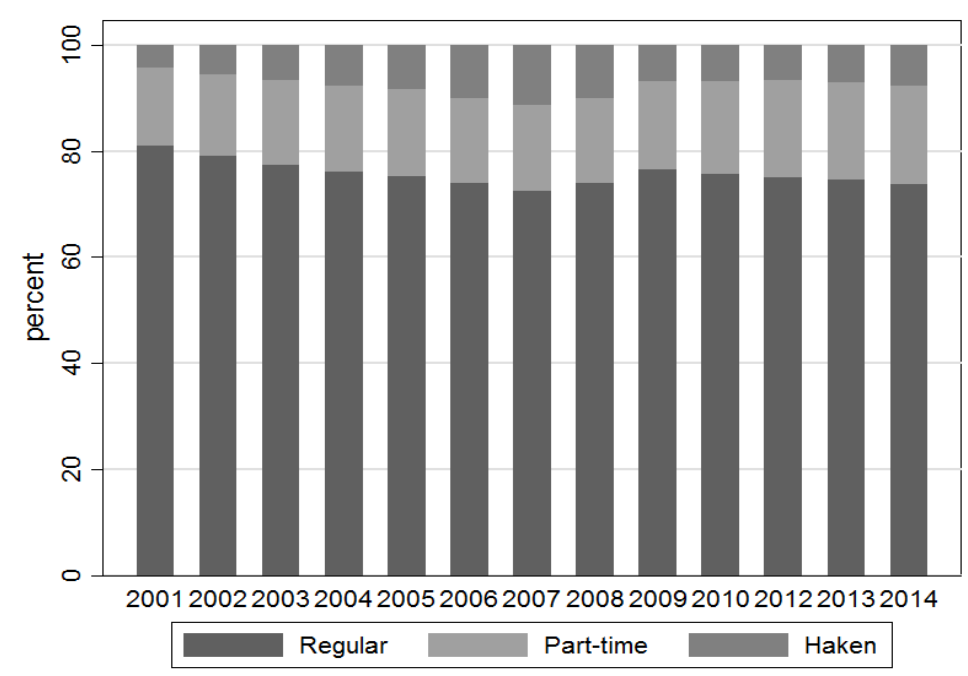

A new analysis using plant-level data on manufacturers in Japan between 2001 to 2014 sheds light on how firm characteristics relate to the use of employment types and how past restructuring impacts employee composition in the future. The data show that while regular full-time workers represent the largest share of employment, the number of non-regular 
workers has been increasing over time. Since regular workers are more expensive to dismiss, firms are more likely to fire haken and part-time employees, in the event of a shock. The figure above depicts an increase in the share of part-time and haken employment until 2007 followed by a drop during the financial crisis and subsequent increase from 2010.

The following Figure shows that the increase in the use of non-regular employees has occurred across most of Japan. Almost every prefecture experienced a rise in the share of haken to regular workers over the sample period. At the same time, certain regions appear to use haken employees more intensively than others, particularly in densely populated areas around Tokyo. Similar trends are found for part-time employees.

\section{Share of Haken to regular full-time workers by prefecture}
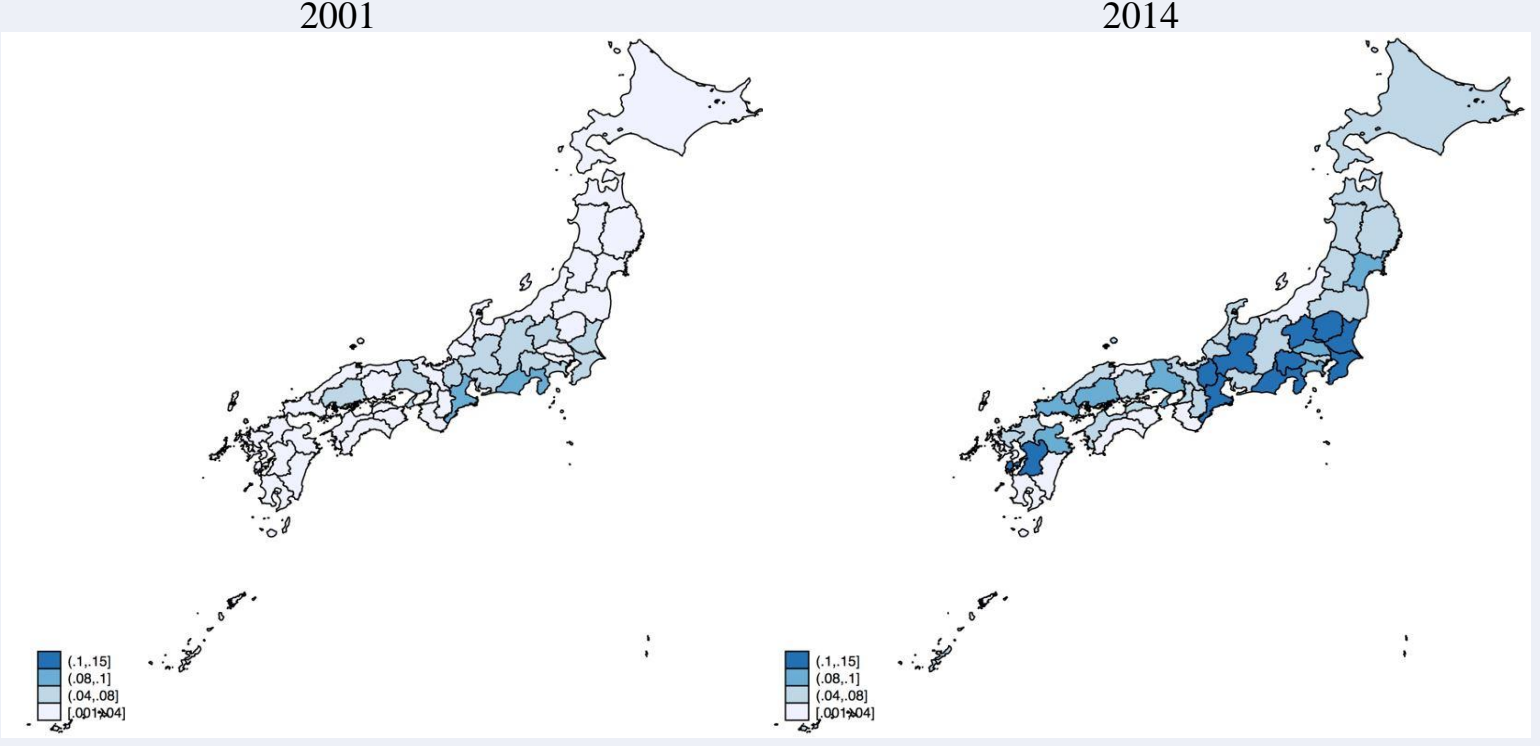

More productive plants use both greater numbers of regular and haken workers in absolute numbers, but employ a greater proportion of regular workers than other types of employees. Exposure to automation also results in the use of a greater proportion of regular workers. Productivity also appears to be an important driver for the dismissal of various types of employees. Plants that become more productive are less likely to dismiss all types of workers. However, those that have achieved high productivity but have not experienced changes in productivity in recent years are less likely to dismiss regular workers and exhibit a higher probability for firing part-time and haken workers. This implies that these types of plants are more likely to use non-regular workers as a buffer for economic turbulence. Finally, the analysis finds that establishment which experienced job turnover in the past substitute away from regular to non-regular workers.

Source: DeStefano, Haneda and Kwon, $\left(2018_{[18]}\right)$ 


\subsection{Data sources and main variables used in the analysis}

The analysis presented in this paper builds upon a combination of information from different OECD databases and external data sources. First the ML data is obtained from the Restructuring Events Database (ERM) maintained by Eurofund, which provides detailed information on ML events in Europe since 2002 and includes data disaggregated both at the region and industry level. Mass lay-offs are defined as planned individual employment actions in which more than 100 employees (or at least $10 \%$ of the workforce in establishments with more than 250 people) were affected. Please note that these data refer to planned restructuring events announced in the media and not from administrative sources. While this may introduce some biases (e.g. different news coverage across countries), such news-based events data have the advantage of reflecting the visibility and prominence of the issue in the policy debate.10 The data are further cleaned to remove events recorded as business expansions as well as information on planned lay-offs that have a time horizon of more than a year. See Annex A for further details.

Second, the Global Trade Alert dataset (GTA) contains useful information on government interventions in support of firms or sectors affecting international markets since 2009 the information is available at the product level and then mapped into the corresponding sector. Data also distinguishes between different types of measures implemented at the border (trade measures) as well as measures implemented behind the border (subsidies and other forms of government support). This report focuses only on the latter. It should also be noted that GTA provides information on government measures in support of firms and does not include support programmes designed to assist workers. An important drawback of the GTA data is however the lack of information on the magnitude of the support programmes. Moreover, the data tend to focus on jurisdictions that are more transparent. The measures used in the regression analysis described in this paper partially correct these biases - see the detailed description of variables in Annex A.

Third, firm-level data from Bureau van Dijk's ORBIS dataset is used to calculate indicators of the prevalence of multinational enterprises in each sector-country-year, as well as a sector-specific indicator of the degree of "lumpiness" in capital adjustments. Fourth, information on the use of ICT to construct indicators of technological change is drawn from the EU-KLEMS database.

Finally, information from several OECD databases is used to construct indicators of labour market institutions (e.g. employment protection legislation; trade union density) or to normalise variables constructed on the basis of external sources (e.g. STAN for total employment and trade volumes). Data from the OECD Regional Statistics database are also used for the analysis described in Section 3.5. Table 1 provides an overview of the data sources and main variables. Further details are provided in Annex A. 
Table 1. Overview of main indicators and data sources

\begin{tabular}{|c|c|c|c|}
\hline Variable & Short description & Source & Variation $(c, y, i)$ \\
\hline ML & $\begin{array}{l}\text { Planned individual employment actions in which more than } 100 \text { employees (or at least } 10 \% \text { of the } \\
\text { workforce in establishments with more than } 250 \text { people) were affected. See Annex A. }\end{array}$ & ERM; STAN & C-Y-I \\
\hline ICT & Contribution of ICT capital services to value added growth (percentage points). & EUKLEMS & C-Y-I \\
\hline ICTcap & Computing equipment (real fixed capital stock, 2010 prices). & EUKLEMS & C-Y-I \\
\hline GLOBAL & Foreign value added share of gross exports. & TiVA & C-Y-I \\
\hline $\begin{array}{l}\text { GLOBAL_ } \\
\text { backward }\end{array}$ & Foreign value added embedded in final domestic demand. & TiVA & C-Y-I \\
\hline EMP growth & Change in employment ( $\%$ change): measured as the total number of persons employed (headcounts). & STAN & C-Y-I \\
\hline $\begin{array}{l}\mathrm{EPL}_{-} \\
\text {collective }\end{array}$ & $\begin{array}{l}\text { Labour protection (collective) This indicator measures additional costs and procedures involved in } \\
\text { dismissing more than one worker at a time (compared with the cost of individual dismissal). }\end{array}$ & $\begin{array}{l}\text { OECD } \\
\text { Employment }\end{array}$ & C-Y \\
\hline $\begin{array}{l}\mathrm{EPL}_{-} \\
\text {individual }\end{array}$ & $\begin{array}{l}\text { Labour protection (individual). This indicator measures the strictness of regulation of individual } \\
\text { dismissal of employees on regular/indefinite contracts. }\end{array}$ & $\begin{array}{l}\text { OECD } \\
\text { Employment }\end{array}$ & C-Y \\
\hline TFPva_I & Total Factor Productivity (value added based) growth, index $2010=100$. & EUKLEMS & C-Y-I \\
\hline $\begin{array}{l}\% \text { EMP by } \\
\text { MNE }\end{array}$ & $\begin{array}{l}\text { Employment in foreign MNEs (\%). Total number of persons employed by MNEs divided by total } \\
\text { employment. }\end{array}$ & ORBIS & C-Y-I \\
\hline LUMPY & Index of Lumpiness. See Annex A. & ORBIS & I \\
\hline Govt foreign & Number of active measures weighted by exports (in other countries). See Annex A. & GTA & C-Y-I \\
\hline Govt domest & Number of active measures in own country. See Annex A. & GTA & C-Y-I \\
\hline TUD & Trade union density defined as the ratio of union members divided by the total number of employees. & $\begin{array}{c}\text { OECD } \\
\text { Employment }\end{array}$ & C-Y \\
\hline Robot & Stock of robots, assuming 10\% rate depreciation - see De Backer, K., et al. (2018). & IFR & C-Y-I \\
\hline $\begin{array}{l}\% \text { EMP } \\
\text { Med/Large }\end{array}$ & Total employment in firms with more than 100 employees, as a percentage of total employment. & $\begin{array}{l}\text { ORBIS; } \\
\text { STAN }\end{array}$ & C-Y-I \\
\hline TRD-IM_int & Share of gross imports on gross output. & TiVA; STAN & C-Y-I \\
\hline TRD_inputs & Share of imported intermediate inputs on total intermediate inputs (proxy for offshoring). & TiVA & C-Y-I \\
\hline
\end{tabular}

Note: *Mapping of industry classification to the common sector classification was required. See Annex A for further details. The Column "Variation" indicates whether the variable varies across country (C), time (Y) and sector (I).

There are a number of caveats in the analysis that emanate from the data and are important to keep in mind. First, the analysis presented in this paper only includes information on a selected number of E.U. economies. Future work may extend the analysis to other economies, conditional on data availability.

Second, the ERM database collects information on planned (not actual) mass lay-off events. While the data captures the visibility of the ML events in the policy debate, it is possible that this generates coverage biases - i.e. some unobserved ML events are missing and some other observed planned ML events never took place. While the extent of coverage biases across countries can be accounted for in regression analysis by using country fixed effects, disaggregated firm-level data for some economies would help create an alternative indicator of mass layoffs to validate the analysis.

Third, the results hide considerable heterogeneity within the broadly defined sectors. It is reasonable to expect that for example the dynamics in the shipbuilding sector are quite different from the automotive or aircraft sectors - e.g. the different technological features that are reflected in this paper in the "lumpiness" variable are likely to vary substantially even within narrowly defined industries. While in theory it would be possible to conduct some empirical analysis at the firm-level, this would require considerable resources to match firm information from different data sources and would be particularly challenging for some variables such as government support. 
Fourth, the indicators of government support used in this paper do not reflect the magnitude of interventions. The analysis controls for the number of interventions in each country provided to the different sectors as a share of total interventions in that country, but if support for a sector is concentrated in few sectors and dispersed across several interventions in others, then indicator will underrepresent the amount of support provided for those few sectors. Furthermore, the data are only available since 2009, meaning that the sample upon which regressions using this variable are performed is reduced to less than half and fails to capture pre-financial crisis years. Finally, the indicators only measure support directed at firms. Future work should focus on indicators of support provided to workers at the industry-country-year level that would allow exploring the effects of the two distinct types of approaches - helping firms vis a vis helping workers.

\subsection{Descriptive statistics of planned mass lay-offs}

As with job displacement, it would be expected that the incidence of MLs is countercyclical $\left(\mathrm{OECD}, 2018_{[4]}\right)$. Figure 2 shows that on average the ERM database reports around 300000 dismissals due to mass layoff on average every year, with a peak above 600000 dismissals in year 2009. It is interesting to note that while the immediate effects of the 2008-09 financial crisis appear to be captured by MLs in these years, the number of workers affected by ML in the years after the financial crisis is not larger than in the period before. Moreover, the number of MLs is also particularly high during 2002-05, a period of economic expansion. This suggests that ML might not always be associated with cyclical downturns, but more importantly with structural pressures arising in different industries across different economies, in line with the evidence on job displacement trends presented in $\operatorname{OECD}\left(\mathrm{OECD}, 2017_{[3]}\right)$.

Figure 2. Number of employees affected by planned mass lay-off events (2002-16)

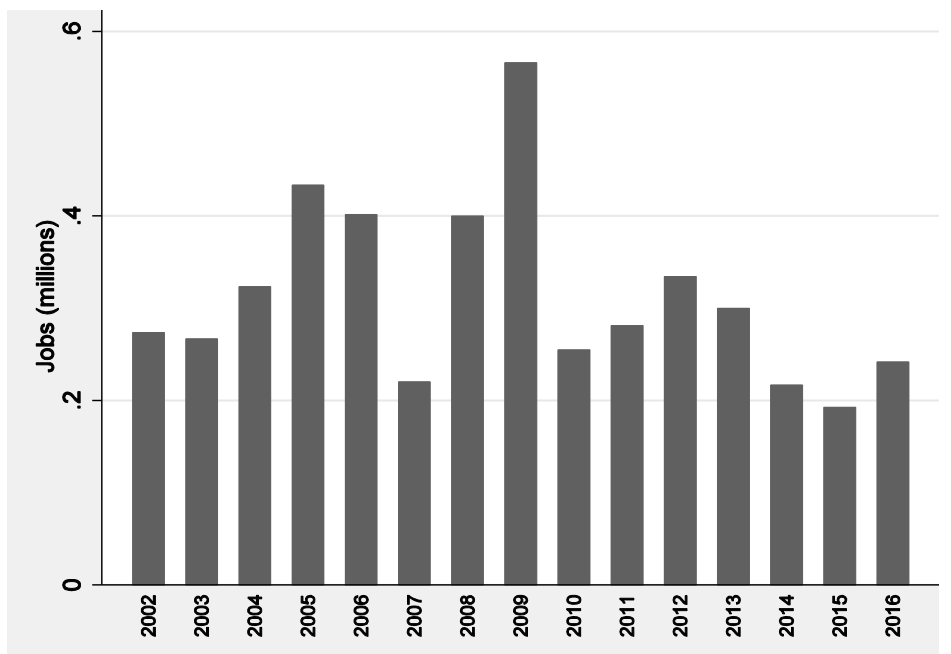

Note: Total planned job reductions through ML across all sectors and economies in the ERM database. Source: OECD calculations based on ERM data

Figure 3 shows the relative importance of MLs, given the size of the labour force in each sector. The sectors most affected by ML are telecommunications, computer and electronics and transport equipment, where the number of people affected by mass layoffs amounts to $1 \%$ of the labour force, on average across economies and years. In some of these sectors, such as telecommunications or computer and electronics where failure and success happen 
to a larger degree, MLs might reflect resource reallocation and economic dynamism, which are important drivers of economic growth. This is consistent with reports from the United States (The Washington Post, 2015 ${ }_{[19]}$ ) and point to the possible role of fast technological change in accelerating job turnover due to advent of labour-substituting technologies and the rapid obsolescence of workers' skills.

Figure 3. Share of employees affected by planned mass lay-off events by sector

Average across economies and years of the share of ML in total employment in each sector, 2002-15

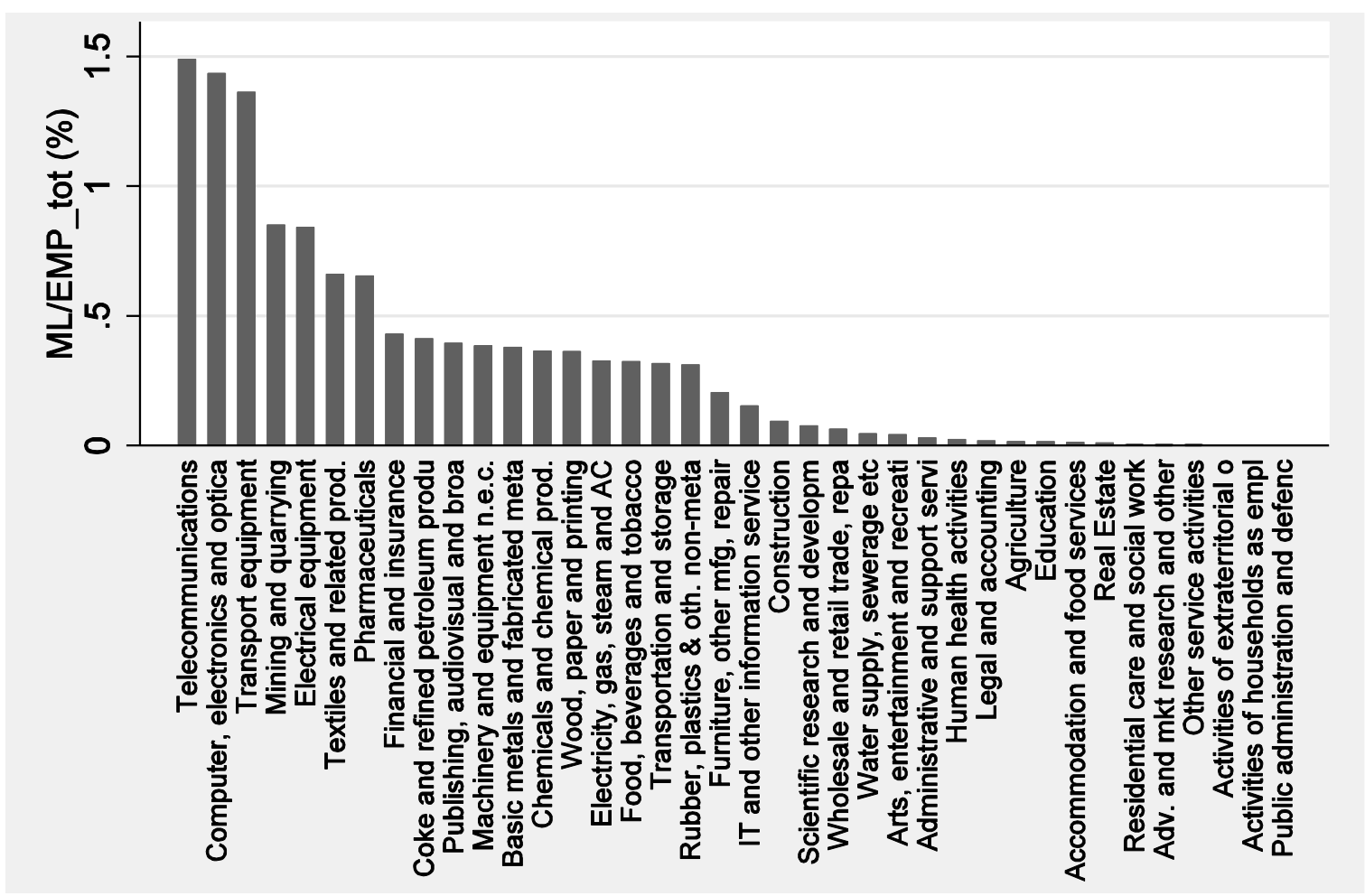

Note: Arithmetic average, of the share of planned ML in total employment in each economy-sector-year, across all available economies and years. Mass lay-off data from ERM are only available for E.U. member countries. Total employment data from STAN are only available for OECD countries.

Source: OECD calculations based on ERM data for ML and STAN data for total employment.

An important question from the policy viewpoint is whether workers affected by ML events in one sector might be able to avoid long-term unemployment and find a job, either in the same sector or in sectors where comparable skills are required. Finding an occupation in the same sector would be more likely if ML is the symptom of a process of resource reallocation and "creative destruction", in which the shrinking or exit of least productive businesses is instrumental to the expansion of younger or more productive companies. Conversely, if ML is the result of a steady decline of the sector, re-employment prospects in the same sector would be extremely unlikely. Figure 4 compares the incidence of ML with the net change in total employment across industries over the period 2002-16. This matrix allows distinguishing between four types of sectors, according to whether they are growing or shrinking, on the one hand, and the margin of adjustment along which labour adjustments take place, on the other hand. 
Figure 4. The pace of labour adjustment across sectors

Average intensity of mass lay-offs and changes in total employment, 2002-16

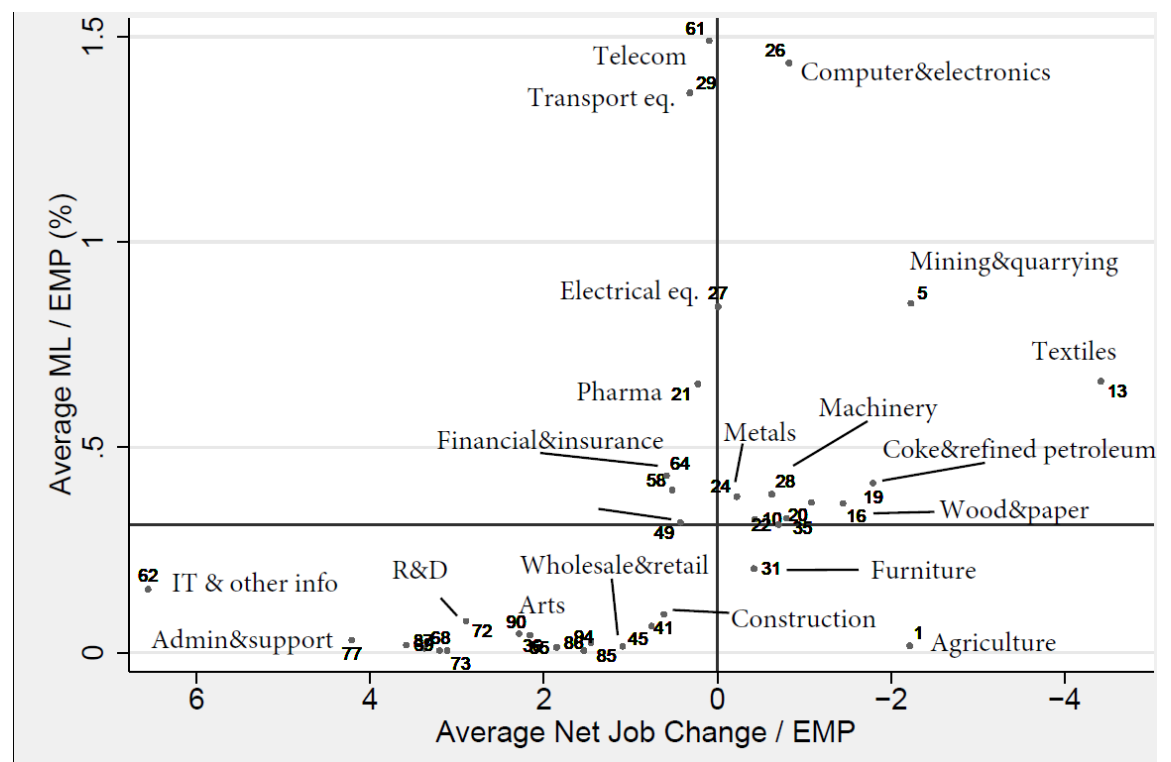

Note: The vertical axis plots the arithmetic average of the share of planned ML in total employment in each economy-sector-year, across all available economies and years. The horizontal axis plots the arithmetic average of the net percentage change of employment in each economy-sector-year, across all available economies and years. This axis is inverted (decreasing in value) to be aligned with the vertical axis that represents declines in employment (in the form of ML). The comparison with job destruction rates, once available, would facilitate the interpretation of the figure. Mass lay-off data from ERM are only available for E.U. member countries. Employment data from STAN are only available for OECD countries. The figure includes two lines for reference purposes. First, a vertical line indicating stable employment (employment change $=0$ ), Second, a horizontal line at the median of the distribution of ML intensity (ML/EMP=0.31\%).

Source: OECD calculations based on ERM data for ML and STAN data for total employment

First, in sectors such as telecommunications or transport equipment, total employment has on average increased, but ML events throughout the period of analysis account for a considerable share of total employment. This indicates a high labour churning rate and suggests that part of the workers affected by ML might have been re-employed in the same sector during the period (within sector reallocation). Structural adjustments involving ML in sectors positioned in the second (top-left) quadrant of Figure 4 where there is positive employment growth might be relatively less socially costly when compared to other sectors where ML are prevalent. The analysis focusing on the re-employability prospects for unemployed workers suggests that workers in sectors such as finance or information and communication are more likely to quickly re-join the workforce after becoming unemployed, irrespective of whether they were dismissed in the context of a ML event (see Section 3.4).

Second, employment in several service sectors such as IT and other information services, arts and entertainment, or administrative and support services has been increasing considerably (bottom-left quadrant of Figure 4). It would therefore be reasonable to assume that workers dismissed through the rare ML events in these sectors could rapidly be absorbed by the same sector. The results presented in Section 3.4 confirm that employees previously working in these sectors have better re-employability prospects, should they become unemployed. 
Third, employment has been declining in sectors such as furniture, other manufacturing and repair industries, or agriculture (bottom-right quadrant of Figure 4). However, the labour adjustment in these sectors has been relatively smooth, with agriculture standing out as a sector where employment declined at a yearly average above $2.2 \%$ - but seldom through ML that averaged less than $0.02 \%$ of total employment. Workers dismissed from these sectors might have difficulties in finding jobs in the same sector, but because the adjustments seldom involve ML the gradual pace of adjustment might facilitate the reallocation towards other sectors in the economy.

Finally, in certain sectors, such as computer and electronics, mining, and some of the heavy industrial sectors that have experienced a reduction in total employment over the period, a considerable share of the labour adjustment has taken place in the form of ML (top-right quadrant of Figure 4). As employment in these sectors has been shrinking, they have not been able to absorb the displaced workers who are then forced to look for opportunities in other sectors. Given that ML are, by definition, concentrated in time (and in geography), this type of adjustment may have important socioeconomic implications. Interestingly, sectors in this group are rather heterogeneous.

While comparing ML to total changes in the workforce is important to better understand the ML phenomenon and its implications, exploring the economic factors behind ML will help shed some light on the scope for possible policy actions that could facilitate structural adjustment, by making it smoother and less costly.

\subsection{Main factors associated with mass lay-offs}

This section investigates how MLs correlate with a number of potential drivers, while controlling for net employment changes, scale, and a number of other sector characteristics. ${ }^{11}$ Ideally, the regression analysis should explore the effects of the different explanatory variables on ML compared to their impact on total job dismissals. Data on gross job destruction at country-sector level, however, are not available, therefore the regressions include a variable controlling for net employment changes instead. In the future, it may be possible to use an aggregation of the EU-LFS data at 2-digit industry level to calculate a worker-based measure of gross job destruction (or total dismissals).

The results of the analysis indicate that some of the important drivers of structural transformation in the labour market (most importantly digitalisation, which has been found to explain job polarisation and de-industrialisation, e.g. OECD 2017), do not explain ML once overall changes in employment are controlled for. This confirms the importance of taking a specific look at the phenomenon.

The adoption of digital technologies and automation does not appear to relate to the MLs (Table 2). However, idiosyncratic technological features that allow sectors to adjust smoothly, labour market institutions, and backward linkages in global value chains are amongst the factors that are found to be associated with ML. Finally, the existence of policy-induced market distortions, in the form of subsidies or other government support, in a given sector is also found to be positively associated with ML. 
Table 2. Factors affecting mass lay-offs

Summary of the regression results

\begin{tabular}{|c|c|c|c|}
\hline Factors analysed & $\begin{array}{l}\text { Indicator used in } \\
\text { regression analysis }\end{array}$ & $\begin{array}{l}\text { Association } \\
\text { with total ML }\end{array}$ & Notes \\
\hline $\begin{array}{l}\text { Digitalisation and } \\
\text { automation }\end{array}$ & ICT & No effect & $\begin{array}{l}\text { Only found to be statistically different from zero (negative) once an } \\
\text { interaction with the indicator of backward GVC linkages is included. }\end{array}$ \\
\hline $\begin{array}{l}\text { International trade and } \\
\text { globalisation }\end{array}$ & GLOBAL & Mixed & $\begin{array}{l}\text { Loses explanatory power once country specificities are taken into } \\
\text { account in the form of country fixed effects. }\end{array}$ \\
\hline $\begin{array}{l}\text { International trade and } \\
\text { globalisation }\end{array}$ & GLOBAL_backward & Positive & $\begin{array}{r}\text { Loses explanatory power if i) interactions with ICT or LUMPY are } \\
\text { included or ii) government measures are included alongside } \\
\text { country fixed effects. }\end{array}$ \\
\hline $\begin{array}{l}\text { Overall employment } \\
\text { dynamics }\end{array}$ & EMP growth & Negative & Control variable always found to be statistically different from zero. \\
\hline Labour market & EPL_collective & Negative & $\begin{array}{l}\text { Loses explanatory power once country specificities are taken into } \\
\text { account in the form of country fixed effects. }\end{array}$ \\
\hline Labour market & EPL_individual & Negative & \\
\hline $\begin{array}{l}\text { International trade and } \\
\text { globalisation }\end{array}$ & $\%$ EMP by MNE & Positive & $\begin{array}{l}\text { Loses explanatory power once country specificities are taken into } \\
\text { account in the form of country fixed effects. }\end{array}$ \\
\hline $\begin{array}{l}\text { Industry technological } \\
\text { features }\end{array}$ & LUMPY & Positive & $\begin{array}{l}\text { This indicator varies only across sectors, thus loses any } \\
\text { explanatory power with the inclusion of sector fixed effects. }\end{array}$ \\
\hline $\begin{array}{l}\text { Industry technological } \\
\text { features }\end{array}$ & TFPva_I & Positive & $\begin{array}{r}\text { Loses explanatory power once country or sector specificities are } \\
\text { accounted for as country or sector fixed effects. }\end{array}$ \\
\hline $\begin{array}{l}\text { Digitalisation and } \\
\text { automation }\end{array}$ & ICT * LUMPY & No effect & \\
\hline $\begin{array}{l}\text { International trade and } \\
\text { globalisation }\end{array}$ & $\begin{array}{l}\text { GLOBAL_back * } \\
\text { LUMPY }\end{array}$ & Positive & $\begin{array}{r}\text { The indicator of backward GVC linkages loses explanatory power } \\
\text { once this interaction is included (see above) }\end{array}$ \\
\hline $\begin{array}{l}\text { Digitalisation \& } \\
\text { globalisation }\end{array}$ & ICT * GLOBAL_back & Positive & $\begin{array}{r}\text { ICT becomes negatively associated with ML once this interaction is } \\
\text { included (see above). }\end{array}$ \\
\hline $\begin{array}{l}\text { Government } \\
\text { interventions }\end{array}$ & Govt foreign & Positive & Statistically significant at the $5 \%$ level \\
\hline $\begin{array}{l}\text { Government } \\
\text { interventions }\end{array}$ & Govt domestic & No effect & \\
\hline
\end{tabular}

Note: This table summarises the regression results provided in detail in 0 . The column "Notes" provide more details on the results.

Source: OECD calculations.

The remainder of this Section analyses each of the different factors in more detail. The tables containing the regression results, robustness tests and additional results are provided in Annex C. The main regression results are obtained using OLS, on a sample containing the maximum number of observations across all the different key explanatory variables. Results from the regressions that extend the coverage to additional countries and sectors by removing selected variables with lower data coverage, are broadly in line with the main regression results. Results exploring the association of ML with additional explanatory variables are also broadly in line with the main conclusions outlined above.

\subsubsection{Digitalisation and automation}

Digitalisation and the diffusion of Information and Communication Technologies (ICTs) have revolutionised a wide number of economic domains. While ICTs represent one of the key general purpose technologies in recent years, the impact of ICT diffusion on employment are still not fully understood - (De Stefano, Kneller and Timmis, 2014 ${ }_{[20]}$ ); (Sabadash, 2013 ${ }_{[21]}$ ); (Spiezia and Vivarelli, 2002 ${ }_{[22]}$ ). On the one hand, digitalisation and 
in particular communication ICTs can be linked with positive scale effects to employment and revenue. This is especially the case for firms with complementary ICT skills, and in knowledge intensive sectors that - possibly due to the diffusion of ICTs - are more productive and can access larger markets thereby creating new job opportunities. On the other hand, digital technologies, particularly those which enable efficiency gains (e.g. enterprise resource planning systems) may result in labour substitution, inducing job destruction in specific sectors (OECD, 2017 $[3])$.

In this context, it is important to highlight the insights provided by the ongoing OECD "Going Digital" project, in particular recent OECD analysis on the impact of digitalisation on employment - e.g. findings that point towards the long term neutrality of ICT in employment OECD $\left(2016_{[23]}\right)$, the changing demand for skills described in OECD $\left(2016_{[24]}\right)$ or more recently on the jobs at risk of automation (Nedelkoska and Quintini, $\left.2018_{[25]}\right)$.

In terms of robotics, the literature up until now has found mixed results for employment. For example, (Graetz and Michaels, 2015 ${ }_{[26]}$ ) find only marginal effects on hours worked, while (Acemoglu and Restrepo, 2017 ${ }_{[27]}$ ) find a negative impact of robots on employment and wages. As for the types of jobs thought to be the most at risk to industrial robots and automation, these include blue collar jobs and routine occupations, while low-skilled males are the workers most at risk of wage decline or job loss - see e.g. (Graetz and Michaels, 2015 $[26]$ ); (Acemoglu and Restrepo, 2017 $[27]$ ); (Frey and Osborne, 2017 ${ }_{[28]}$ ); (Nedelkoska and Quintini, 2018 $\left.8_{[25]}\right)$.

The potentially labour-saving effects of these technologies may be limited by the extent to which different market forces and indirect effects are in place. OECD (2016 $\left.{ }_{[23]}\right)$ highlights a long-run neutrality of ICTs on total labour demand, which however hides a degree of heterogeneity across industries, with sectors such as culture, construction and, to a lesser extent, government and care benefiting more from investments in ICTs.

Even though digitalisation and automation appear to be an important component in explaining net changes in employment across sectors over time, these factors do not seem to be associated with ML adjustments, over and above net changes in employment. The results summarised in Table 2 show that the contribution of ICT to value-added growth, used here as a proxy for digitalisation, is not associated with ML even if taken in conjunction with the indicator of lumpiness in capital adjustments. This latter interaction captures the extent to which the average firm in a given sector is not able to adjust smoothly to digitalisation pressures. Data on job dismissals (or alternatively job destruction) would help explaining the possibly different effects of technological change upon ML and other types of dismissals.

Only when interacted with the indicator of backward GVC linkages, does ICT help explaining the variation in ML. In this case, ICT is found to be negatively associated with ML while the interaction term is positive and statistically different from zero, suggesting that any digitalisation pressures for ML-type adjustments arise from ICT-intensive foreign competitors. Interestingly, the negative sign of the ICT coefficient would suggest that the adoption and use of ICT and digital technologies in a context of increasingly globalised economies would actually help minimise job displacement resulting from ML events. This suggests that companies should ensure that they remain at the technological frontier to avoid costly adjustments caused by more competitive foreign players.

The findings described here contribute to the broader discussion on the impact of technological change upon employment by looking into the effects of ML as one of the 
different margins for labour adjustment. While the debate on the effects of digitalisation on employment is not yet settled, recent work by the OECD in this area finds a negative correlation between technological progress, job polarisation (i.e. the falling share of middle-skill jobs) in manufacturing sectors, and de-industrialisation (OECD, 2017 ${ }_{[3]}$ ). Interestingly, the analysis in this paper is that once net employment changes are controlled for, technology adoption does not appear to have an additional negative impact through mass layoffs. Of course, this is not to say that technology and digitalisation do not impact dismissals more generally. Rather, it leads to the conclusion that technological progress does not have an additional effect on mass layoffs, over and above the one it may have on individual dismissals.

Additional results in line with this view indicate that automation (measured as the stock of robots) is not positively associated with ML - the relationship between robots and ML, if existent, is negative. This means that the use of robots does not have an additional effect on mass layoffs, over and above the one it may have on individual dismissals. One possible interpretation of this result could point to the fact that the current incentives for robot adoption (e.g. high wages, stringent employment protection legislation) are broadly the same that have disincentivised the expansion of the labour force in the past. Therefore, the same countries and sectors that are leading in robotisation would also be those that have a more efficient workforce, thus mechanically less exposed to ML - see e.g. (Presidente, $2017_{[29]}$ ). Moreover, research suggests that the adoption of robots increases productivity (Graetz and Michaels, 2015 ${ }_{[26]}$ ) and thus may intuitively help weather macroeconomic shocks. Another explanation for this result might reside in the pace of robotisation and more specifically in whether the investment and adoption of robots is incremental or discrete. While the data does not allow fully ascertaining whether the investments in robot at the firm-level are lumpy, the regression results could reflect an incremental adoption of robots for most countries and sectors. Further analysis that goes beyond the scope of this paper could explore whether different robot adoption rates influence the ways through which firms adjust their labour force in response to economic pressures.

\subsubsection{International trade and globalisation}

Globalisation together with the emergence of new and sometimes more competitive players in the global marketplace may have important implications for employment in a given sector. While globalisation could be argued to result in ML, this is however not so evident from the analysis.

The results depicted in Table 2 above show that the share of foreign value-added used in domestic final demand - a measure of backward linkages in global value chains (GVCs) - is positively associated with ML. This suggests that an extensive reliance on foreign production for final domestic consumption can increase the risk of ML adjustments at home. Interestingly though, the indicator loses some explanatory power once measures of the extent of government support in a sector are taken into account in the regressions explaining ML.

Nevertheless, imports per se do not seem to be linked to ML - on the contrary import intensity is found to be negatively associated with ML. A plausible explanation rests on the importance of imported intermediate inputs for domestic production (and eventual exports). In fact, the results of regressions exploring the relationship between ML and TiVA indicators of the foreign value added of exports or the share of imported intermediate inputs as a share of total intermediate inputs (a measure of offshoring) are mixed, and highly dependent upon country specificities. ${ }^{12}$ The relationship between globalisation and ML is 
found to be positive if sector fixed effects are not accounted for, and negative if they are taken into account. The effect disappears when country fixed effects are included, suggesting that the effect captured by these globalisation measures is mostly reflecting country framework conditions and comparative advantages.

Policymakers are increasingly faced with pressures to introduce trade policies which limit imports that are perceived as a threat to domestic jobs. While the analysis presented here does not look into the effects of trade on employment, the mixed results described above question whether open trade does actually put workers at the risk of ML. In order to minimise risks of ML resulting from trade and offshoring of production units, policymakers may wish to consider setting the right framework conditions that allow domestic firms to remain competitive - e.g. an efficient public administration, investments in human capital, pro-competitive regulations, etc - and workers to be well equipped with the skills, social protection and safety nets to better cope with globalisation - see the key issues paper for the 2017 OECD Ministerial Council Meeting for an overview (OECD, 2017 [30] $)$.

The relative weight of multinational enterprises (MNEs) is found to have a clear positive association with ML. While country specificities appear to be particularly important in explaining ML arising from international economic relationships, modern economies are increasingly delimited by company rather than national borders (Baldwin, 2016 $6_{[31]}$ ). As such, the presence of MNEs may have important implications for adjustments in industries located in specific countries because it is easier for MNEs to shift production (capital) across borders. Given that labour is not as smoothly adjustable as capital, this can give rise to "lumpy" adjustments in employment. Regression results confirm this expectation by showing that the share of employment in MNEs is associated with a larger number of workers affected by ML. The result holds even after controlling for the share of employment in medium-sized and large companies. While part of the effects of offshoring on ML might also be driven by MNEs, the distance to headquarters might also contribute to the positive association between MNEs and ML - social pressure at local communities might help explain higher rates of dismissals in establishments further away from headquarters (Bassanini, Brunello and Caroli, 2017 ${ }_{[32]}$ )

The policy implication that emerges from this discussion is the need for international cooperation to ensure that MNEs operate in a level playing field and are not given undue advantages by specific jurisdictions that may result in a race to the bottom. In doing so, it seems important to emphasise that MNEs should follow the OECD Guidelines for Multinational Enterprises ${ }^{13}$ and respect the international labour standards set by the International Labour Organisation.

\subsubsection{Industry technological features}

Mass layoffs appear to be strongly associated with industry specificities and technological features. More specifically, the nature of the production process may require that adjustments are not smooth. This is the case in industries where investments are sizeable and entail significant sunk costs (e.g. heavy industry).

Moreover, high costs of facility closure and other barriers to exit tend to result in lower opportunity costs of remaining in operation. Firms may therefore opt to incur losses for a period of time hoping that market condition improve, thus delaying needed adjustment e.g. in the steel industry salvage values are often lower than operating costs (Deily, $1991_{[33]}$ ). In following such strategies in face of mounting adjustment pressures, companies might eventually need to adjust rapidly or face bankruptcy and closure. This entails labour adjustments through ML. Lumpy capital investments in industries where the production 
technology entails a higher degree of complementarity between capital and labour inputs is therefore likely to be strongly associated with ML.

This paper uses a novel measure, constructed using firm-level data from ORBIS to capture the "degree of lumpiness" in the capital adjustments in each industry. Lumpiness is calculated as the sector average of the residual term of a regression of yearly fixed capital investment on the long run investment trend, as well as on demand shocks and firm size (in terms of fixed assets). This indicator reflects how much the yearly investment rate deviates from the medium term trajectory, when a control for demand shocks is included. As such, the indicator captures the specificities of the production process in each sector that limit the extent to which companies are able to adjust their capital smoothly. This indicator is found to be positively associated with ML, insofar as industry fixed effects are not included in the regression.

The scope for policy actions that could help mitigate ML resulting from technological features and other industry specificities is however quite limited. Nonetheless, the removal of barriers to exit - including policy-induced barriers - could help setting the right incentives for firms to adjust smoothly, should the production technology allow.

\subsubsection{Government interventions and displacement of production}

Government interventions that result in the displacement of production across economies are an important concern for policymakers. Subsidies and other forms of government support to the industry are usually justified under a number of reasons including industrial and economic development goals, mitigation of market failures, or sustaining production capacity in sectors considered as strategic. However, government support may result in undue competitive advantages to firms and is likely to result in the displacement of production in other economies, notably when provided to firms in tradable sectors. Firms in tradable sectors compete in an increasingly globalised marketplace, so if granted some form of support that for example lowers financial, labour or other input costs, will be at an advantage vis a vis foreign competitors and may capture market share, thus forcing competitors to adjust.

Comprehensive and harmonised data on public support measures to firms and sectors are extremely difficult to collect. Data collected by Global Trade Alert (GTA) contains relevant information on government support measures such as state loans, financial grants, public procurement preferential access, tax or social insurance reliefs. ${ }^{14}$

The analysis in this report uses these data to construct two unique indicators of the degree of government support to firms and sectors. The first reflects the relative support provided to domestic firms in each sector, compared to support provided across sectors in each economy (domestic measure). Focusing on the share of government interventions in one sector compared to the total number of support measures provided by the jurisdiction allows minimising concerns arising from the lack of information on the magnitude of the support measures as well as correcting for the biases arising from different degrees of transparency in the reporting of government support across jurisdictions.

The second indicator measures the extent to which a sector benefits from support provided by foreign jurisdictions at the global level. More specifically, the measure of foreign support is calculated as the global average share of sector interventions in each foreign jurisdiction (equivalent to the domestic measure for each jurisdiction), weighted by the sector's share of exports by each jurisdiction - the measure varies across time and sector. ${ }^{15}$ 
Weighting the indicator by exports allows taking into account the relative size of each jurisdiction as a trading partner in each specific sector.

As reported in Table 2, the degree of distortions in international markets induced by foreign policy interventions appears to be positively associated with ML, a result that is robust across different specifications. ${ }^{16}$ These results could suggest that a share of mass layoffs might be "imported" from abroad - when firm exit and job destruction in one country is averted through policy support, necessary adjustments may be shifted abroad, notably in tradable sectors. In other words, sectors that are more prone to government interventions appear to be more affected by ML.

Moreover, it is interesting to note that in the regression results, the coefficient of the indicator of domestic policy interventions is never found to be statistically different from zero. ${ }^{17}$ This result indicates that government measures do not directly avert the occurrence of ML. Further analysis on the use of domestic measures as well as trade measures in response to policy-induced distortions abroad could help enrich this analysis.

The two findings described above are extremely relevant from the policy viewpoint. They suggest that it is important to refrain from government interventions that result in distortions in international markets, notably because policies to support (or provide relief to) domestic industries might not necessarily be helpful in preventing ML, while resulting in important ripple effects internationally. Given the international dimension of the challenge, multilateral cooperation in global policy fora would be crucial for the removal of distortive policy measures.

\subsubsection{Employment protection legislation and trade union density}

National policies and framework conditions are key in shaping firm behaviour and employment trends. The institutional features of the labour market are likely to affect the possible margins along which structural adjustment takes place. Labour market flexibility can help firms cope with structural change. For example, in economies where employment protection regulations are less stringent, firms might find it easier to adjust in the face of structural pressures - notwithstanding important implications for job security and income — whereas economies with stringent employment protection regulation might provide the incentives for firms to retain workers despite such pressures.

While there are several other labour markets features that would have important implications for ML, the analysis in this report resorts to indicators of employment protection legislation (EPL) and trade union density (TUD) that are readily available from the OECD Employment database. ${ }^{18}$ The EPL indicators have different components and only two were selected for the analysis given their pertinence for ML. First, the individual protection indicator measures the strictness of regulation of individual dismissal of employees on regular/indefinite contracts. Second, the collective protection indicator measures costs and procedures involved in dismissing more than one worker at a time, in addition to the cost of individual dismissal. While the latter would be the most relevant indicator for the analysis of ML, it should not be used in isolation from the former, since it is meant to capture additional dismissal costs from the baseline (individual) indicatorsee Annex A for further details on the sourcing of labour market data. ${ }^{19}$

The results of the empirical analysis exploring the relationship between ML and EPL indicate that the costs associated with the collective (as well as individual) dismissal of workers are negatively associated with ML. These results appear to be quite robust across 
specifications, despite the explanatory power of the collective indicator is reduced once country specificities are controlled for.

Additional results that control for TUD (as a proxy for collective bargaining) also reveal a negative association with ML (see Annex C). While the TUD indicator does not fully capture the complexities of a collective bargaining system (OECD, 2017 $\left.7_{[3]}\right)$, this result could suggest that collective bargaining may result in a smoothing of labour adjustments. Such a conclusion, however, conceals considerable heterogeneity across a varied landscape of collective bargaining and employment protection regimes. It is nevertheless important to note that there is an association between TUD and firm size, as union members tend to be more numerous in large and medium firms - only $7 \%$ of employees in small firms (compared to $30 \%$ in large firms and $19 \%$ in medium-sized firms) belong to a union on average across OECD countries $($ OECD, 2017 $[3])$. This could provide an alternative explanation for the result, since ML are, by construction, more likely to take place in medium-large firms.

While fully investigating the implications of EPL stringency and collective bargaining for (un)employment, wages and income, allocative efficiency, firm dynamism and aggregate productivity is beyond the scope of this paper, the results presented here suggest that more stringent legislation on collective dismissals and higher trade union density is likely to result in lower propensity for MLs to be used as a channel of adjustment. In light of this result, it is important to note that a number of training and active labour market policy tools, described in Section 4.2.1, can be deployed to enhance the re-employability prospects of laid-off workers.

\subsection{The re-employability of workers moving out of different sectors}

Mass layoffs are a hotly debated issue, which tends to attract considerable media attention and to be a key preoccupation for policy makers. Aside from the fact that mass layoffs tend to affect large amounts of workers concentrated in a specific area, this preoccupation tends to be motivated by the presumption that the affected workers have particularly low reemployment prospects. Understanding whether this presumption is supported by the data and how the picture varies across countries will be the key objective of this section.

First, survival analysis will be used to study the probability of re-employment after leaving different sectors. The second part of this section will paint a detailed picture of the reemployability prospects for laid-off workers on the basis of skill-similarity across sectors. These analyses will be further expanded in the next phase of the project. ${ }^{20}$

\subsubsection{How quickly do displaced workers find a new job?}

One of the main concerns regarding mass layoffs is that those who lose their jobs face a negative shock to their income. While unemployment benefits can provide a cushion to this shock, these individuals need to find a new job in order to return to a comparable level of earnings. In the event of a mass layoff, the geographic concentration of the newly unemployed can increase competition for scarce jobs. Investigating the duration of unemployment by prior industry of employment can shed light on the re-employment opportunities of dismissed workers.

The European Labour Force Survey (EU-LFS) contains information on respondents' employment status both currently and one year prior to the interview. It is thus possible to investigate the duration of unemployment up to a maximum of 12 months by focusing on workers who have changed their employment status over the year prior to the interview 
(i.e. those who have been employed or unemployed for more than one year do not feature in the analysis). In particular, the estimation is based on the experience of two categories of workers: (a) those who are employed both at the time of the interview and one year before but have been in their current job for less than 12 months; and (b) those who are unemployed at the time of the interview and employed 12 months before. ${ }^{21}$ Information derived from the labour market experiences of these two groups enables a survival analysis of unemployment by previous sector of employment (where remaining unemployed is considered "survival"). A detailed discussion of the methodology is provided in 5. Annex B.

Figure 5. Workers in professional service industries are more likely to quickly re-join the workforce.

Average hazard rate by broad sector group ${ }^{\mathrm{a}}, 2016$.

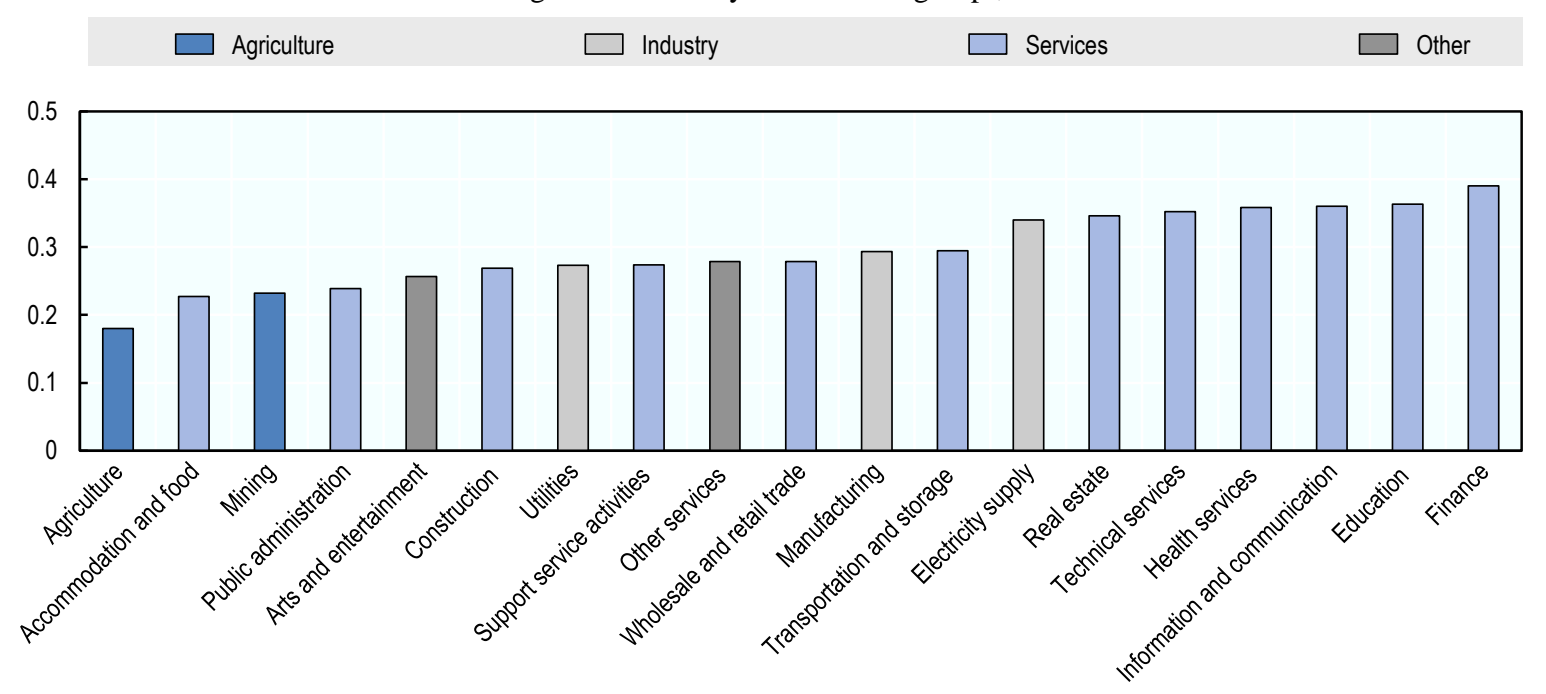

Note: The hazard rate can be interpreted as the probability that an unemployed worker will find a job in a given month, with a value of 1 representing certainty. The figure above depicts the average hazard rate. Hazard rates were modelled using a parametric analysis that accounted for interval censoring. The underlying survival distribution was assumed to be Weibull. The model includes country controls.

a) The "Agriculture" group contains NACE Rev2 industries A and B; the "Industry" group contains industries C, D, E, and F; the "Services" group contains industries G through Q; and the "Other" group contains industries R and S.

Source: European Labour Force Survey (EU-LFS).

The analysis shows the opportunities for re-employment vary greatly by sector of origin. The chances of finding a new job within a year are around twice as large for an unemployed worker who was previously employed in finance as for an unemployed worker who used to be in the agriculture sector (Figure 5 above). More generally, workers who move out of jobs in service sectors appear to face higher probabilities to be re-employed than workers in the primary or secondary sectors. Figure 6 decomposes these differences by country and presents the risk of remaining unemployed after 12 months. Clearly, cross-country differences in the probability of getting a new job dwarf cross-sector differences. These differences can have very deep welfare implications. Figure 7 underscores this point by showing that longer unemployment spells are associated with significantly lower earnings upon regaining employment. 


\section{Figure 6. Re-employment potential vary more across economies than across sectors}

Share of workers that remain unemployed after 12 months by country and broad sector group ${ }^{\mathrm{a}}, 2016$

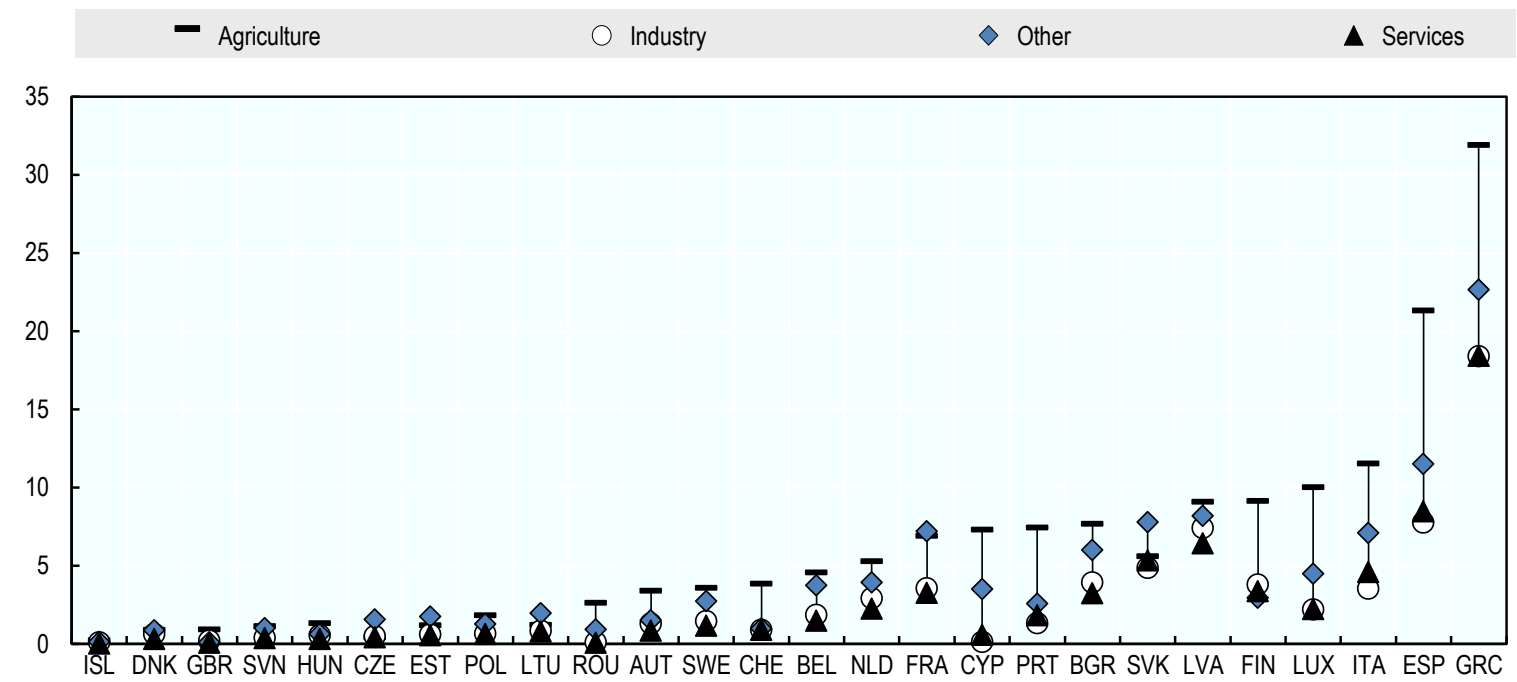

Note: The hazard rate can be interpreted as the probability that an unemployed worker will find a job in a given month, with a value of 1 representing certainty. The figure above depicts the average hazard rate. Hazard rates were modelled using a parametric analysis that accounted for interval censoring. The underlying survival distribution was assumed to be Weibull.

a) The "Agriculture" group contains NACE Rev2 industries A and B; the "Industry" group contains industries C, D, E, and F; the "Services" group contains industries G through Q; and the "Other" group contains industries $\mathrm{R}, \mathrm{S}, \mathrm{T}$, and $\mathrm{U}$.

Note by Turkey:

1. The information in this document with reference to "Cyprus" relates to the southern part of the Island. There is no single authority representing both Turkish and Greek Cypriot people on the Island. Turkey recognises the Turkish Republic of Northern Cyprus (TRNC). Until a lasting and equitable solution is found within the context of the United Nations, Turkey shall preserve its position concerning the "Cyprus issue."

2. Note by all the European Union Member States of the OECD and the European Union:

The Republic of Cyprus is recognised by all members of the United Nations with the exception of Turkey. The information in this document relates to the area under the effective control of the Government of the Republic of Cyprus.

Source: European Labour Force Survey (EU-LFS). 
Figure 7. The longer an individual remains unemployed, the less they earn in their next job

Change in median monthly earnings between jobs on either side of a period of unemployment.

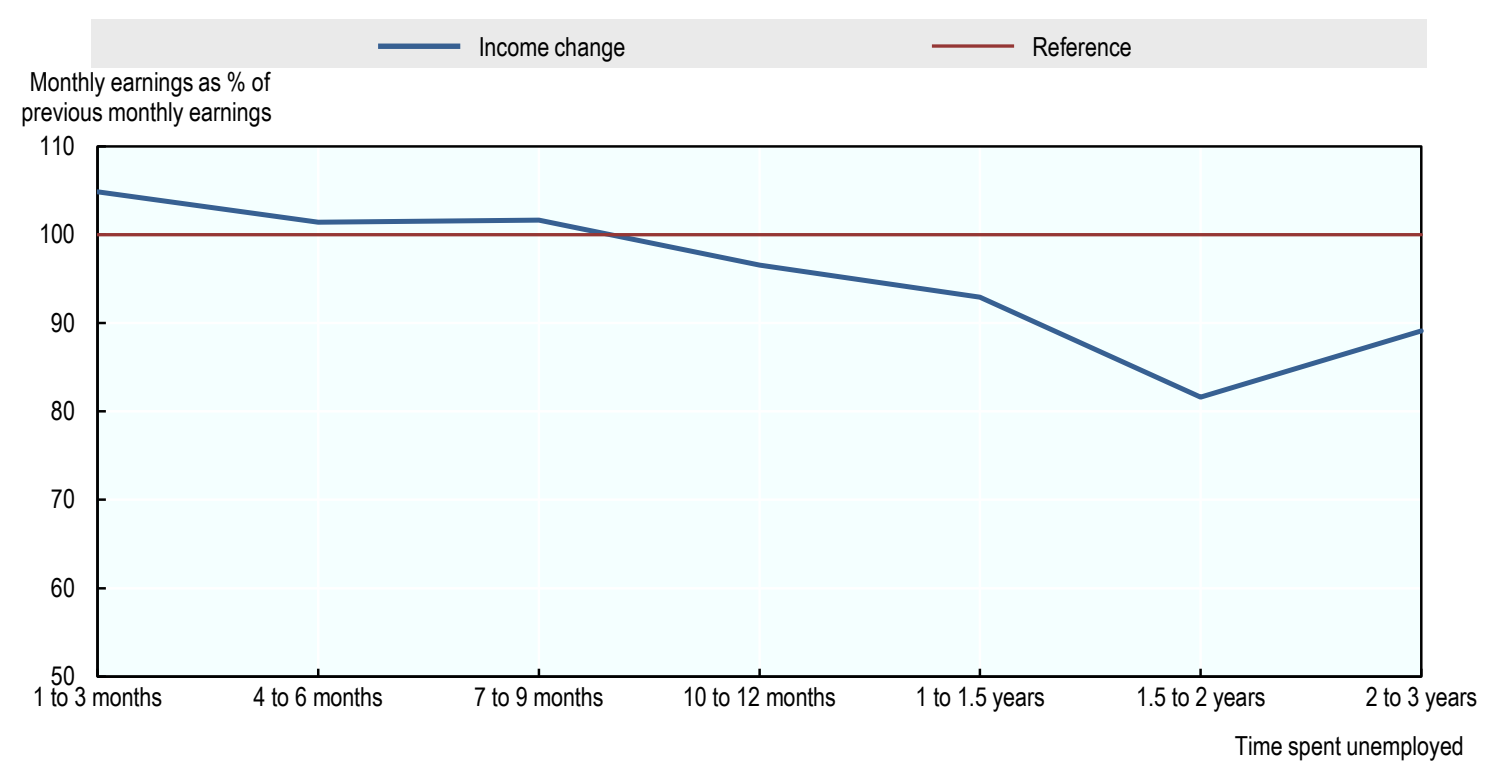

Note: The median change is derived from pooled data from 24 countries over the years 2005 to 2015 . The included countries were: Austria, Belgium, Czech Republic, Denmark, Spain, Estonia, Finland, France, Greece, Hungary, Ireland, Iceland, Italy, Lithuania, Luxembourg, Latvia, Netherlands, Norway, Poland, Portugal, Slovak Republic, Slovenia, Sweden, and the United Kingdom. All income data is transformed into 2010 USD using consumption based PPP adjustment. The data includes all individuals who were working at one period, stopped working, and resumed work at a later period, regardless of the reason for leaving work. In order to obtain two income measures for comparison, only those unemployment spells that spanned income reference periods were included.

Source: EU-SILC.

Given the focus of this report, Figure 8 links the estimation of unemployment duration with the incidence of ML at sectoral level. The resulting matrix shows that, on average, workers in sectors with high incidence of MLs do not face longer unemployment spells than workers who are dismissed from sectors where mass layoffs are less prevalent. ${ }^{22}$ However, manufacturing is a notable and important exception, as the industry is characterised by values higher than the median for both unemployment duration and ML incidence. Forthcoming analysis at 2-digit industry level will shed more light on the issue. 
Figure 8. Workers in sectors with high incidence of ML do not face long unemployment spells

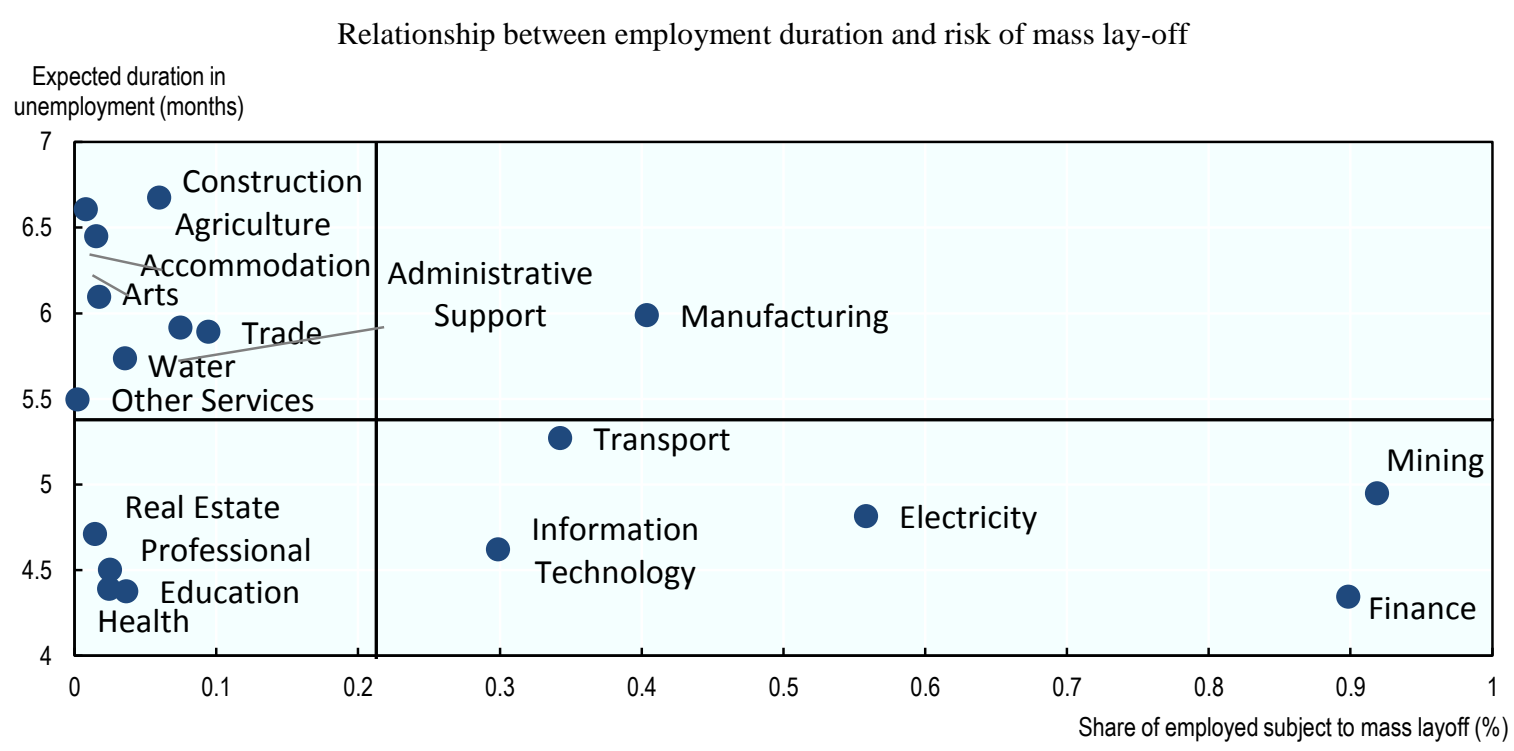

Note: Reference lines are the median ration of mass layoff to employment by industry, and the median expected duration in unemployment by industry. Results are calculated based on pooled data for the years 2008 to 2016. Industries are coded according to NACE Rev2 1-digit classification. The industry mapping is: Agriculture (A), Mining (B), Manufacturing (C), Electricity (D), Water (E), Construction (F), Trade (G), Transport (H), Accommodation (I), IT (J), Finance (K), Real Estate (L), Professional (M), Administrative Support (N), Education (P), Health (Q), Arts (R), Other Services (S).

Source: OECD calculations based on EU-LFS, based on ERM data for ML, and based on STAN data for total employment.

\subsubsection{How big is the skills distance between workers at high-risk of mass layoff and those in other sectors?}

To better understand the re-employability potential of laid-off workers, this section constructs a simple measure of skills shortage for workers in each sector relative to those in other sectors. In doing so, it provides an indication of how distant workers in sectors at high risk of mass-layoff are from job opportunities in other sectors, based on their skills. This exercise is based on other analyses presented to the Committee on Industry, Innovation and Entrepreneurship (e.g. Grundke et al. (2017 $\left.{ }_{[34]}\right)$ and Bechichi et al. $\left(2018_{[35]}\right)$ ) and in the Employment, Labour, and Social Affairs Committee (e.g. $\left(\right.$ OECD, 2013 $\left.{ }_{[36]}\right)$ ), which make use of the Survey of Adult Skills (PIAAC) to measure skill distance.

The measure compares industries on the basis of the tasks performed by workers. Specifically, the measure uses five specific task-based skills available in PIAAC as identified by Grundke et al. $\left(2017_{[34]}\right)$. These are ICT skills, management and communication skills, accountancy and selling skills, advanced numeracy skills, and selforganisation skills. For each skill, the measure estimates the gap (i.e. shortage) in the intensity of its use in a particular industry relative to the others ${ }^{23,24}$. These distances are then aggregated up to the country level to obtain an overall measure of skill distance between the average worker in a given industry and all the other available jobs in the country.

Importantly, results from the PIAAC survey have demonstrated that the work content of jobs may differ across both individuals and countries. By developing a measure of skills distance based on the skills workers say they use, the metric is able to capture cross-country 
differences in job content. However, this comes at a cost. PIAAC is as comprehensive survey, but does not query respondents on the entire universe of plausible tasks. Other datasets, most notably the O*NET database developed in the United States, would allow a more detailed analysis, but using them for cross-country comparisons would necessitate assuming that the task structure of occupations is the same across countries.

Some peculiar aspects of this measure of skill-similarity are worth noting. First, by weighting the skill distance by the employment shares within sectors, the measure effectively takes into account how likely it is that workers might be able to move to different types of jobs (based on how common those jobs are). This is a desirable feature, as the measure does not describe distance in the abstract but rather on the basis of actual opportunities. It also implies that workers are going to be less distant from a larger sector than they are from a smaller one, even if the two require the same skill mix (because the former offers more opportunities by virtue of being larger). This feature of the methodology should be kept in mind when interpreting the results, and will be subject to further scrutiny going forward. Second, the distance from one industry to itself is zero. This is a result of the measure being computed at the industry level. In practice, this may not be the case, where some workers could find themselves laid-off and yet still have trouble finding a job within the same industry as a result of a shifting occupational mix within that sector. In general, however, it is plausible to assume that within-sector distances are much smaller than cross-sector distances.

The analysis of skills shortages shows great heterogeneity across sectors. Figure 9 plots the average skills shortage of workers in each sector relative to all the other sectors against the average "cognitive skills demand" within each sector (calculated as the average of three general competences measured in PIAAC: numeracy, literacy, and problem-solving skills). ${ }^{25}$ As expected, it shows that sectors with higher cognitive skill demands have lower task-based shortages relative to other sectors. It also shows, however, that for similar levels of cognitive skills demanded, sectors can differ significantly in the skill shortages their workers face. Workers in sectors like Chemicals and non-metallic mineral products (8) and Transport, storage, post and telecommunication (15), for instance, face similar levels of average cognitive skill demands, but workers from the latter face a significantly higher skills distance (shortage) compared to workers in other sectors, lowering their reemployability prospects in the event of a layoff. While workers from both sectors face skills shortages relative to high-skill service sectors such as finance or real estate, the Transport, storage, post and telecommunication workers further lack the skills to move into a number of other manufacturing sectors.

Importantly for the purpose of this paper, the analysis reveals that sectors at high risk of mass-layoffs do not uniformly display higher levels of skills shortages. For example, Electrical and optical equipment (9) and Transport equipment (10) are two sectors with relatively similar levels of skills demanded and with a relatively high risk of mass layoff, but the latter shows considerably higher levels of workers with skills shortages.

Summing up, the unemployment duration and skills shortages analysis points to the following conclusions. There are sizeable differences across sectors in re-employability prospects of workers. However, sectoral differences are dwarfed by cross-country differences. This implies that countries with more dynamic labour markets and more effective active labour market policies succeed in significantly reducing the social costs of ML. Furthermore, the analysis indicates that considering workers in sectors with higher risk of mass layoff as universally less employable than others is an oversimplification. The 
evidence is more nuanced and considerable variation exists across industries. Further analysis is needed to clarify the existing patterns.

\section{Figure 9. The gap between workers' competences and the skill requirements of jobs in other} sectors varies significantly across industries

Average skills shortage relative to other sectors, European OECD countries.

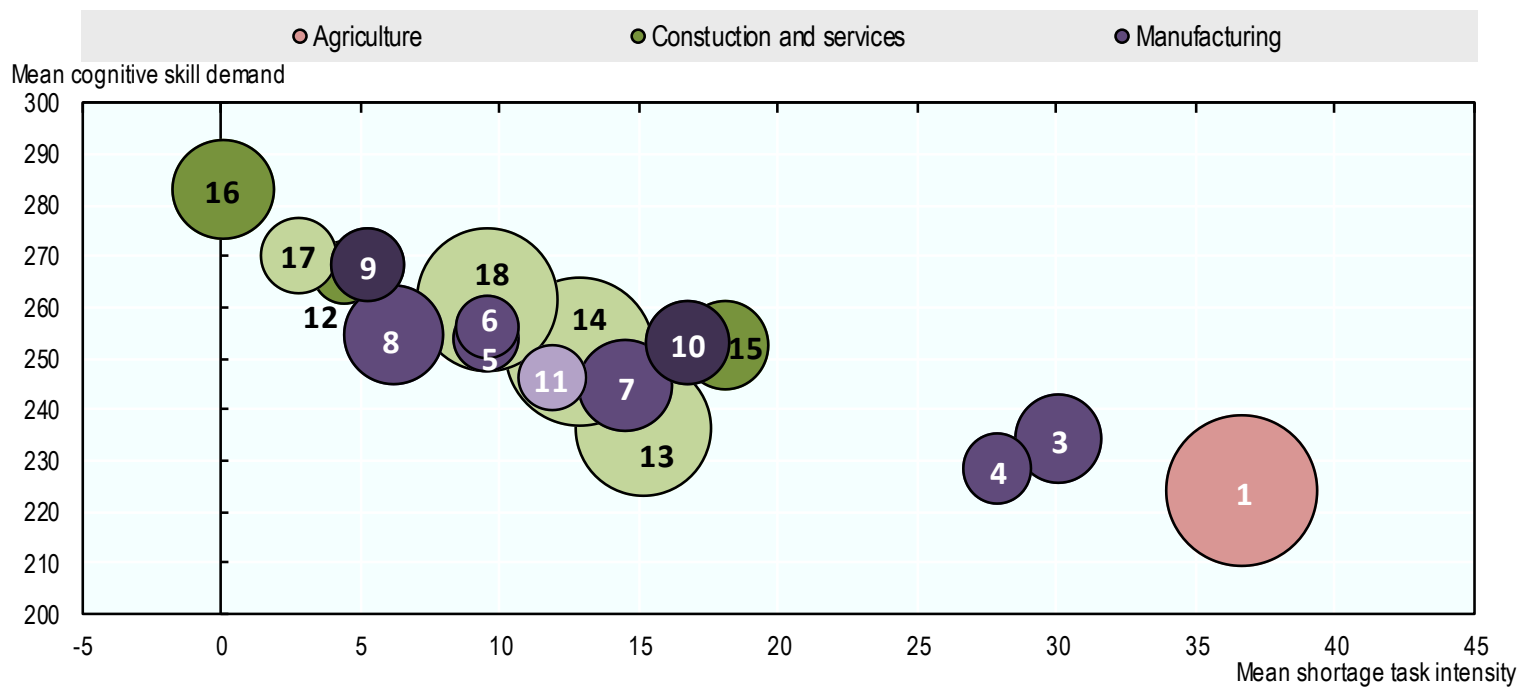

Note: The measure of task shortage intensity is built using five specific task-based skills within PIAAC as identified by Grundke et al. (2017 $[34)$ : ICT skills, management and communication skills, accountancy and selling skills, advanced numeracy skills, and self-organisation skills. The measure is constructed as the weighted sum of the task intensity deficit between sectors, given that there is, in fact, a deficit (Bechichi et al., 2018 $\left.{ }_{[35]}\right)$ The average skill demand is the average of the numeracy, literacy, and problem-solving skills of the workers in each sector. The size of the circle indicates the relative size of each industry. Industries are also shaded according to their likelihood of mass layoff. Darker circles (9 and 10) have an annual likelihood above 0.5 percent, while lighter circles $(1,11,13,14,17$, and 18) have an annual likelihood below 0.1 percent. The remaining circles $(3,4,5,6,7,8,12,15$, and 16) indicate an annual likelihood between 0.1 percent and 0.5 percent. Industries are grouped according to the 18 trade in value added (TiVA) aggregation of the ISIC R4 industry classification. Industry labels are as follows: Agriculture, hunting, forestry and fishing (1), Food products, beverages and tobacco (3), Textiles, textile products, leather and footwear (4), Wood, paper, paper products, printing and publishing (5), Chemicals and non-metallic mineral products (6), Basic metals and fabricated metal products (7), Machinery and equipment n.e.c (8), Electrical and optical equipment (9), Transport equipment (10), Manufacturing n.e.c; recycling (11), Electricity, gas and water supply (12), Construction (13), Wholesale and retail trade; Hotels and restaurants (14), Transport, storage, post and telecommunication (15), Finance and insurance (16), Real estate, renting and business activities (17) and Community, social and personal services (18). The Mining and quarrying (2) sector is not shown due to the small size of the industry in most countries. Industry size is the average annual employment over the period 2011 to 2014. European OECD countries included in the analysis are as follows: Austria, Belgium, Switzerland, Czech Republic, Germany, Denmark, Estonia, Spain, Finland, France, Greece, Hungary, Ireland, Iceland, Italy, Luxembourg, Latvia, Netherlands, Norway, Poland, Portugal, Sweden, Slovenia, Slovak Republic, Turkey, and the United Kingdom.

Source: EU-LFS, PIAAC (2013, 2015). 


\subsection{Location, location, location: which regions are most affected by ML and why?}

As mentioned above, the definition of ML adopted in this analysis entails a "spatial" component: the dismissals are concentrated in the same area. Given that workers are not typically perfectly mobile as migration entails a number of economic and social costs, the socio-economic characteristics of the regions in which ML are more likely to take place are important dimensions to analyse in order to fully characterise the phenomenon.

This part of the analysis assesses which socio-economic indicators are associated with the incidence of ML at the regional level. ${ }^{26}$ The regional variables under scrutiny include the share of manufacturing employment; the unemployment rate; the share of older workers (age class 50 to 64 years); and the share of population without tertiary education. These variables are included both in their yearly level and as a five-year cumulate change, in order to disentangle a potentially different effect of the level of a given variable, and of its medium-term trend, respectively. All regressions also include the (log of) total population in the region, and a set of country-year fixed effects, which partial-out the effect of all factors that are constant within countries and years (e.g., employment protection legislations or other national policies). Therefore, all results have to be interpreted as "within country". It is important to stress that these regressions are estimating some simple partial correlations, in order to understand where - rather than why - ML are more likely to happen. The adopted regional classification follows the NUTS2 Eurostat taxonomy. ${ }^{27}$

The results are reported in Table C.6, Annex C. Each explanatory variable is included separately, except in the last column, which reports a "horse-race" regression in which all variables are included. Not surprisingly, the results indicate that those regions that are more affected by the process of structural change - as measured by the decline in the manufacturing share - are those where the incidence of ML is higher. Similarly to the regressions above, this reflects especially the fact that ML are an important channel for structural change also at the regional level. However, regions most affected by ML are not necessarily the most lagging ones in term of economic wellbeing. These regions still have a manufacturing share that is higher than the country average, and their unemployment rate is not different from the national value. The share of older workers also appears to be associated with more ML, while the education level variable is not significant.

Localised mass lay-offs entail important political economy challenges. In some cases, a city or a region can be highly dependent upon a specific industry that serves as the basis for a big share of economic activity and income (see e.g. Moretti, 2010; Greenstone et al., 2010 for local multiplier effects). Examples can be found in the automotive industry in Detroit, U.S., or the steel industry in Tangshan, People's Republic of China. These industries have a disproportionate importance for local policymakers whose objective function often weights on employment. As such, failing to rescue these industries or pushing reforms that would facilitate restructuring can be extremely unpopular, and potentially costly in the face of rigid housing and other markets.

New OECD analysis using highly disaggregated data on MLs from the U.S. (county level) shows considerable heterogeneity as well as concentration of MLs in certain counties (Box 2). Concentration might result in additional challenges to promote the reemployability of laid-off workers, with potential scarring effects over time. This new analysis also suggests that MLs take place in poorer regions where the population has lower levels of education. 


\section{Box 2. Mass lay-offs in U.S. counties}

Official data from the U.S. Bureau of Labor Statistics (BLS) allows for the analysis of ML in the United States in great detail. California and Illinois are the states where the share of ML in total employment is highest (above 1.4\%), while South Dakota and Wyoming show the lowest ML intensities (lower than $0.1 \%$ ). These numbers are broadly in line with ML intensity in E.U. countries, even though the definition is slightly different (the BLS defines ML as collective dismissals involving at least 50 initial claims for unemployment insurance filed against them during a 5-week period). ML are highly spatially concentrated also at county level, and the pattern accentuated strongly during the 2007-09 crisis.

\section{Evolution of the distribution of ML across U.S. counties}

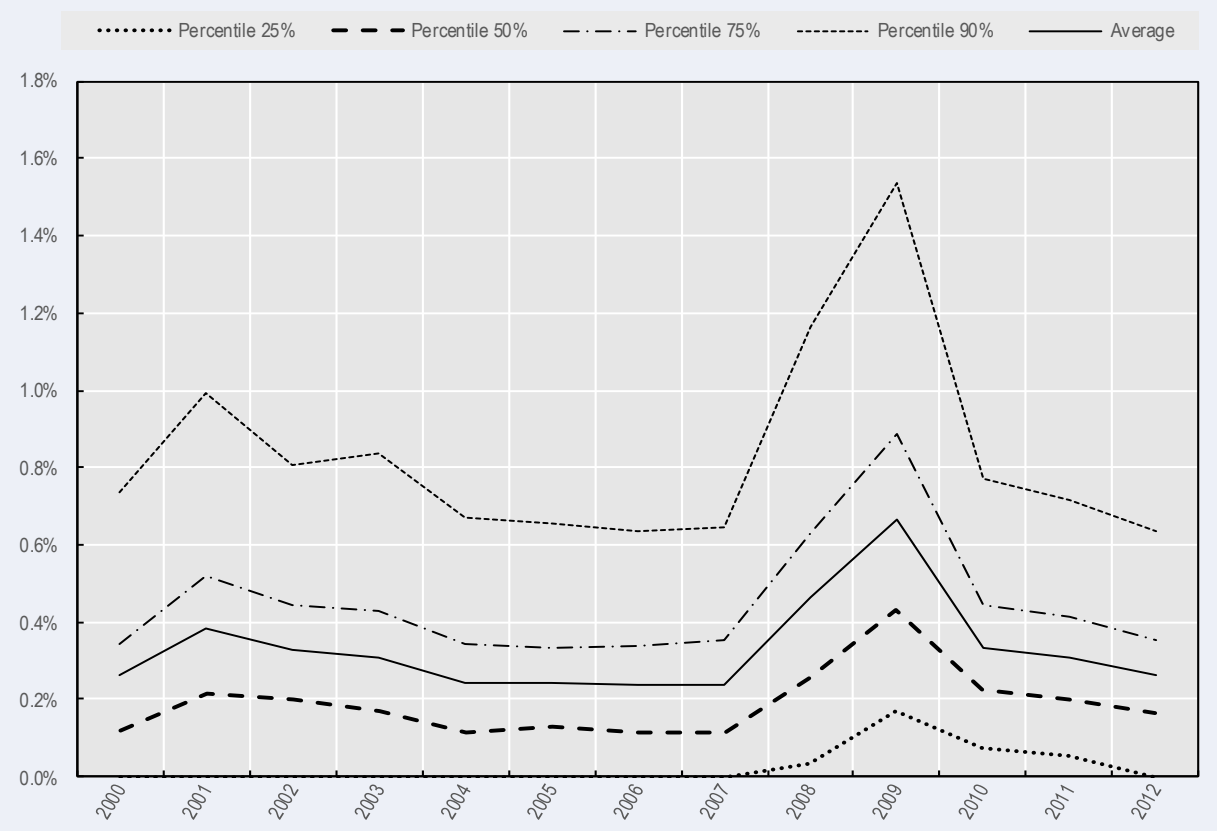

Note: In some cases dismissals by ML do not have a county correspondent and data on population for 5 counties is not available because of definitional inconsistencies.

Source: Authors' elaboration on BLS data (Menon, Moussiegt and Yildiran, 2018[37]).

The determinants of ML by U.S. Metropolitan Statistical Areas (MSA) are examined for the period 2001-12 with an econometric analysis. Not surprisingly, the results show that MLs tend to take place in manufacturing intensive areas. This is broadly in line with the results from the analysis of Table C.6, for European regions, despite methodological differences.

The analysis also suggests that MLs are more prevalent in poorer areas with higher ex-ante levels of unemployment. This finding - which is different from what is found for Europe - might reflect either the different labour market specificities or the more detailed level of geographical analysis (concentration of ML effects in rather delimited geographies). Nevertheless, it raises important concerns regarding the extent to which areas affected by 
MLs can recover from such shocks, given that lower economic performance and higher unemployment rates are likely to make it more difficult for dismissed workers to find new local employment opportunities. This is in line with literature suggesting a relatively high persistence in local unemployment levels (Amior and Manning, 2018 ${ }_{[38]}$; OECD, 2005 [39]). Interestingly, the results also point towards a possible positive association between ML and patents, suggesting that MLs might be more prevalent in more innovative regions. This could be associated with changing product landscapes, changing production process and other pressures driving structural adjustment. It could also be that these regions contain technology intensive firms, which are found to be more dynamic and volatile (Brynjolfsson et al., 2008 $\left.{ }_{[40]}\right)$. The econometric analysis indicates that this result should however be seen as part of a broader set of local specificities driving MLs.

In line with the E.U. data, MLs in the United States tend to take place in regions with older working population. This is likely to add to the policy challenges since older workers are more likely to have obsolete skills and may be less responsive to re-training efforts. Finally, regions where the share of the population without tertiary education is higher tend to be more prone to MLs. As skill-biased technological change drives job creation in sectors requiring higher competences, these may end up trapped in lower-skilled jobs or face a growing risk of long-term unemployment. This result reinforces the importance of policy efforts to retrain and reskill workers.

Source: Menon, Moussiegt and Yildiran (2018[37]) 


\section{Policy implications}

Localised mass lay-offs in mature sectors raise a number of policy challenges. Supposedly, their prominence in the policy debate can be explained by at least two concomitant reasons. First, laid-off workers in mature sectors are often low-skilled with rather limited reemployability prospect in other sectors of the economy. Second, in order to minimise the costs of operating labour- and space-intensive plants, affected plants tend to be historically located in areas characterised by lower wages and land prices. Insofar as lower wages are associated with a low-skilled labour force, the exposure to globalisation and digitalisation challenges might mean that the capacity of reabsorption of the dismissed workforce in these regions could be very limited. The joint effect of these two factors may contribute to explain why localised mass lay-offs in mature sectors constitute a very complex challenge.

\subsection{Implications of the main empirical findlings}

The results in this paper show that some of the factors that have been found to drive overall changes in employment across industries (e.g. technology and globalisation) do not seem to work through the channel of mass layoffs. For instance, digitalisation and automation are not found to be associated with an increase in the likelihood of ML, once overall employment changes are controlled for - data on job dismissals and on gross jobdestruction at country-industry level would further refine this analysis. ${ }^{28}$ The results for globalisation are less clear-cut. While both the relative weight of multinational enterprises (MNEs) and backward GVC linkages are positively associated with ML, the evidence is mixed for other measures of globalisation, raising questions about the extent to which free trade puts workers at significant risk of ML.

The empirical results also suggest that policy-induced distortions in international markets, in the form of subsidies or other forms of government support to firms and sectors, are found to be associated with ML. Mass lay-offs are also found to be associated with idiosyncratic technological features that allow (or inhibit) sectors to adjust smoothly, as well as labour market characteristics.

The concerns about ML should be put into the context of the broader discussion about job displacement. This report shows that MLs are a relatively small share of all dismissals and affect a rather small fraction of the labour force. ${ }^{29}$ Moreover, results suggest that the reemployment prospects of workers who are dismissed in the sectors where mass-layoffs prevail are not universally worse than those of displaced workers from other industries. This points to the conclusion that addressing mass-layoff problems should be part of a broader strategy to help displaced workers, one based on well-designed lifelong learning and activation policies. This is in line with the idea that policy action should aim at protecting workers, rather than at protecting specific jobs in certain industries. In the area of labour market policies, discussed below, some countries are already adopting policies that avoid offering support to certain industries and instead offer re-employment services that are tailored to the effective severity of the layoff episode and to the capacity of the local public employment service (PES). The Rapid Re-employment and Training Service (RRTS) that exists in Ontario (Canada) offers a clear example.

Of course, it should be acknowledged that the concentration of ML in specific regions, particularly manufacturing-intensive regions who are undergoing a sharp deindustrialisation process, may justify a special focus to avoid growing regional disparities 
and mounting social costs. Concentration of ML events in particular, might result in additional challenges to promote the re-employability of laid-off workers, with potential scarring effects over time. Policymakers might wish to consider whether there is any scope for targeted regional development policies in alleviating the socioeconomic costs of localised ML. Policies that can facilitate labour mobility across regions (and countries) might also help to minimise the scarring effects of ML that are locally concentrated. However, a more detailed analysis of regional development and migration policies goes beyond the current scope of this paper.

\subsection{The role of policy}

Policy action can affect the incidence and respond to the consequences of mass lay-offs in a number of ways. Interventions in this area can be divided in two broad categories: policies to assist firms, and policies that target workers - the empirical analysis in this report focuses only on the former. Policies directed towards firms can include rescue and restructuring interventions (and other support policies), but also more general policies which affect framework conditions, such as international trade agreements. The policies directed towards workers, on the other hand, cover re-skilling and training, other active labour market policies, and social protection. Interventions within these two broad policy areas can be further classified along the dimensions illustrated in Table 3.

Table 3. Taxonomy for policies affecting mass lay-offs

\begin{tabular}{ccccc}
\hline Level of intervention & Timing of intervention & Geographical scope & Sectoral scope & Spillovers \\
\hline Firm & Ex-ante & International & Horizontal & Narrow \\
Worker & Ex-post & National & Targeted & Broad \\
& & Regional / Local & & \\
\hline
\end{tabular}

First, policies can be preventive in nature (e.g. profiling workers at risk of dismissal, and providing counselling prior to a potential layoff) and aim at either reducing the incidence of mass layoffs or helping workers to prepare for the possibility of a layoff. The crosscountry heterogeneity in the incidence of mass layoffs documented above may itself be partly driven by differences in the kinds of preventive policies countries have in place. An example, which is unique to the United States, is the experience rating of employer contributions to the unemployment insurance (UI) system, which constitutes a disincentive to mass layoffs. ${ }^{30}$ Alternatively, policies can provide ex-post remedies (e.g. worker jobsearch assistance). Second, policies might target or favour certain sectors considered to be strategic, either explicitly or implicitly (e.g. policies designed to reward energy efficiency is likely to favour energy intensive sectors). Third, policies also vary according to their spatial scope. Active labour market policies, for example, can be targeted at local communities affected by mass-layoffs. Policies that facilitate labour mobility across regions (and countries) might influence the social costs associated with mass lay-offs in the targeted area.

Beyond these dimensions, it is worth stressing that policies may have important unintended consequences, both domestically and internationally. For instance, support measures aimed at preventing the relocation or closure of certain plants may be effective in limiting the direct societal costs of large lay-offs as well as the sunk costs of capital investment in the short- and medium-term. However, they may result in employment and capital being "trapped" in inefficient firms, with low wage and profit levels. 
Insofar as some policy actions in one country may affect other countries - as it is suggested by the empirical analysis - an important policy discussion is related to multilateral coordination efforts, at international level, of domestic policy interventions towards firms with possible distortionary effects.

\subsubsection{Helping firms: rescue and restructuring interventions, and other support policies}

A number of national policy interventions have been introduced to encourage the restructuring of firms in mature sectors. The aim of these policies typically is to temporarily support firms that are experiencing major difficulties, but which operate a potentially viable business. The support is conditional on a restructuring plan and generally takes the form of direct grants, public guarantees, or equity injections.

In the European Union, state aid spending by EU member countries for rescue and restructuring ${ }^{31}$ is admitted only in certain circumstances, and it is closely monitored by the competition authority of the European Commission. The most recent guidelines, released in 2014, states that "Rescue and restructuring aid are among the most distortive types of State aid" (European Commission, 2014 ${ }_{[41]}$ ) and deeply reformed the previous framework under which these interventions can be authorised. In particular, the new 2014 guidelines state that aid should pursue an objective of common interest, by preventing social hardship or addressing market failures (European Commission, 2014 ${ }_{[41]}$ ). ${ }^{32}$ Between 2005 and 2014, and without counting aid granted under special crisis regimes, Member States together granted around EUR 9.5 billion in rescue and restructuring aid (Figure 10).

Figure 10. State aid spending by EU member countries: rescue and restructuring

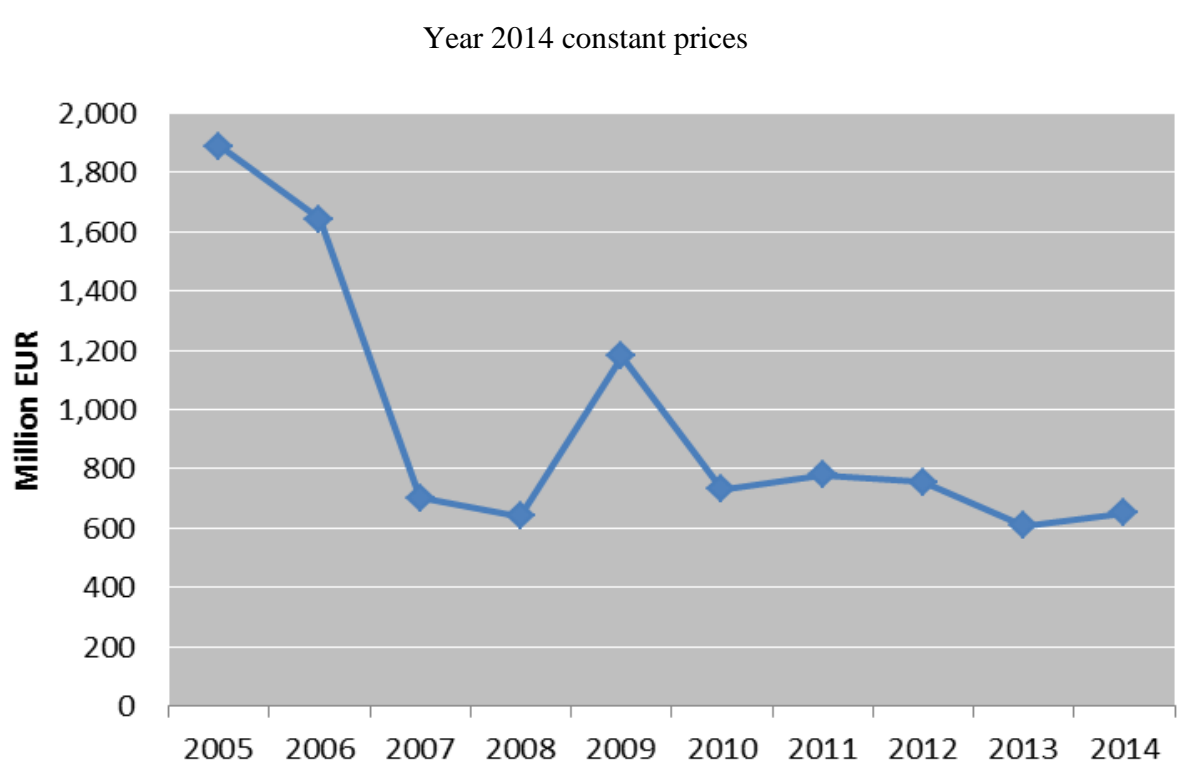

Note: the figure includes aid measures to manufacturing industries, services, agriculture and fisheries, for which the European Commission adopted a formal decision or received an information fiche from the EU28 Member States regarding measures qualifying for exemption under the General Block Exemption Regulation. Source: European Commission (2015), State Aid Scoreboard 2015. DG-COMP, Bruxelles.

Structural adjustment is complex and can be particularly challenging in regions where economic activity is concentrated around a sector or a cluster of industries. It is therefore 
important that companies and industries are given some time to adjust, notably when facing shocks and disruptive changes. However, it is equally important to ensure that relief (in its most varied forms) is not providing a lifeline to a declining industry, supporting "zombie" companies or hampering the forces of allocative efficiency across (as well as within) industries.

Ensuring that firms can remain competitive might help avoid costly adjustments. Contrary to policies deployed to explicitly slowdown the adoption of new technologies and innovative production processes - which are unlikely to help prevent ML as shown in this paper - public resources could instead be redirected to support the research and deployment of innovative technologies that would help industries remain competitive. The latter approach is consistent with the actions taken by some governments in the context of the so-called "industry 4.0 " plans.

In light of the absence of any meaningful association between domestic government interventions and ML, policymakers may wish to consider focusing on addressing market failures and removing policies that act as barriers to firm exit and resource reallocation. In the meantime, providing support for workers - rather than firms (see e.g. the case of the Swedish shipbuilding restructuring in the late 1970s (Hamilton, 1983 ${ }_{[42]}$ )) — in regions affected by structural change could greatly facilitate the structural adjustment process. This is also part of a very timely policy discussion around the effectiveness of support programmes provided to workers affected by trade - see for example the recent reports by (Claeys and Sapir, 2018 ${ }_{[43]}$ ) on the E.U.'s Globalisation Adjustment Fund scheme and by (USITC, 2017 ${ }_{[44]}$ ) on the U.S.'s Trade Adjustment Assistance Program.

\subsubsection{Helping workers: training, active labour market policies and social protection}

A comprehensive strategy to assist workers in the face of labour market transformations that may lead to MLs (or, more generally, to individual dismissals), needs to combine training policies to help workers acquire new skills, active labour market policies to assist with their job search, and effective social protection to support them during the transition period. The new OECD Jobs Strategy provides a structured framework to design such a comprehensive policy package (OECD, 2018 $\left.8_{[1]}\right)$.

In order to enhance the re-employability prospects of laid-off workers, an effective system of re-training is crucial. Scaling up and improving the effectiveness of lifelong learning systems for adults should be a policy priority. Lack of re-training opportunity is a particularly acute problem among the most disadvantaged groups. Throughout the OECD, low- and medium-skill workers are the least likely to receive training, even though they may be facing the greatest risk of job loss $\left(\mathrm{OECD}, 2013_{[36]}\right)$. This is partly the reflection of limited opportunities offered to these groups, and partly the result of lower returns to training which weaken the incentives for workers' participation. An index of readiness to learn calculated by the OECD in Education at a Glance (OECD, 2016 ${ }_{[45]}$ ) shows how the low-skilled are the least well prepared for further participation in learning. Strengthening lifelong learning systems entails offering better incentives for workers and firms to re-skill and up-skill. Training opportunities should be widely available and not necessarily linked to one's work status or workplace. A recent example is the introduction in France of the Compte personnel d'activité, which allows workers to preserve accumulated training rights throughout their careers, even when they switch employer.

To help laid-off workers transition to new opportunities, it is also essential to (a) provide them with a safety net to ensure that they and their families do not fall into poverty, and (b) 
assist them in their job search with active labour market policies. The former include unemployment benefits and other forms of social assistance that might help to compensate for the loss of income resulting from displacement. The latter encompass both pre-emptive measures (carried prior to displacement), such as skills-profiling and counselling, and expost measures such as job-search assistance. Crucially, the provision of welfare benefits should be designed in conjunction with activation measures to maximise the chance of reemployment and minimise disincentives to work, including in the difficult case of midcareer workers who are displaced by structural economic change and need to switch industry or occupation. As highlighted in recent OECD work, an effective activation framework should have three key objectives: i) motivate jobseekers to actively pursue employment; ii) improve their employability; and iii) expand the set of opportunities for them to be placed and retained in appropriate jobs (OECD, 2015 $[46])$.

As much as possible, activation measures for workers should also be preventive (OECD, $\left.2018_{[1]}\right)$, taking into account ongoing megatrends and the likely risk of job loss in different sectors, and providing workers with adequate information, counselling and re-employment support ahead of their potential displacement (e.g. during the notice period prior to a mass redundancy). Using statistical profiling techniques to provide tailored support on the basis of workers' characteristics and interests can increase the effectiveness of these measures. Social partners can play an important role in providing adjustment assistance to workers who will be displaced, tailoring the support offered to the specific needs of the affected workers and already beginning to deliver that assistance during the notification period. The Swedish Job Security Councils (JSCs) are an example of the fundamental contribution social partners can make. The councils are based on collective agreements between the social partners in a sector or occupational field, such as white-collar workers in the private sector. JSCs are actively involved in all stages of the process of restructuring, including by providing advice to employers and trade unions at an early stage in the process. They also provide transition services and guidance to workers who are made redundant, through individual counselling, career planning, job-search assistance, outplacement services and retraining (OECD, 2018 $\left.8_{[4]}\right)$.

While these are the general principles that should guide the design of a broad array of labour market policies, it is important to recognise that displaced workers, and especially certain groups among them, may need tailored interventions to address specific challenges. In particular, less skilled (blue collar) workers who are dismissed after a relatively long tenure in their job may face a high risk of long-term unemployment and the prospects of significant earning drops when re-employed. This may require specific and timely solutions. In light of these challenges, policy makers in a number of countries have devised specific programs for such groups at risk.

In Ontario (Canada), for instance, the Rapid Re-employment and Training Service (RRTS) provides an immediate response to large-scale layoffs with the objective of connecting individuals with Employment Ontario (PES) services to help them regain employment. The level and type of support offered is tailored to the severity of the layoff and the capacity of the local employment service providers, which are typically third-party providers, such as non-profit firms, that the PES has engaged to offer employment services in a particular locality. Similarly, other countries have set up public programmes to provide reemployment assistance (and sometimes income benefits) to certain subgroups of displaced workers that require more intensive or somewhat different types of assistance than is provided by general ALMPs. Often, these programmes focus on workers who are adversely affected by increased import competition or were employed in one or a few declining sectors. Trade Adjustment Assistance (TAA) in the United States and the more recently 
established European Globalisation Adjustment Fund (EGF) in the European Union are the most prominent examples of programmes targeted at trade displaced workers, while Australia has placed a particular emphasis on sectoral adjustment programmes (for additional details, see OECD $\left.\left(2018_{[4]}\right)\right)$. To mitigate the risk of significant earning drops once displaced workers are re-employed, an additional possibility would be to design systems of wage-insurance. The design, however, would pose a number of challenges and the existing evidence to assess the effectiveness of such schemes is limited.

\subsubsection{Trade and international co-operation}

Trade tensions have been rapidly increasing as globalisation, on the one hand, and unfair trade practices, on the other hand, are blamed for de-industrialisation trends, plant closures, job losses, and income decline. Insofar as job losses resulting from mass-layoffs are concerned, the analysis in this paper suggests that while a number of policy levers and strategies could help lowering the risks of ML, trade in itself does not appear to be the underlying reason for ML. However, while government support to companies and sectors in one country does not reduce the likelihood of ML in that same country, it might increase the risk of ML for trade partners. Policymakers should therefore consider working towards ensuring that trade can remain not only open, but also as free of distortions as possible.

To achieve this, it would be important to rely on international dialogue and make full use of the different multilateral mechanisms and global fora that can help addressing unfair trade, and more importantly its root causes. The root causes of trade tensions often reside in undue advantages granted to companies and industries both in the form of subsidies and other forms of government support. The results shown in this paper suggest that the extent to which a sector is subsidised by foreign competitors increases the incidence of domestic MLs. Therefore, international co-operation working towards the removal of policy-induced distortions and a level playing field amongst trade partners could greatly contribute to avoiding ML and the associated socioeconomic costs that result from unfair trade. Strengthening international co-operation, the OECD is very well placed to support multilateral work to level the international playing field, a topic that was key in the discussions of the 2018 OECD Ministerial Council Meeting (OECD, 2018 $8_{[2]}$ ). 


\section{Conclusions and next steps}

This paper is a first step towards a better understanding of the drivers and implications of structural adjustment and employment reallocation, with a focus on mass lay-offs, i.e., collective dismissals of a large number of workers in a short period of time and in a single establishment. The incidence of mass lay-offs - despite accounting for a relatively small share of all dismissals - may create in some circumstances disproportionate social costs, including the risk of long unemployment spells for affected workers. Additional complexity in this policy area arises because of the possible distortionary effects of policy interventions in support of companies or sectors.

The findings from the analysis bear important policy implications. On the one hand, they underscore the importance of sound training, activation, and social protection policies to minimise the welfare and social costs of mass-layoff, especially in the regions where they are most frequent. On the other hand, the analysis highlights that mass-layoffs are only a small fraction of total job displacement and tackling the challenges they entail should be part of a broader policy strategies aimed at dealing with job displacement more generally.

Moreover, the results suggest that domestic government interventions in support of firms and sectors might not directly prevent mass lay-offs, while foreign government interventions appear to be associated with mass-layoffs. This points to an important policy recommendation: governments should work towards co-ordinated responses to policyinduced market distortions that result in trade frictions and can lead to the displacement of workers in the economies of trade partners. Furthermore, systematic support to declining sectors or companies may distort the optimal allocation of labour and hamper productivity in the long run. This may also result in welfare losses for the affected workers, to the extent that it would be possible for them to be employed in a more productive job. Policy action should aim at protecting workers, rather than at protecting specific jobs in certain industries. Policymakers might also wish to consider whether there is any scope for targeted regional development policies in alleviating the socioeconomic costs of geographically concentrated MLs.

The data used for the analysis entails a number of limitations (e.g. geographical scope, level of aggregation, and lack of detailed information on the magnitude of government support) and strengthening the research agenda in this area should be a priority. A number of research initiatives could be pursued, ranging from a careful impact assessment of rescue and restructuring interventions to a cross-country investigation of the repercussions of ML on local labour markets.

For instance, work in this area may identify the sectors and types of business which are more likely to hire workers that were formerly employed in sectors with high incidence of ML. Similarly, further analysis may look at the geographical component of reabsorption patterns, assessing whether cities and regions differ in the extent to which they are able to reabsorb displaced workers, as well as the extent to which unemployed workers migrate to areas with better employment prospects.

A further extension of this project could consist in assessing whether the incidence of ML is associated with distortionary domestic policies and to resource misallocation in the affected countries and sectors. Rescue interventions may result in employment and capital being "trapped" in inefficient firms, with low wages and profit levels. This stream of research may also contribute to building the evidence base that could help to strike the right 
balance between policies aimed at preventing dismissals, on the one hand, and policies aimed at facilitating the re-employment of dismissed workers, on the other. The evidence presented in this report shows that national framework conditions account for a larger share of the difference in the probability of workers being affected by ML, compared to crosssector differences. This suggests that the adequate mix of active labour market policies and measures to foster economic dynamism may play a very important role in fostering and streamlining employment reallocation in the event of ML.

An improvement of the indicators of government support would also be an important area for further work. The availability of comprehensive information on government support measures to firms and sectors, including the order of magnitude and targeted firms is lacking. There are two main avenues for improving information in this area. First, member countries could help by contributing with additional and more detailed data (e.g. on the magnitude of policy interventions), as well as clarifications that would help ensure that coverage is as exhaustive as possible and that support measures are accurately recorded. Second, the increased availability of web scrapping tools, combined with semantic analysis and machine learning could, in theory, be used to construct more accurate measures of government support. An identical methodology could also be used to collect information on actual lay-offs to help improve the ML indicator and disentangle whether public intervention can affect the difference between planned and actual ML - i.e. business strategy. Any of these suggested methodological approaches would however be extremely resource intensive and not necessarily guarantee full coverage. In addition, the indicators discussed thus far only measure support directed at firms. It would be important to scope for the possibility of constructing detailed indicators of support measures provided to workers (at the firm-level, or at least by industry). Such data would be instrumental for an analysis explicitly comparing two distinct types of approaches (helping firms vis-à-vis helping workers) that could inform the design of policies to minimise the social and economic costs associated with mass lay-offs, and dismissals more broadly. 


\section{Notes}

${ }^{1}$ Defined as collective dismissals affecting more than 100 employees in an establishment (or at least $10 \%$ of the workforce in establishments with more than 250 people).

${ }^{2}$ Recent OECD work on seven European countries (Germany, Sweden, Denmark, Portugal, Finland, the United Kingdom, and France) indicates that mass layoffs account for only $15 \%$ of all layoffs $\left(\mathrm{OECD}, 2018_{[4]}\right)$. The same study suggests that a comparable figure for the United States is around $20 \%$.

${ }^{3}$ The steel industry is a paradigmatic case. While the industry represents on average only $0.3 \%$ of total employment in the OECD area, the risk of lay-offs and closures resulting from the excess capacity crisis since 2015 have gathered considerable media and policy attention - see e.g. (FT, $\left.2016_{[54]}\right)$ for steel closures in the U.K. or (FT, 2016 $\left.6_{[55]}\right)$ for closures in the U.S.- , and prompted the deployment of an increasing number of trade remedy measures targeting steel products (OECD, $\left.2017_{[3]}\right)$.

${ }^{4}$ For empirical purposes, defined as collective dismissals affecting more than 100 employees (or at least $10 \%$ of the workforce in establishments with more than 250 people) - see Annex A for further details.

${ }^{5}$ Mass layoffs only account for $15 \%$ of mass layoffs in 7 European countries (Germany, Sweden, Denmark, Portugal, Finland, the United Kingdom, and France) analysed in a recent OECD study on displaced workers $\left(\mathrm{OECD}, 2018_{[4]}\right)$. The same study suggests that a comparable figure for the United States is around $20 \%$.

${ }^{6}$ Job separations are defined as the difference between the hiring rate and net employment change. Data on the share of displacements in job separations is available for a selected number of countries and in most cases only up until 2008. The share of displacements in total separations varies between 8.6 and $36.1 \%$ across countries, but more recent data might yield higher estimates.

7 Cf. http://eur-lex.europa.eu/legal-content/EN/TXT/?uri=celex\%3A52014XC0731\%2801\%29 visited on 22 March 2018.

8 Cf. http://www.mise.gov.it/index.php/it/194-comunicati-stampa/2037816-calenda-da-cipe-1miliardo-e-50-milioni-per-gestire-reindustrializzazioni visited on 22 March 2018.

${ }^{9}$ Huttunen, Møen and Salvanes $\left(2011_{[13]}\right.$ ) focus on male workers displaced by plant closure and job separations from Norwegian plants that downsize by $30 \%$ or more in the years 1991-1998. The analysis uses administrative data that allows to track workers (and plants) through time, regardless of their labour market status

10 The extent of any cross-country biases is limited by the introduction of country-fixed effects in the regression analysis.

${ }^{11}$ Net employment change is included as an explanatory variable. Economies of scale and other size effects are taken into account both in terms of industry fixed effects in the main regressions, as well as in additional regressions that include an explanatory variable controlling for the share of 
employment in medium-sized and large firms. Regressions using lagged values of the employment variables to address endogeneity concerns yield comparable results.

${ }^{12}$ See the additional regression results for trade measures (Table 5) in Annex C.

${ }^{13}$ See http://mneguidelines.oecd.org/guidelines/

${ }^{14}$ Measures implemented at the border (either to protect certain industries or to address unfairly traded products) are not directly relevant for this project. Information on support programmes designed to assist workers is not available.

${ }^{15}$ The measure also varies slightly across countries, as the value of each country is excluded from the average of its own indicator.

${ }^{16}$ The results are also robust to a specification that allows for a lagged time effect between the policy interventions and the ML events. Tests indicating the domestic and foreign indicator are not strongly correlated suggest that collinearity between these variables should not be a concern.

${ }^{17}$ Robustness tests using an indicator of domestic interventions weighted by the jurisdiction's global share of imports in the specific sector - to account for the importance of that jurisdiction in global trade — do not yield different results.

${ }^{18}$ See http://www.oecd.org/els/emp/onlineoecdemploymentdatabase.htm.

${ }^{19}$ Regression results using an indicator that incorporates both individual and collective protection are broadly in line with the findings described in this Section.

${ }^{20}$ A more detailed extraction of the European Labour Force Survey micro-data is required in order to present more in-depth results.

${ }^{21}$ A third group of respondents is not included: those who were unemployed one year before the interview and are currently employed. This group is excluded because the exact duration of their unemployment spell prior to getting their current job is unknown.

${ }^{22}$ Clearly, given the small incidence of mass layoffs as a fraction of total employment, one might not expect the risk of mass layoff to be strongly correlated with differences in re-employability prospects across sectors. This is an important result, nonetheless, since it points to the conclusion that equal policy attention should be dedicated to workers at high risk of mass layoff as to those who are dismissed from sectors where the incidence of mass layoff is lower.

${ }^{23}$ Industries are aggregated from the NACE Revision 2 classification into 18 separate sectors outlined in the Trade in Value Added (TiVA) database.

${ }^{24}$ This estimate is weighted, taking into account country-specific distributions of employment in each industry. The distances are weighted by average annual employment within each sector-country pairing according PIAAC. While the benchmark year for the weighting differs for each country, PIAAC Round 1 countries in general use 2011 as the benchmark, while Round 2 countries use 2014.

${ }^{25}$ Some countries did not conduct a measurement of problem-solving skills, namely France, Italy, and Spain. For these countries problem-solving skills ability was imputed using the average skill level for each industry in countries that did evaluate problem-solving.

${ }^{26}$ The sectoral breakdown of the ML data is not exploited, as other regional variables are generally not available at sectoral level.

27 NUTS2 taxonomy corresponds for example to Régions in France, Regioni in Italy, Regierungsbezirke in Germany. The countries covered are Austria, Belgium, Czech Republic, 
Estonia, Finland, Greece, Hungary, Ireland, Italy, Lithuania, Luxembourg, Latvia, the Netherlands, Poland, Portugal, Spain, Sweden, Slovak Republic and the United Kingdom.

${ }^{28}$ Such data would be instrumental to an analysis explaining the differences between ML and other types of dismissals.

${ }^{29}$ Further analysis using data on gross job destruction would help shed some more light on this.

30 Experience rating of employer contributions is a method by which employer contribution payments are varied on the basis of each individual employer's experience with unemployment: higher payroll tax rates are imposed on firms that have laid-off more workers in the past. Experience rating is based on the proposition that the cost of unemployment compensation should be shared in such a way that employers whose workers experience the most involuntary unemployment contribute at a higher rate to provide incentives to firms to minimise layoffs (OECD, 2016[58]).

${ }^{31}$ The European Commission distinguishes between rescue aid and restructuring aid. Rescue aid is designed to allow firms that are facing imminent collapse to stay in business for long enough to prepare a restructuring plan. The support must be in the form of liquidity support (loans or guarantees) and has a maximum duration of six months. If further public support is needed after that, it must be in the form of restructuring aid. Restructuring aid aims at supporting firm restructuring and their return to long-term viability. It can be granted for a longer period than rescue aid, but must be accompanied by a detailed restructuring plan (although a simplified procedure is admitted for SMEs) that meets a number of conditions, including - under the new guidelines - a comparison with a credible alternative scenario not involving State aid.

${ }^{32}$ Furthermore, losses that the firm has accumulated in the past must be allocated to the firm stockholders before any State aid can be granted. The new regime also requires that the State receive a fair share of the upside benefits. 


\section{References}

Acemoglu, D. and P. Restrepo (2017), Robots and Jobs: Evidence from US Labor Markets, National Bureau of Economic Research, Cambridge, MA, http://dx.doi.org/10.3386/w23285.

Amior, M. and A. Manning (2018), "The persistence of local joblessness", American Economic Review, http://dx.doi.org/10.1257/aer.20160575.

Andrews, D. and A. Saia (2017), "Coping with creative destruction: Reducing the costs of firm exit”, OECD Economics Department Working Papers, No. 1353, OECD Publishing, Paris, http://dx.doi.org/10.1787/bbb44644-en.

Asao, Y. (2011), "Overview of non-regular employment in Japan", in JILPT Report: Nonregular employment, issues and challenges common to the major developed countries, The Japan Institute for Labour Policy and Training.

Baldwin, R. (2016), The great convergence : information technology and the new globalization, Harvard University Press.

Bassanini, A., G. Brunello and E. Caroli (2017), "Not in My Community: Social Pressure and the Geography of Dismissals", Journal of Labor Economics, Vol. 35/2, pp. 429-483, http://dx.doi.org/10.1086/689285.

Bechichi, N. et al. (2018), "Moving between jobs: An analysis of occupation distances and skill needs", OECD Science, Technology and Industry Policy Papers, No. 52, OECD Publishing, Paris, http://dx.doi.org/10.1787/d35017ee-en.

Blanchard, O. and L. Katz (1992), "Regional Evolutions", Brookings Papers on Economic Activity, Vol. 23/1, pp. 1-76,

https://econpapers.repec.org/article/binbpeajo/v_3a23_3ay_3a1992_3ai_3a1992-1_3ap_3a176.htm (accessed on 28 March 2018).

Bloom, N. et al. (2014), "The Distinct Effects of Information Technology and Communication Technology on Firm Organization", Management Science, Vol. 60/12, pp. 2859-2885, http://dx.doi.org/10.1287/mnsc.2014.2013.

Bound, J. and H. Holzer (2000), "Demand Shifts, Population Adjustments, and Labor Market Outcomes during the 1980s", Journal of Labor Economics, Vol. 18/1, pp. 20-54, http://dx.doi.org/10.1086/209949.

Brynjolfsson, E. et al. (2008), "Scale without Mass: Business Process Replication and Industry Dynamics", Technology \& Operations Mgt. Unit Research Paper, No. No. 07-016, Harvard Business School, http://ssrn.com/abstract=980568http://ssrn.com/abstract=980568http://ssrn.com/abstract=980 $\underline{568}$ (accessed on 26 October 2018).

Claeys, G. and A. Sapir (2018), "The European Globalisation Adjustment Fund: Easing the pain from trade?", Policy Contribution, No. 5, Bruegel, http://bruegel.org/wpcontent/uploads/2018/03/PC-05_2018_2303.pdf (accessed on 28 March 2018).

De Backer, K. et al. (2018), "Industrial robotics and the global organisation of production", OECD Science, Technology and Industry Working Papers, No. 2018/03, OECD Publishing, Paris, http://dx.doi.org/10.1787/dd98ff58-en.

De Stefano, T., S. Haneda and H. Kwon (2018), "The nature of employee composition amongst Japanese manufacturers", RIETI Discussion Paper Series, No. forthcoming. 
De Stefano, T., R. Kneller and J. Timmis (2016), "Information Communication Technologies and Firm Performance: Evidence for UK Firms", Discussion Papers in Economics, No. 2016/01, University of Nottingham, https://www.nottingham.ac.uk/economics/documents/discussion-papers/2016-01.pdf (accessed on 28 March 2018).

De Stefano, T., R. Kneller and J. Timmis (2014), "The (Fuzzy) Digital Divide: The Effect of Broadband Internet Use on UK Firm Performance", Discussion Papers in Economics, No. 14/06, University of Nottingham, https://www.nottingham.ac.uk/economics/documents/discussion-papers/14-06.pdf (accessed on 28 March 2018).

Deily, M. (1991), "Exit Strategies and Plant-Closing Decisions: The Case of Steel”, The RAND Journal of Economics, Vol. 22/2, pp. 250-263, http://dx.doi.org/10.2307/2601021.

Dobson, A. and A. Barnett (2008), An introduction to generalized linear models, CRC Press, https://www.crcpress.com/An-Introduction-to-Generalized-Linear-Models-ThirdEdition/Dobson-Dobson-Barnett/p/book/9781584889502 (accessed on 28 March 2018).

European Commission (2014), Guidelines on State aid for rescuing and restructuring nonfinancial undertakings in difficulty, European Commission, http://eur-lex.europa.eu/legalcontent/EN/TXT/PDF/?uri=CELEX:52014XC0731(01)\&from=EN (accessed on 28 March 2018).

Evenett, S. and J. Fritz (2017), The Global Trade Alert database handbook, Manuscript, https://www.dropbox.com/s/i5hnf27nnnz21nq/GTA\%20handbook.pdf?dl=1.

Foote, A., M. Grosz and A. Stevens (2015), Locate Your Nearest Exit: Mass Layoffs and Local Labor Market Response, National Bureau of Economic Research, Cambridge, MA, http://dx.doi.org/10.3386/w21618.

Frey, C. and M. Osborne (2017), "The future of employment: How susceptible are jobs to computerisation?", Technological Forecasting and Social Change, Vol. 114, pp. 254-280, http://dx.doi.org/10.1016/J.TECHFORE.2016.08.019.

FT (2016), Cheap imports put US Steel under pressure, Financial Times, https://www.ft.com/content/fd25e75c-fd40-11e5-b5f5-070dca6d0a0d (accessed on 28 March 2018).

FT (2016), “Tata UK: the options for rescuing Britain's biggest steelmaker", Financial Times, https://www.ft.com/content/c10017aa-f653-11e5-803c-d27c7117d132 (accessed on 28 March 2018).

Gathmann, C., I. Helm and U. Schönberg (2017), "Spillover Effects of Mass Layoffs", University College London, https://www.uniheidelberg.de/md/awi/professuren/amnpoe/displacementeffects_12march2017combined.pdf (accessed on 28 March 2018).

Gathmann, C., I. Helm and U. Schönberg (2014), "Spillover Effects in Local Labor Markets: Evidence from Mass Layoffs", Annual Conference 2014 (Hamburg): Evidence-based Economic Policy, https://ideas.repec.org/p/zbw/vfsc14/100378.html (accessed on 28 March 2018).

Graetz, G. and G. Michaels (2015), "Robots at work", http://eprints.lse.ac.uk/61155/ (accessed on 28 March 2018). 
Grundke, R. et al. (2017), "Having the right mix: The role of skill bundles for comparative advantage and industry performance in GVCs", OECD Science, Technology and Industry Working Papers, No. 2017/03, OECD Publishing, Paris, http://dx.doi.org/10.1787/892a4787en.

Hamilton, C. (1983), "Public subsidies to industry: the case of Sweden and its shipbuilding industry", Staff Working Paper, No. SWP566, World Bank, http://documents.worldbank.org/curated/en/659851468777616048/Public-subsidies-toindustry-the-case-of-Sweden-and-its-shipbuilding-industry (accessed on 28 March 2018).

Hane-Weijman, E., R. Eriksson and M. Henning (2018), "Returning to work: regional determinants of re-employment after major redundancies", Regional Studies, Vol. 52/6, pp. 768-780, http://dx.doi.org/10.1080/00343404.2017.1395006.

Hardy, W. (2016), Occupation classifications crosswalks - from O*NET-SOC to ISCO - IBS Instytut Badań Strukturalnych, Institute for Structural Research (IBS), http://ibs.org.pl/en/resources/occupation-classifications-crosswalks-from-onet-soc-to-isco/ (accessed on 28 March 2018).

Hoekman, B. (2015), "Subsidies and Spillovers in a Value Chain World: New Rules Required", RSCAS Policy Papers, No. 03, Robert Schuman Centre for Advanced Studies, http://cadmus.eui.eu/bitstream/handle/1814/36635/RSCAS_2015_03.pdf?sequence=1\&isAllo wed $=y$ (accessed on 25 October 2017).

Huttunen, K., J. Møen and K. Salvanes (2018), “Job Loss and Regional Mobility”, Journal of Labor Economics, Vol. 36/2, pp. 479-509, http://dx.doi.org/10.1086/694587.

Huttunen, K., J. Møen and K. Salvanes (2011), "How destructive is creative destruction? Effects of job loss on job mobility, withdrawal and income", Journal of the European Economic Association, Vol. 9/5, pp. 840-870, http://dx.doi.org/10.1111/j.1542-4774.2011.01027.x.

Huynh, K. et al. (2017), "Industry shutdown rates and permanent layoffs: evidence from firmworker matched data", IZA Journal of Labor Economics, Vol. 6/1, p. 7, http://dx.doi.org/10.1186/s40172-017-0057-0.

Jofre-Monseny, J., M. Sánchez-Vidal and E. Viladecans-Marsal (2018), "Big plant closures and local employment", Journal of Economic Geography, Vol. 18/1, pp. 163-186, http://dx.doi.org/10.1093/jeg/lbx026.

Menon, C., L. Moussiegt and C. Yildiran (2018), "Analysis of U.S. mass lay-offs", $O E C D$ Science, Technology and Industry Working Papers, No. forthcoming.

Nedelkoska, L. and G. Quintini (2018), “Automation, skills use and training”, OECD Social, Employment and Migration Working Papers, No. 202, OECD Publishing, Paris, http://dx.doi.org/10.1787/2e2f4eea-en.

Notowidigdo, M. (2011), “The Incidence of Local Labor Demand Shocks", NBER Working Paper, No. 17167, National Bureau of Economic Research, Cambridge, MA, http://dx.doi.org/10.3386/w17167.

OECD (2018), "Draft key issues paper", 2018 OECD Ministerial Council Meeting, No. Internal working document C(2018)32/REV1, OECD.

OECD (2018), Good jobs for all in a changing world of work: The OECD jobs strategy, OECD, internal working document $\mathrm{C}(2018) 34$.

OECD (2018), OECD Employment Outlook 2018, OECD (forthcoming). 
OECD (2017), "Making globalisation work: better lives for all", Key Issues paper, Meeting of the OECD Council at Ministerial Level, http://www.oecd.org/mcm/documents/C-MIN-20172-EN.pdf (accessed on 30 March 2018).

OECD (2017), OECD Employment Outlook 2017, OECD Publishing, Paris, http://dx.doi.org/10.1787/empl_outlook-2017-en.

OECD (2017), Steel market developments: Q4 2017, OECD, https://www.oecd.org/sti/ind/steelmarket-developments-Q42017.pdf (accessed on 28 March 2018).

OECD (2016), Back to Work: United States: Improving the Re-employment Prospects of Displaced Workers, Back to Work, OECD Publishing, Paris, https://dx.doi.org/10.1787/9789264266513-en.

OECD (2016), Education at a Glance 2016: OECD Indicators, OECD Publishing, Paris, http://dx.doi.org/10.1787/eag-2016-en.

OECD (2016), “ICTs and Jobs: Complements or Substitutes?”, OECD Digital Economy Papers, No. 259, OECD Publishing, Paris, http://dx.doi.org/10.1787/5jlwnklzplhg-en.

OECD (2016), "New Skills for the Digital Economy", OECD Digital Economy Papers, No. 258, OECD Publishing, Paris, http://dx.doi.org/10.1787/5jlwnkm2fc9x-en.

OECD (2015), "Activation policies for more inclusive labour markets", in OECD Employment Outlook 2015, OECD Publishing, Paris, http://dx.doi.org/10.1787/empl_outlook-2015-7-en.

OECD (2013), "Back to work: Re-employment, earnings and skill use after job displacement", in OECD Employment Outlook 2013, OECD Publishing, Paris, http://dx.doi.org/10.1787/empl_outlook-2013-8-en.

OECD (2005), "How Persistent are Regional Disparities in Employment?", in $O E C D$ Employment Outlook, OECD, https://www.oecd.org/els/emp/36780856.pdf (accessed on 10 December 2018).

Oesch, D. and I. Baumann (2015), "Smooth transition or permanent exit? Evidence on job prospects of displaced industrial workers", Socio-Economic Review, Vol. 13/1, pp. 101-123, http://dx.doi.org/10.1093/ser/mwu023.

Presidente, G. (2017), "Labor Services At Will Regulation of Dismissal and Investment in Industrial Robots *", http://conference.iza.org/conference files/MacroEcon 2017/presidente g25613.pdf (accessed on 28 March 2018).

Sabadash, A. (2013), "ICT-induced Technological Progress and Employment: a Happy Marriage or a Dangerous Liaison? A Literature Review", JRC Working Papers, No. JRC76143, Joint Research Centre, Seville, http://publications.jrc.ec.europa.eu/repository/bitstream/JRC76143/jrc76143.pdf (accessed on 28 March 2018).

Spiezia, V. and M. Vivarelli (2002), "Innovation and employment: A critical survey.", in N. Greenan, L. Y., A. (ed.), Productivity, Inequality and the Digital Economy: A Transatlantic Perspective, Cambridge, MA: MIT Press.

The Washington Post (2015), "The biggest mass layoffs of the past two decades", https://www.washingtonpost.com/news/on-leadership/wp/2015/01/28/the-biggest-masslayoffs-of-the-past-two-decades/?noredirect=on \&utm term=.07b41913aa5e. 
UNCTAD (2017), The International Classification of Non-Tariff Measures (NTMs), UNCTAD, https://unstats.un.org/unsd/class/intercop/expertgroup/2017/AC340-12.PDF (accessed on 28 March 2018).

USITC (2017), Evaluations of the Trade Adjustment Assistance Program for Workers: A Literature Review, U.S. International Trade Commission, https://www.usitc.gov/publications/332/executive_briefings/ebot_taaevaluationsguthlee.pdf (accessed on 28 March 2018).

WWG (2016), Responding to major job losses, What Works Centre for Local Economic Growth (WWG), http://www.whatworksgrowth.org/public/files/Toolkits/16-1011 Responding to major job losses.pdf (accessed on 28 March 2018). 


\section{Annex A. Data}

\section{Data Sources}

\section{Mass lay-off events}

For Europe, the main source of data on localised mass lay-off is the Restructuring Events Database (ERM), maintained by Eurofound, a European Union Agency. The Database contains factsheets with data on large-scale restructuring events reported in the principal national media in each EU member state. Created in 2002, it has recorded more than 19,700 restructuring events to date and is updated daily. ${ }^{33}$ Information is originally sourced from news articles rather than official administrative data sources. Restructuring events are defined as individual employment actions in which more than 100 employees (or at least $10 \%$ of the workforce in establishments with more than 250 people) were affected. The database reports the nature of the restructuring event, the name of the company involved, as well as its sector, location, and the number of affected workers.

\section{Globalisation and digitalisation and automation}

The latest version of the Trade in Value Added (TiVA) database (December 2016) is used to build proxies for the impact of globalisation at country-sector level. For the purposes of this study the indicators are available from 1995 to 2015 (including "TiVA nowcast" data), and cover indicators by industry such as domestic and foreign value added content of gross exports, the share of imported intermediate inputs in total intermediate inputs, foreign value added content of domestic final demand and other decompositions of traded goods and services. The database covers 63 economies, including the OECD, EU28, G20, and most of Asia. Variables are classified into 34 industries, which are based on aggregations of successive versions of the ISIC industry classification.

Regarding measures of digitalisation, the EU KLEMS database provides some measures of technological input. The most recent version of EU KLEMS, released in September 2017, provides indicators of ICT capital services for 16 countries for which data was available. These countries are: Austria, Belgium, Czech Republic, Denmark, Finland, France, Germany, Italy, Latvia, Luxembourg, the Netherlands, Slovakia, Slovenia, Spain, Sweden, and the United Kingdom (UK). Additionally data are available for the United States (US). These data are provided between the years 1995 and 2015 within Europe, and between the years 1997 and 2015 for the US. The data are provided for 34 industries classified according to ISIC Rev.4 for all countries, including the US.

For indicators of automation, data on the use of robots across countries and industries are provided by the International Federation of Robotics (IFR). The definition of industrial robots used by IFR comes from the International Organization for Standardization (ISO) 8373:2012: a robot refers to "a machine that embodies the following characteristics: can be reprogrammed, is multipurpose in function, allows for physical alteration, and is mounted on an axis". IFR constructs this dataset by consolidating information on industrial robot sales from almost every industrial robot supplier in the world. The robot stock indicator is constructed following De Backer et al. $\left(2018_{[47]}\right)$. Data on robot stock are available for roughly 100 geographic locations and industries from 1993-2016. These data only available for manufacturing enterprises only. 


\section{Labour market characteristics}

Information on labour markets specificities are retrieved from the OECD Employment database. ${ }^{34}$ This database contains several indicators that allow comparing countries according to their labour market policies and institutions. The analysis in this report resorts to indicators of employment protection legislation (EPL) and trade union density (TUD). The OECD indicators of EPL measure the procedures and costs involved in dismissing individuals or groups of workers and the procedures involved in hiring workers on fixedterm or temporary work agency contracts. The EPL indicators are constructed based on an appreciation of statutory laws, collective bargaining agreements and case law, as well as contributions from officials from OECD member countries and advice from country experts. Data are available for OECD countries as well as some non-member economies for the period 1985-2013 (2015 for some economies). The TUD data are obtained from a rich set of survey and administrative data and using detailed information collected by the OECD, covering OECD countries, with data available since 1960 (for selected economies) until 2016. Trade union density measures the percentage of workers in a country that are members of a trade union. It is however important to note that TUD does not fully reflect collective bargaining coverage, notably in countries with multi-level bargaining systems in which cases TUD might underrepresent the number of workers with the right to bargain.

\section{Government support measures}

Comprehensive and harmonised data on public support measures to sectors and firms in temporary distress are extremely difficult to collect. However, a promising new source of information on policy interventions is the Global Trade Alert (GTA) database. ${ }^{35}$

The GTA database was first launched in 2009, amidst increased trade tensions resulting from the global financial crisis. While the main goal of GTA is to provide timely data on state interventions that may affect international trade, the coverage of policy interventions is broad enough to include different types of national support measures beyond trade policy actions.

GTA data are organised by policy type, implementing jurisdiction, affected jurisdiction, implementation date, and target industry. ${ }^{36}$ The scope of the database covers all policy actions affecting international trade introduced since November 2008, and is updated on an ongoing basis. While measures implemented at the border (either to protect certain industries or to address unfairly traded products) are not directly relevant for this project, the database is a very useful source for other forms of government support measures such as state loans, financial grants, public procurement preferential access, tax or social insurance reliefs etc. In addition, GTA data also allows distinguishing measures that may target a subset of companies in a sector (e.g. firm-specific, state enterprises, SMEs) and their level of implementation (national or local) - see (Evenett and Fritz, 2017 ${ }_{[48]}$ ) for additional details. It is however important to highlight that GTA data do not provide information on support programmes designed to assist workers. 
Figure A.1. Number of relevant government interventions by type (2009-16)

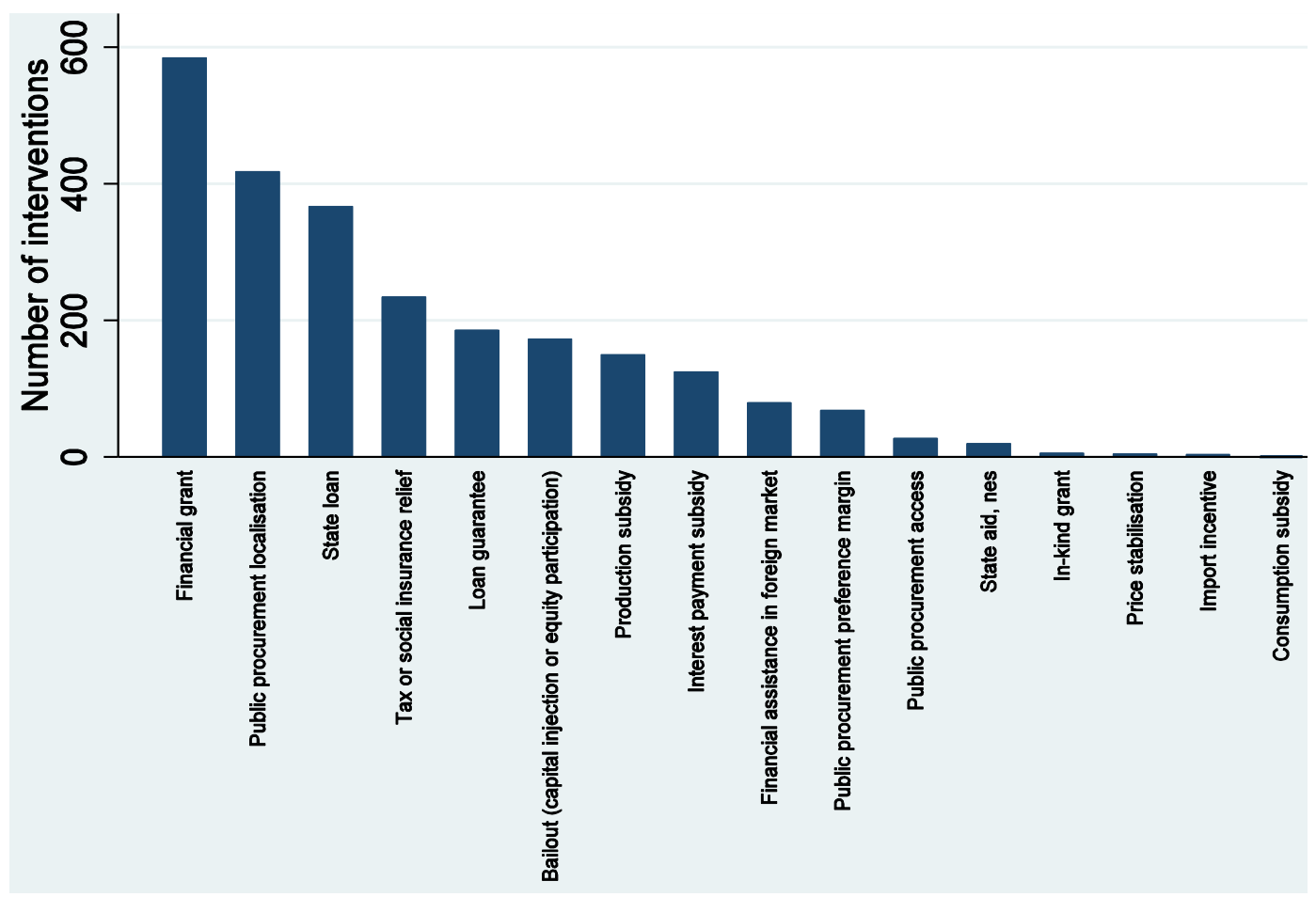

Note: Policy instruments limited to announced subsidies and public procurement policies - UN MAST classification "L" and "M" (see variable description below). Geographical scope limited to OECD countries. Source: GTA. Data extracted on 16 October 2017.

Descriptive statistics focusing on announced policy interventions in the form of subsidies or public procurement policies across OECD countries suggest that financial grants were the most prevalent type of government support in the region since the global financial crisis (Figure A1). Public procurement and tax breaks (including social insurance) have also been important instruments used to provide support to sectors and firms. An important drawback of the GTA data is however the lack of a measure of intensity of the support programme. Moreover, data tend to focus on jurisdictions that are more transparent. The measures used in the regression analysis described in this paper attempt to partially correct these biases see the detailed description of variables below.

Figure A2 below show that the government support has disproportionally targeted specific sectors. Since 2009, the most targeted industries included basic metals, food, beverages and tobacco and chemicals. 
Figure A.2. Number of relevant government interventions by sector (2009-16)

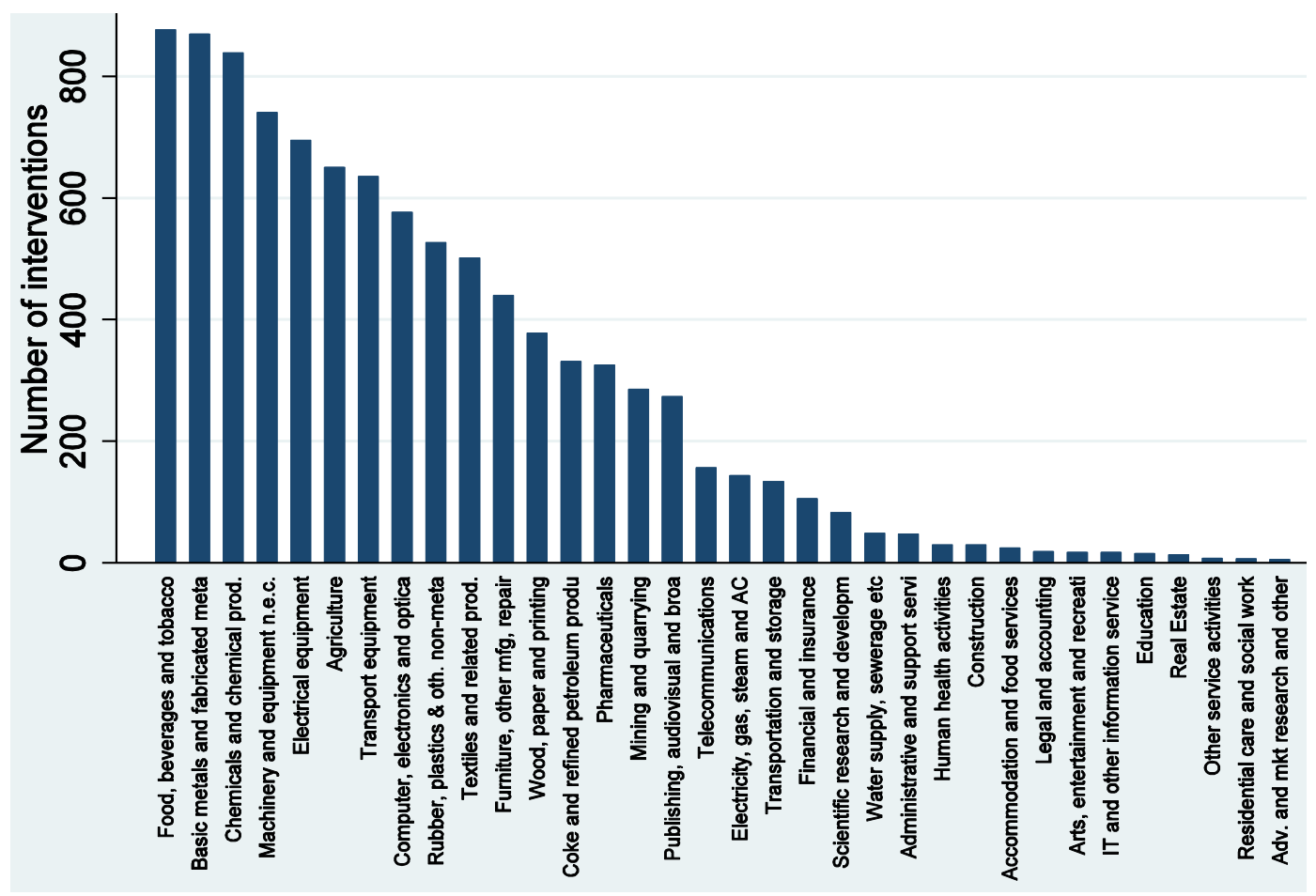

Note: Policy instruments limited to announced subsidies and public procurement policies — UN MAST classification "L" and "M" (see variable description below). Geographical scope limited to OECD countries. Source: GTA. Data extracted on 16 October 2017.

\section{Other data sources}

Firm-level data from Bureau van Dijk's ORBIS dataset is used to calculate indicators of the prevalence of multinational enterprises in each sector-country-year, as well as a sectorspecific indicator of the degree of "lumpiness" in capital adjustments. Furthermore, firm level data are also used to calculate the share of employment in firms with more than 100 employees used in some robustness regressions. Firm-level data from ORBIS entails some coverage biases, but these are more acute for emerging economies (see e.g. Gal, 2013 for an overview of ORBIS coverage). ORBIS data used in this paper are limited to the period 2003-16 for data quality reasons.

The OECD STAN database for industrial analysis contains several indicators at the industry-country-year level that are very useful for the empirical analysis. ${ }^{37}$ These include for example total employment and gross output data that are used to scale ML and import intensity, respectively.

\section{Main variables used in the analysis}

The analysis in this report follows the sector aggregation provided by the OECD STAN database for industrial analysis (IND_A38).$^{38}$ Ensuring that all variables are disaggregated at the same IND_A38 level is one of the important challenges of using data from several different sources. For example, GTA data are available at the product level and classified in Central Product Classification (CPC) that are then mapped into ISIC 4 codes using the 
United Nations correspondence tables and finally aggregated to IND_A38. ${ }^{39}$ The level of industry aggregation of some databases also entails the loss of some observations notably the case with EUKLEMS or TiVA data, as shown in the Table below. A minimum of 24 industries are included in the main regression analysis.

Country coverage also varies across the different databases. This is particularly relevant for the regressions and the construction of indicators of ML intensity because they resort to employment data from STAN. While ML data are only available for the E.U 28 member countries, STAN data are only available to OECD member countries, thus the analysis is limited to E.U. countries that are also OECD members. The availability of the selected indicators from EUKLEMS across countries is also quite limited as shown in the Table below. A minimum of 12 countries are included in the main regression analysis.

The Table below provides an overview of the coverage and a short description of how each variable is constructed. Several of them are readily constructed or require minor adjustments/scaling. The variables requiring additional explanation are described in more detail in the subsections below. 
Table A.1. List of variables used in the regression analysis

\begin{tabular}{|c|c|c|c|c|c|}
\hline Variable & Short description & Source & $\begin{array}{l}\text { Country } \\
\text { coverage }\end{array}$ & $\begin{array}{l}\text { Sector } \\
\text { coverage }\end{array}$ & Year coverage \\
\hline ML & $\begin{array}{l}\text { Planned individual employment actions in which more than } 100 \text { employees } \\
\text { (or at least } 10 \% \text { of the workforce in establishments with more than } 250 \\
\text { people) were affected }\end{array}$ & ERI & $\begin{array}{l}\text { E.U. } 28 \text { member } \\
\text { countries }\end{array}$ & $\begin{array}{l}35 \text { at ind_a38 } \\
\text { disaggregation* }\end{array}$ & $2002-2016$ \\
\hline ICT & $\begin{array}{l}\text { Contribution of ICT capital services to value added growth (percentage } \\
\text { points) }\end{array}$ & EUKLEMS & $\begin{array}{l}\text { Selected EU; } \\
\text { JAP; USA }\end{array}$ & $\begin{array}{l}34 \text { at ind_a38 } \\
\text { disaggregation* }\end{array}$ & 1995-2015 \\
\hline ICTcap & Computing equipment (real fixed capital stock, 2010 prices) & EUKLEMS & $\begin{array}{l}\text { Selected EU; } \\
\text { JAP; USA }\end{array}$ & $\begin{array}{l}34 \text { at ind_a38 } \\
\text { disaggregation* }\end{array}$ & 1995-2015 \\
\hline GLOBAL & Foreign value added share of gross exports & TiVA & $\begin{array}{l}63 \text { economies, } \\
\text { incl OECD }\end{array}$ & $\begin{array}{l}34 \text { at ind_a38 } \\
\text { disaggregation* }\end{array}$ & $\begin{array}{l}\text { 1995-2014 (incl. } \\
\text { TiVA nowcast) }\end{array}$ \\
\hline $\begin{array}{l}\text { GLOBAL } \\
\text { backward }\end{array}$ & Foreign value added embedded in final domestic demand & TiVA & $\begin{array}{l}63 \text { economies, } \\
\text { incl. OECD }\end{array}$ & $\begin{array}{l}34 \text { at ind_a38 } \\
\text { disaggregation* }\end{array}$ & $\begin{array}{l}\text { 1995-2014 (incl. } \\
\text { TiVA nowcast) }\end{array}$ \\
\hline $\begin{array}{l}\text { EMP } \\
\text { growth }\end{array}$ & $\begin{array}{l}\text { Change in employment (\% change): measured as the total number of } \\
\text { persons employed (headcounts). }\end{array}$ & STAN & OECD & $\begin{array}{l}\text { All at ind_a38 } \\
\text { disaggregation }\end{array}$ & $1995-2016$ \\
\hline $\begin{array}{l}\mathrm{EPL} \\
\text { collective }\end{array}$ & $\begin{array}{l}\text { Labour protection (collective) This indicator measures additional costs and } \\
\text { procedures (beyond individual dismissal) involved in dismissing more than } \\
\text { one worker at a time. }\end{array}$ & $\begin{array}{l}\text { OECD } \\
\text { Employment }\end{array}$ & $\begin{array}{l}\text { OECD and some } \\
\text { non-OECD }\end{array}$ & No variation & $\begin{array}{l}1985-2013 \\
\text { (2015 for some } \\
\text { economies) }\end{array}$ \\
\hline $\begin{array}{l}\mathrm{EPL} \\
\text { individual }\end{array}$ & $\begin{array}{l}\text { Labour protection (individual). This indicator measures the strictness of } \\
\text { regulation of individual dismissal of employees on regular/indefinite } \\
\text { contracts. }\end{array}$ & $\begin{array}{l}\text { OECD } \\
\text { Employment }\end{array}$ & $\begin{array}{l}\text { OECD and some } \\
\text { non-OECD }\end{array}$ & No variation & $\begin{array}{l}\text { 1985-2013 } \\
\text { (2015 for some } \\
\text { economies) }\end{array}$ \\
\hline TFPva_I & Total Factor Productivity (value added based) growth, index $2010=100$ & EUKLEMS & $\begin{array}{l}\text { Selected EU; } \\
\text { JAP; USA }\end{array}$ & $\begin{array}{l}34 \text { at ind_a38 } \\
\text { disaggregation* }\end{array}$ & $1995-2015$ \\
\hline $\begin{array}{l}\% \quad \text { EMP } \\
\text { by MNE }\end{array}$ & $\begin{array}{l}\text { Employment in foreign MNEs (\%). Total num } \\
\text { MNEs divided by total employment in each co }\end{array}$ & ORBIS & $\begin{array}{l}\text { Several, see Gal } \\
\quad(2013)\end{array}$ & All & $2003-2016$ \\
\hline LUMPY & Index of Lumpiness (see below for further details) & ORBIS & $\begin{array}{l}\text { Several, see Gal } \\
\quad(2013)\end{array}$ & All & No variation \\
\hline $\begin{array}{l}\text { Govt } \\
\text { foreign }\end{array}$ & $\begin{array}{l}\text { Number of active measures weighted by exports (in other countries), } \\
\text { industry-time variant (minor country variation) }\end{array}$ & GTA & No variation & $\begin{array}{l}35 \text { at ind_a38 } \\
\text { disaggregation* }\end{array}$ & $2009-2016$ \\
\hline $\begin{array}{l}\text { Govt } \\
\text { domest }\end{array}$ & Number of active measures in own country & GTA & $\begin{array}{l}\text { World, different } \\
\text { coverage }\end{array}$ & $\begin{array}{l}35 \text { at ind_a38 } \\
\text { disaggregation* }\end{array}$ & $2009-2016$ \\
\hline TUD & $\begin{array}{l}\text { Trade union density defined as the ratio of union members divided by the } \\
\text { total number of employees. }\end{array}$ & $\begin{array}{l}\text { OECD } \\
\text { Employment }\end{array}$ & OECD & No variation & $1960-2016$ \\
\hline Robot & $\begin{array}{l}\text { Stock of robots, assuming } 10 \% \text { rate depreciation - see De Backer et al. } \\
(2018[45])\end{array}$ & IFR & $\begin{array}{l}\text { Several, see De } \\
\text { Backer et al. } \\
\left(2018_{[47])}\right.\end{array}$ & Manufacturing* & $1993-2016$ \\
\hline $\begin{array}{l}\% \text { EMP } \\
\text { Med/Larg } \\
\text { e }\end{array}$ & $\begin{array}{l}\text { Total employment in firms with more than } 100 \text { employees, as a percentage } \\
\text { of total employment in country-sector-year }\end{array}$ & $\begin{array}{l}\text { ORBIS; } \\
\text { STAN }\end{array}$ & $\begin{array}{l}\text { Several, see Gal } \\
\qquad(2013)\end{array}$ & All & 2003-2016 \\
\hline $\begin{array}{l}\text { TRD- } \\
\text { IM_int }\end{array}$ & Share of gross imports on gross output & TiVA; & OECD & $\begin{array}{l}34 \text { at ind_a38 } \\
\text { disaggregation* }\end{array}$ & $\begin{array}{l}\text { 1995-2014 (incl. } \\
\text { TiVA nowcast) }\end{array}$ \\
\hline $\begin{array}{l}\text { TRD } \\
\text { inputs }\end{array}$ & $\begin{array}{l}\text { Share of imported intermediate inputs on total intermediate inputs (proxy } \\
\text { for offshoring) }\end{array}$ & $1 \pi \mathrm{V}$ & $\begin{array}{l}63 \text { economies, } \\
\text { incl. OECD }\end{array}$ & $\begin{array}{c}34 \text { at ind_a38 } \\
\text { disaggregation* }\end{array}$ & $\begin{array}{l}\text { 1995-2014 (incl. } \\
\text { TiVA nowcast) }\end{array}$ \\
\hline
\end{tabular}

Notes: *Mapping of industry classification to the common denominator IND_A38 was required. 


\section{Mass lay-offs}

The ML variable is constructed based on information the ERM database. Using this information it is possible to construct an indicator of ML intensity - ML as a share of total employment in each country-sector-year The ERM database does not cover ML in the following three IND_A38 sectors: Public administration and defence; Activities of households as employers and Activities of extraterritorial organisations. Any missing ML data for the country-sector-year observations within the coverage of the ERM database are assigned the value zero.

\section{Lumpiness}

The measure of lumpiness is constructed based on firm-level data from ORBIS. Lumpiness is calculated as the sector average of the residual term of a regression of yearly fixed capital investment on the long run investment trend, as well as on demand shocks and firm size (in terms of fixed assets). In other words, this indicator reflects how much the yearly investment rate deviates from the medium term trajectory, once demand shocks, firm size and country-year fixed effects are controlled for. The equations below describe the construction of this indicator in more detail.

$$
\Delta F A_{c, i, t}=\alpha+\beta_{1} * \Delta Y+\beta_{2} \Delta^{t-2, t+2} F A_{c, i, t}+\beta_{3} F A_{c, i, t-1}+\theta_{c, y}+\varepsilon_{c, i, t}
$$

$$
A b_{-} r e s_{c, i, t}=\left|\left(\widehat{F A_{c, l, t}}-\Delta F A_{c, i, t}\right)\right|_{c, i, t}
$$

, where $F A$ are a firm's total fixed assets, $Y$ is turnover, $\Delta \widehat{F A_{c, l, t}}$ are the predicted values of an ordinary least squares (OLS) regression and $\Delta^{t-2, t+2} F A_{c, i, t}$ is the five-year change in fixed assets from $t-2$ until $t+2$.

$$
\text { Lumpy }_{i}=\sigma_{A b_{-} r e s_{c, i, t}} / \mu_{A b_{-} r e s_{c, i, t}}
$$

, where $\sigma_{A b_{-} r e s_{c, i, t}}$ and $\mu_{A b_{-} r e s_{c, i, t}}$ are respectively the standard deviation and mean of distribution of the absolute value of the regression residuals.

\section{Government interventions}

The two indicators of government support (domestic and foreign) are calculated using data from GTA. Data collected by GTA contains relevant information on government support measures such as state loans, financial grants, public procurement preferential access, tax or social insurance relief. Measures implemented at the border (trade measures) are not included in the indicators. The indicators of government interventions include all measures that fall under Chapter "L" (subsidies, excluding export subsidies) or "M" (government procurement restriction) of the UNCTAD's International Classification of Non-tariff measures (UNCTAD, 2017 $[49])$.

The raw data provided by GTA only contains information on the counts of government interventions. While this measure is informative, it should be highlighted that the lack of information on the magnitude of the measure is an important caveat. In order to partially overcome this caveat, this paper uses a measure relative support provided to domestic firms in each sector, compared to the total support provided across sectors in each economy (domestic measure). The construction of the domestic indicator is formalised in equation (4) below. This approach also provides a correction for the biases arising from different degrees of transparency in the reporting of government support across jurisdictions (c.f. the 
discussion on the GTA data source above). The domestic indicator varies across jurisdictions, sectors and time.

$$
\text { Govt_dom }_{c, i, t}=\frac{\text { Measures }_{c, i, t}}{\sum_{i=1}^{I} \operatorname{Measures}_{c, i, t}}
$$

1. The measure of foreign support builds upon the domestic one to reflect the amount of government support provided by foreign jurisdictions. The challenge here is to be able to reflect the relative weight of each jurisdiction in the world trade of products corresponding to each sector of activity. Weighting the indicator by exports allows taking into account the relative size of each jurisdiction as a trading partner in each specific sector. The foreign measure for each economy (c) is therefore calculated as the global average share of sector interventions in each foreign jurisdiction (equivalent to the domestic measure for each foreign jurisdiction), weighted by the sector's share of exports by each jurisdiction. The construction of the foreign indicator for the economy $\mathrm{c}=1$ is illustrated in equation (5) below. The foreign indicator is a global average thus only varies across sectors, time and to a lesser extent across countries. ${ }^{40}$ Challenges in separating the distortive effect of government support from the competitiveness of companies in a sector-country-year are partially addressed by the global nature of the indicator. The resulting indicator is shown in Figure A3 below.

$$
\begin{aligned}
& \text { Govt_foreign }_{c=1, i, t}=\sum_{c=2}^{C}\left[\frac{\text { Measures }_{c \neq 1, i, t}}{\sum_{i=1}^{I} \text { Measures }_{C \neq 1, i, t}} * \frac{\text { Exports }_{c \neq 1, i, t}}{\sum_{c=1}^{C} \operatorname{Exports}_{c \neq 1, i, t}}\right]= \\
& =\sum_{c=2}^{C}\left[\text { Govt_dom }_{C \neq 1, i, t} * \text { Exports }_{c \neq 1, i, t}\right] * 1 / \sum_{c=1}^{C} \text { Exports }_{C \neq 1, i, t}
\end{aligned}
$$

The GTA database also allows distinguishing whether measures are active or have been removed. For example, a measure to provide support to a sector or "bail-out" a company is likely to be temporary. In contrast measures related to tax benefits might remain in place for a considerable period of time. Only measures that are active are included in the analysis. Moreover, the indicators include all measures provided to any type of companies in a given sector and irrespective whether they are implemented at the national or sub-national level. Any missing data for the country-sector-year observations within the coverage of the GTA database are assigned the value zero. 
Figure A.3. Government interventions affecting trade

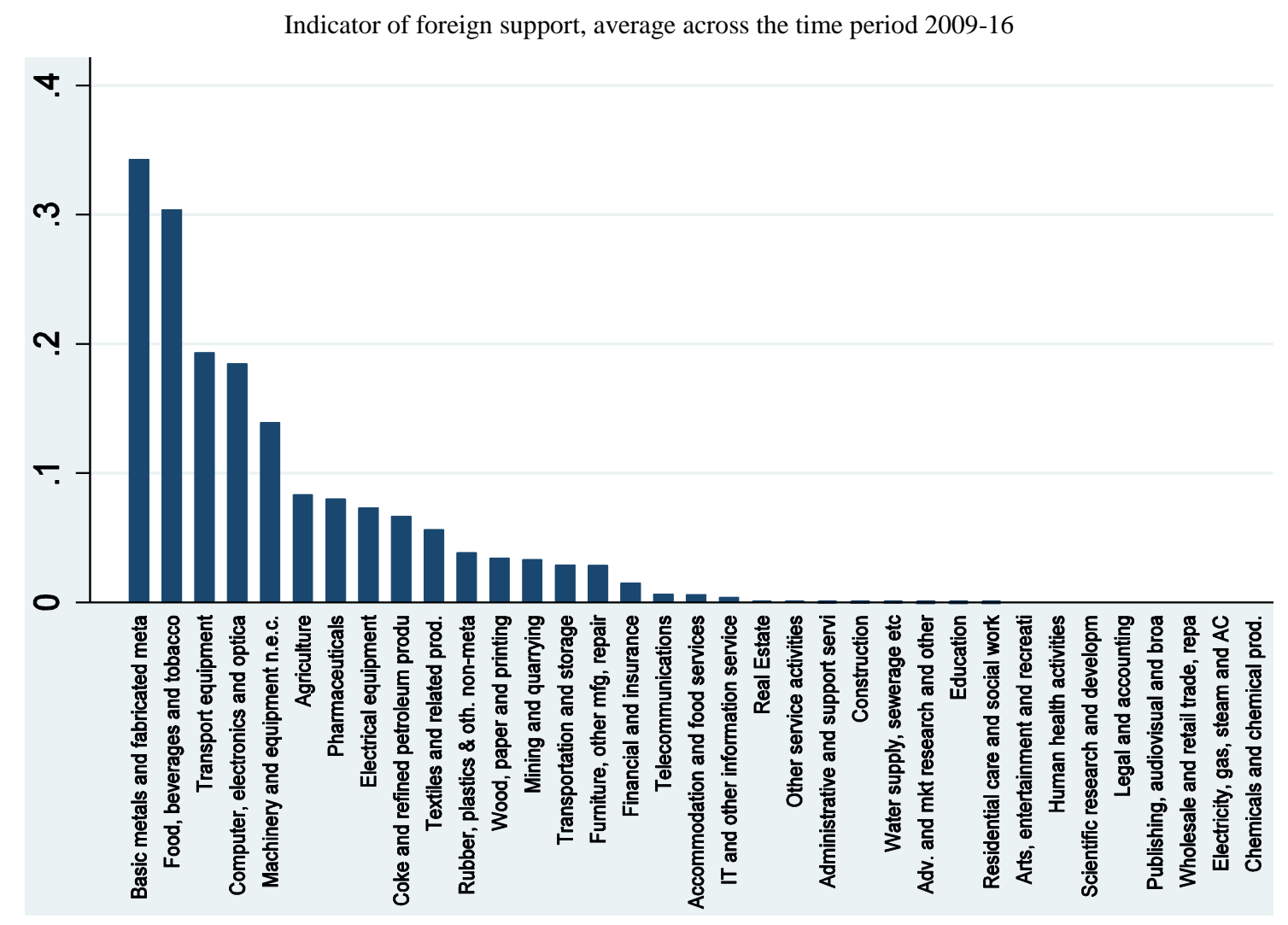

Source: OECD calculations based on GTA data. 


\section{Annex B. Unemployment duration analysis: econometric model}

\section{Description of the Data}

When considering mass layoffs, a crucial question is whether the workers left unemployed will be able to easily find another job. While the question cannot be directly tackled due to the impossibility of focusing on laid-off workers, an indirect strategy can be adopted to answer the question. Data from the European Labour Force Survey (EU-LFS) can be used to investigate how quickly workers from different sectors who become unemployed (not necessarily as a result of mass layoffs) regain employment.

The European Labour Force Survey (EU-LFS) contains information on respondents' employment status both currently and one year prior to the interview. Crucially, the information includes their sector of employment.

Based on these data, it is possible to group respondents into five categories:

1. Currently employed who have not changed jobs in the last year

2. Currently employed who were unemployed last year

3. Currently employed who have changed jobs over the past year

4. Currently unemployed who have been unemployed for more than one year

\section{Currently unemployed who became unemployed over the past year}

The analysis of re-employability is restricted to the 12 month period and thus only includes groups 3 and 5 (highlighted). Including group 2 in the analysis would be preferable, but the EU-LFS does not provide unemployment duration data for individuals who are currently employed.

The two selected groups present themselves in the data in different ways. For group 3 (the currently employed), it is known that they have changed jobs over the past 12 months, but not the exact date of the change. To narrow the range of uncertainty, the months of tenure are subtracted from the twelve month upper bound. In this way, the range of possible months is between twelve months ago and twelve months less the respondents' months of tenure. These respondents are said to be interval censored, as their period of unemployment can only be narrowed down to an interval.

For the currently unemployed (Group 5), the exact date when they have become unemployed is known, but the date when they will find their next job is unknown. In fact, some of these individuals could end up as long-term unemployed, with unemployment lengths longer than one year. These respondents are said to be right censored, as the upper bound of their unemployment length is unknown.

Combining these two groups provides a partial picture of re-employment prospects over a twelve month period. For one group, it is known when they found a job, but not how long they were unemployed for, and for the other group it is known how long they have been unemployed for, but not when they will find a job.

Treating these data as survival data, where the length of unemployment is considered "survival", it is possible to generate an interval-censored regression by adding some parametric assumptions (see the next section). As there is no information about the period 
of time within the interval for those who have changed jobs over the year, an assumption is made about the distribution of the survival over the time that is unobserved. ${ }^{41}$ Two common distributions used for this purpose are the exponential and the Weibull distributions. An important distinction is that the Weibull hazard varies over time while the exponential does not.

This analysis uses the Weibull distribution and models the "risk" of finding a job by sector. This "risk" is presented as the hazard rate. That is, the rate at which in a given month unemployed workers from a given sector and country will find a job. For easiness of interpretation, the share of the unemployed that will remain unemployed after one year (effectively becoming long-term unemployed) is also computed. For each country $c$ and industry $i$, this is calculated as:

Share to remain unemployed after 12 months $_{c, i}=100 *\left(1-\operatorname{hazard}_{c, i}\right)^{12}$

\section{Specifics of interval censored survival analysis}

If $Y$ is a random variable representing a "survival" time and $f(y)$ and $F(y)$ represent the probability distribution and cumulative distribution of $Y$, respectively, then the probability of an individual surviving beyond time $y$ can be written as:

$$
S(y)=\operatorname{Pr}(Y \geq y)=1-F(y)
$$

In the context of the current project, $y$ is duration of unemployment. If "survival" is duration of unemployment, then "death" is the event of finding a job. The hazard function, that is the instantaneous risk of "death", is written as:

$$
h(y)=\frac{f(y)}{S(y)}
$$

The survival function can be empirically estimated as:

$$
\hat{S}(y)=\frac{\# \text { of obs with unemployment duration } \geq y}{\text { total number of obs }}
$$

When analysing the risk of "death" (that is, finding a job) in survival analysis it is helpful to make assumptions about how the events are distributed. Two common distributions for this are the exponential distribution and the Weibull distribution, of which the exponential is a special case. ${ }^{42}$ As the exponential distribution is a special case of the Weibull, it is natural to prefer the Weibull distribution. If the data implies that an exponential is a good fit, it will be evident from the parameter estimates. ${ }^{4344}$ The Weibull distribution can be written as:

$$
f(y ; \lambda, \theta)=\frac{\lambda y^{\lambda-1}}{\theta^{\lambda}} \exp \left[-\frac{y^{\lambda}}{\theta}\right], \quad y \geq 0, \lambda \geq 0, \theta \geq 0
$$

Here $\lambda$ and $\theta$ are the shape parameters of the Weibull distribution. Writing $\theta^{-\lambda}=\phi$ we can rewrite the Weibull distribution as:

$$
f(y ; \lambda, \phi)=\lambda \phi y^{\lambda-1} \exp \left(-\phi y^{\lambda}\right)
$$

The survival and hazard functions for the Weibull are thus:

$$
\begin{gathered}
S(y ; \lambda, \phi)=\exp \left(-\phi y^{\lambda}\right) \\
h(y ; \lambda, \phi)=\lambda \phi y^{\lambda-1}
\end{gathered}
$$


The hazard function links the parameters of the Weibull distribution to the instantaneous chance of "death" (that is, of becoming employed). To link the dependence of the parameters to the explanatory variables, $x$, it is common to use a multiplicative form (Dobson and Barnett, 2008 $[50]$ ):

$$
\phi=\alpha e^{x^{T} \beta}
$$

In the current report, the explanatory variables are the country and industry of the respondents. The hazard function can then be rewritten as:

$$
h(y)=\lambda \alpha y^{\lambda-1} e^{x^{T} \beta}
$$

This can be re-written as a proportion hazard model in terms of a baseline hazard, $h_{0}(y)$ :

$$
h(y)=h_{0}(y) e^{x^{T} \beta}
$$

And the survival function can be written as:

$$
S(y)=\exp \left(-\alpha e^{x^{T} \beta} y^{\lambda}\right)
$$

In general, when estimating the model, four types of data need to be considered: uncensored, interval censored, right censored, and left censored. The previous section describes the data available in the context of this analysis. Each type of observation presents differently with respect to the two possible time variables representing the upper and lower bounds, $y_{U}$ And $y_{L}$. Uncensored data (UC) has a precise event time, and so $y_{U}=y_{L}$. With interval censored data (IC) the event time, $y$, falls within a known range, thus $y_{U}>y_{L}$. With right censored data (RC) the lower bound is known while the upper bound is not $\left(y_{L}=y\right)$, while with left censored data (LC) the upper bound is known while the lower bound is not $\left(y_{U}=y\right)$. When estimating the parameters of the model each type of data is considered separately and included into the following likelihood function, which is the product of these four components:

$$
L=\prod_{i \in U C} f\left(y_{L, i}\right) \cdot \prod_{i \in R C} S\left(y_{L, i}\right) \cdot \prod_{i \in L C} 1-S\left(y_{U, i}\right) \cdot \prod_{i \in I C}\left[S\left(y_{L, i}\right)-S\left(y_{U, i}\right)\right]
$$

In the current dataset, there are only interval censored data and right censored data (groups 3 and 5 as identified in the previous section). Taking the natural log we obtain the loglikelihood:

$$
\begin{gathered}
\log L=\sum_{i \in R C} \log S\left(y_{L, i}\right)+\sum_{i \in I C}\left[\log S\left(y_{L, i}\right)-\log S\left(y_{U, i}\right)\right] \\
\log L=\sum_{i \in I C} \alpha e^{x^{T} \beta}\left[y_{U, i}{ }^{\lambda}-y_{L, i}{ }^{\lambda}\right]-\sum_{i \in R C} \alpha e^{x^{T} \beta} y_{L, i}{ }^{\lambda}
\end{gathered}
$$

This log-likelihood can be optimised numerically to obtain estimates of the parameters that provide the best fit to the data. The estimates of these parameters can then be used to estimate the hazard rate, and subsequently the risk of long-term unemployment described in the end of the previous section. 


\section{Annex C. Detailed regression results}

Table C.1. Main regression results

\begin{tabular}{|c|c|c|c|c|c|c|c|c|}
\hline \multirow{2}{*}{\begin{tabular}{|ll} 
& Total ML \\
ICT & \\
\end{tabular}} & \multicolumn{3}{|c|}{ Baseline } & \multicolumn{3}{|c|}{ Government interventions } & \multicolumn{2}{|c|}{ Selected interactions } \\
\hline & -0.078 & -0.140 & -0.232 & -0.348 & -0.359 & -0.337 & 0.196 & $-0.416^{* *}$ \\
\hline & $(0.21)$ & $(0.17)$ & $(0.16)$ & $(0.31)$ & $(0.26)$ & $(0.26)$ & $(0.34)$ & $(0.19)$ \\
\hline \multirow[t]{2}{*}{ GLOBAL } & $0.017^{* *}$ & $-0.048^{* * *}$ & 0.009 & 0.003 & $-0.042^{* \star *}$ & 0.006 & 0.008 & 0.009 \\
\hline & $(0.01)$ & $(0.01)$ & $(0.01)$ & $(0.01)$ & $(0.01)$ & $(0.02)$ & $(0.01)$ & $(0.01)$ \\
\hline \multirow[t]{2}{*}{ GLOBAL_backward } & $0.044^{* * *}$ & $0.046^{* \star *}$ & $0.015^{* *}$ & $0.026^{*}$ & $0.045^{\star * *}$ & 0.010 & -0.009 & 0.010 \\
\hline & $(0.01)$ & $(0.01)$ & $(0.01)$ & $(0.02)$ & $(0.01)$ & $(0.01)$ & $(0.01)$ & $(0.01)$ \\
\hline \multirow[t]{2}{*}{ EMP growth } & $-44.104^{\star \star \star}$ & $-19.900^{* * *}$ & $-19.747^{\star \star *}$ & $-40.495^{* * *}$ & $-21.675^{\star * \star}$ & $-20.650^{* * *}$ & $-20.090^{* * *}$ & $-19.442^{\star * *}$ \\
\hline & $(8.93)$ & $(5.81)$ & $(5.16)$ & $(7.92)$ & $(5.37)$ & $(5.15)$ & $(5.00)$ & $(5.15)$ \\
\hline \multirow[t]{2}{*}{ EPL_collective } & $-0.331^{* * *}$ & $-0.355^{\star \star \star}$ & -0.166 & $-0.238^{*}$ & $-0.267^{\star \star \star}$ & -1.376 & -0.136 & -0.136 \\
\hline & $(0.12)$ & $(0.08)$ & $(0.66)$ & $(0.13)$ & $(0.09)$ & $(1.00)$ & $(0.66)$ & $(0.66)$ \\
\hline \multirow[t]{2}{*}{ EPL_individual } & $-0.550^{* *}$ & $-0.623^{* * *}$ & $-1.364^{*}$ & -0.116 & $-0.322^{*}$ & 1.502 & $-1.368^{*}$ & $-1.419^{*}$ \\
\hline & $(0.24)$ & $(0.16)$ & $(0.74)$ & $(0.27)$ & $(0.18)$ & $(1.18)$ & $(0.74)$ & $(0.74)$ \\
\hline \multirow[t]{2}{*}{$\%$ EMP by MNE } & $2.150^{\star \star \star}$ & $0.740^{* *}$ & -0.016 & $2.368^{\star \star \star}$ & $0.759^{*}$ & 0.324 & 0.087 & -0.014 \\
\hline & $(0.36)$ & $(0.31)$ & $(0.30)$ & $(0.44)$ & $(0.42)$ & $(0.42)$ & $(0.29)$ & $(0.30)$ \\
\hline \multirow[t]{2}{*}{ LUMPY } & $0.137^{* * *}$ & 0.000 & 0.000 & $0.137^{* * *}$ & 0.000 & 0.000 & 0.000 & 0.000 \\
\hline & $(0.02)$ & (.) & (.) & $(0.02)$ & (.) & (.) & (.) & (.) \\
\hline \multirow[t]{2}{*}{ TFPva_I } & $0.018^{* *}$ & -0.007 & -0.004 & 0.014 & -0.006 & -0.002 & -0.003 & -0.004 \\
\hline & $(0.01)$ & $(0.01)$ & $(0.01)$ & $(0.01)$ & $(0.01)$ & $(0.01)$ & $(0.01)$ & $(0.01)$ \\
\hline \multirow[t]{2}{*}{ ICT * LUMPY } & & & & & & & -0.033 & \\
\hline & & & & & & & $(0.02)$ & \\
\hline \multirow{2}{*}{ GLOBAL_back*LUMPY } & & & & & & & $0.001^{* *}$ & \\
\hline & & & & & & & $(0.00)$ & \\
\hline \multirow[t]{2}{*}{ ICT * GLOBAL_back } & & & & & & & & $0.029^{*}$ \\
\hline & & & & & & & & $(0.02)$ \\
\hline \multirow[t]{2}{*}{ Govt foreign } & & & & $3.101^{* *}$ & $3.415^{\star *}$ & $3.343^{* *}$ & & \\
\hline & & & & $(1.39)$ & $(1.44)$ & $(1.43)$ & & \\
\hline \multirow[t]{2}{*}{ Govt domest } & & & & 0.698 & -0.386 & -0.193 & & \\
\hline & & & & $(0.91)$ & $(0.90)$ & $(0.84)$ & & \\
\hline Observations & 3196 & 3196 & 3196 & 1313 & 1313 & 1313 & 3196 & 3196 \\
\hline R-squared_a & 0.24 & 0.43 & 0.46 & 0.24 & 0.44 & 0.47 & 0.46 & 0.46 \\
\hline Country FE & No & No & Yes & No & No & Yes & Yes & Yes \\
\hline Industry FE & No & Yes & Yes & No & Yes & Yes & Yes & Yes \\
\hline Year FE & Yes & Yes & Yes & Yes & Yes & Yes & Yes & Yes \\
\hline Time Period & $2003-2014$ & $2003-2014$ & $2003-2014$ & $2009-2014$ & $2009-2014$ & $2009-2014$ & $2003-2014$ & $2003-2014$ \\
\hline No. Industry & 25 & 25 & 25 & 24 & 24 & 24 & 25 & 25 \\
\hline No. Ctry & 12 & 12 & 12 & 12 & 12 & 12 & 12 & 12 \\
\hline
\end{tabular}

Note: Robust standard errors are in parenthesis. $* * *, * *$, and $*$ denote statistical significance at the $.01, .05$, and .10 levels, respectively. The dependent variable is $\log (\mathrm{ML}+1)$. Results are obtained using OLS regression, weighted by total employment. Because of data availability, only the following European economies are included in these regressions: Austria, Belgium, Czech Republic Finland, France, Germany, Italy, Netherlands, Slovak Republic, Spain, Sweden and United Kingdom. Moreover, some sectors are excluded from the analysis given lack of data - these include Chemicals, Pharma, Electrical equipment, Publishing and audio-visual, Legal and accounting, Scientific R\&D, Advertising and mkt research, Public administration and defence, Human health activities, Residential care and social work, Arts and entertainment, Households as employers, and Extraterritorial organisations, as well as wholesale and retail trade when the measure of government interventions is included. Please see the robustness table below for regression results covering a broader range of industries and countries.

Source: OECD calculations. 
Table C.2. Robustness of results with different coverage

Removal of variables with lower industry coverage

\begin{tabular}{|c|c|c|c|c|c|c|c|c|}
\hline Total ML & 1-Baseline & 2-Tech & 3-Trade & 4-Tech-Trade & 5-Baseline & 6-Tech & 7-Trade & 8-Tech-Trade \\
\hline \multirow[t]{2}{*}{ ICT } & -0.078 & & -0.240 & & -0.348 & & -0.414 & \\
\hline & $(0.21)$ & & $(0.20)$ & & $(0.31)$ & & $(0.32)$ & \\
\hline \multirow[t]{2}{*}{ GLOBAL } & $0.017^{\star *}$ & $0.015^{\star *}$ & & & 0.003 & 0.002 & & \\
\hline & $(0.01)$ & $(0.01)$ & & & $(0.01)$ & $(0.01)$ & & \\
\hline \multirow[t]{2}{*}{ GLOBAL_backward } & $0.044^{* * *}$ & $0.047^{* * *}$ & & & $0.026^{*}$ & $0.025^{\star *}$ & & \\
\hline & $(0.01)$ & $(0.01)$ & & & $(0.02)$ & $(0.01)$ & & \\
\hline \multirow[t]{2}{*}{ EMP growth } & $-44.104^{\star \star *}$ & $-13.414^{\star * *}$ & $-46.896^{\star \star *}$ & $-14.211^{\star \star \star}$ & $-40.495^{\star \star *}$ & $-12.117^{\star * *}$ & $-40.604^{\star \star *}$ & $-11.587^{\star \star \star}$ \\
\hline & $(8.93)$ & $(2.52)$ & $(9.61)$ & $(2.46)$ & $(7.92)$ & $(3.92)$ & $(7.80)$ & (3.94) \\
\hline \multirow[t]{2}{*}{ EPL_collective } & $-0.331^{* * *}$ & $-0.220^{* *}$ & $-0.219^{*}$ & -0.129 & $-0.238^{*}$ & -0.122 & -0.197 & -0.078 \\
\hline & $(0.12)$ & $(0.11)$ & $(0.12)$ & $(0.10)$ & $(0.13)$ & $(0.12)$ & $(0.13)$ & $(0.12)$ \\
\hline \multirow[t]{2}{*}{ EPL_individual } & $-0.550^{* *}$ & $-0.584^{\star * *}$ & $-0.561^{* *}$ & $-0.637^{\star * *}$ & -0.116 & $-0.411^{* *}$ & -0.101 & $-0.437^{* *}$ \\
\hline & $(0.24)$ & $(0.16)$ & $(0.24)$ & $(0.14)$ & $(0.27)$ & $(0.20)$ & $(0.27)$ & $(0.19)$ \\
\hline \multirow[t]{2}{*}{$\%$ EMP by MNE } & $2.150^{\star * \star}$ & $1.984^{* * *}$ & $2.862^{* \star *}$ & $2.429^{\star \star \star}$ & $2.368^{* * *}$ & $2.170^{* \star *}$ & $2.714^{\star \star \star}$ & $2.439^{\star * *}$ \\
\hline & $(0.36)$ & $(0.26)$ & $(0.37)$ & $(0.24)$ & $(0.44)$ & $(0.36)$ & $(0.44)$ & $(0.33)$ \\
\hline \multirow[t]{2}{*}{ LUMPY } & $0.137^{* * *}$ & $0.112^{* * *}$ & $0.149^{\star \star \star}$ & $0.127^{* * *}$ & $0.137^{* * *}$ & $0.101^{* * *}$ & $0.131^{* * *}$ & $0.094^{* * *}$ \\
\hline & $(0.02)$ & $(0.01)$ & $(0.02)$ & $(0.01)$ & $(0.02)$ & $(0.02)$ & $(0.02)$ & $(0.02)$ \\
\hline \multirow[t]{2}{*}{ TFPva_I } & $0.018^{\star *}$ & & $0.015^{\star *}$ & & 0.014 & & 0.014 & \\
\hline & $(0.01)$ & & $(0.01)$ & & $(0.01)$ & & $(0.01)$ & \\
\hline \multirow[t]{2}{*}{ Govt foreign } & & & & & $3.101^{* *}$ & $4.984^{\star \star *}$ & $3.496^{\star \star \star}$ & $5.268^{\star \star \star}$ \\
\hline & & & & & $(1.39)$ & (1.17) & (1.33) & $(1.16)$ \\
\hline \multirow[t]{2}{*}{ Govt domest } & & & & & 0.698 & -0.032 & 0.675 & -0.103 \\
\hline & & & & & $(0.91)$ & $(0.80)$ & $(0.91)$ & $(0.81)$ \\
\hline Country FE & No & No & No & No & No & No & No & No \\
\hline Industry FE & No & No & No & No & No & No & No & No \\
\hline Year FE & Yes & Yes & Yes & Yes & Yes & Yes & Yes & Yes \\
\hline Time period & $2003-2014$ & $2003-2014$ & $2003-2014$ & $2003-2014$ & 2009 - 2014 & 2009 - 2014 & $2009-2014$ & 2009 - 2014 \\
\hline No. Ctry & 12 & 20 & 12 & 20 & 12 & 20 & 12 & 20 \\
\hline No. Industry & 25 & 28 & 28 & 35 & 24 & 27 & 24 & 27 \\
\hline Observations & 3196 & 5450 & 3567 & 6801 & 1313 & 2260 & 1313 & 2260 \\
\hline R-squared_a & 0.24 & 0.18 & 0.21 & 0.15 & 0.24 & 0.17 & 0.23 & 0.17 \\
\hline
\end{tabular}

Note: Robust standard errors are in parenthesis. $* * *, * *$, and $*$ denote statistical significance at the $.01, .05$, and .10 levels, respectively. The dependent variable is $\log (\mathrm{ML}+1)$. Results are obtained using OLS regression, weighted by total employment. This table reports the results obtained from regressions that exclude variables that have lower industry coverage and constrain the sample used for the main regression results. Columns 2 and 6 report the results of regressions that do not include indicators of technological change drawn from EUKLEMS. Columns 3 and 7 report the results of regressions that do not include indicators of globalisation drawn from TiVA. Columns 4 and 8 report the results of regressions that neither include EUKLEMS indicators of technological change nor TiVA indicators of globalisation. Results are broadly in line with the main regression results, despite the increased coverage of sectors and countries.

Source: OECD calculations. 
Table C.3. Robustness of results for different types of layoffs

Comparing results across main types of layoffs

\begin{tabular}{|c|c|c|c|c|c|c|}
\hline \multirow{2}{*}{$\begin{array}{ll} & \text { Total ML } \\
\text { ICT } & \end{array}$} & \multicolumn{3}{|c|}{ ML Offshoring } & \multicolumn{3}{|c|}{ ML Closure } \\
\hline & -0.048 & 0.084 & 0.071 & $-0.490^{* * *}$ & -0.121 & -0.161 \\
\hline & $(0.11)$ & $(0.12)$ & $(0.13)$ & $(0.13)$ & $(0.12)$ & $(0.12)$ \\
\hline \multirow[t]{2}{*}{ GLOBAL } & $0.017^{\star * \star}$ & $-0.013^{\star *}$ & 0.000 & $0.023^{* \star \star}$ & $-0.026^{* *}$ & -0.015 \\
\hline & $(0.00)$ & $(0.01)$ & $(0.01)$ & $(0.01)$ & $(0.01)$ & $(0.01)$ \\
\hline \multirow[t]{2}{*}{ GLOBAL_backward } & $0.007^{* *}$ & $0.011^{* * *}$ & 0.001 & $0.041^{* * *}$ & $0.043^{* * *}$ & $0.029^{* * *}$ \\
\hline & $(0.00)$ & $(0.00)$ & $(0.00)$ & $(0.01)$ & $(0.01)$ & $(0.01)$ \\
\hline \multirow[t]{2}{*}{ EMP growth } & $-11.272^{\star \star \star}$ & -3.571 & -4.008 & $-26.218^{\star \star \star}$ & $-13.001^{\star \star *}$ & $-13.144^{\star * *}$ \\
\hline & (3.10) & (2.53) & (2.46) & $(5.60)$ & $(4.25)$ & (4.12) \\
\hline \multirow[t]{2}{*}{ EPL_collective } & $-0.108^{\star *}$ & $-0.129^{\star * \star}$ & 0.173 & -0.025 & -0.058 & 0.154 \\
\hline & $(0.05)$ & $(0.05)$ & $(0.46)$ & $(0.08)$ & $(0.06)$ & $(0.55)$ \\
\hline \multirow[t]{2}{*}{ EPL_individual } & $-0.377^{* *}$ & $-0.371^{* * *}$ & -0.321 & $-0.725^{\star * *}$ & $-0.664^{* * *}$ & 0.437 \\
\hline & $(0.15)$ & $(0.12)$ & $(0.45)$ & $(0.19)$ & $(0.15)$ & $(0.51)$ \\
\hline \multirow[t]{2}{*}{$\%$ EMP by MNE } & $0.491^{* \star *}$ & 0.210 & -0.027 & $0.462^{*}$ & $0.559^{\star *}$ & 0.222 \\
\hline & $(0.16)$ & $(0.16)$ & $(0.15)$ & $(0.26)$ & $(0.24)$ & $(0.23)$ \\
\hline \multirow[t]{2}{*}{ LUMPY } & $0.026^{* * *}$ & 0.000 & 0.000 & $0.075^{\star \star *}$ & 0.000 & 0.000 \\
\hline & $(0.01)$ & (.) & (.) & $(0.01)$ & (.) & (.) \\
\hline \multirow[t]{2}{*}{ TFPva_I } & 0.004 & -0.005 & -0.004 & 0.007 & -0.000 & 0.001 \\
\hline & $(0.00)$ & $(0.00)$ & $(0.00)$ & $(0.01)$ & $(0.00)$ & $(0.00)$ \\
\hline Country FE & No & No & Yes & No & No & Yes \\
\hline Industry FE & No & Yes & Yes & No & Yes & Yes \\
\hline Year FE & Yes & Yes & Yes & Yes & Yes & Yes \\
\hline Time Period & $2003-2014$ & $2003-2014$ & $2003-2014$ & $2003-2014$ & $2003-2014$ & $2003-2014$ \\
\hline No. Ctry & 12 & 12 & 12 & 12 & 12 & 12 \\
\hline No. Industry & 25 & 25 & 25 & 25 & 25 & 25 \\
\hline Observations & 3196 & 3196 & 3196 & 3196 & 3196 & 3196 \\
\hline R-squared_a & 0.08 & 0.17 & 0.18 & 0.17 & 0.27 & 0.30 \\
\hline
\end{tabular}

Note: Robust standard errors are in parenthesis. ***,**, and * denote statistical significance at the $.01, .05$, and .10 levels, respectively. The dependent variable is $\log (\mathrm{ML}+1)$. Results are obtained using OLS regression, weighted by total employment. This table reports the results obtained from regressions focus on specific types of mass-layoff events: dismissals resulting from offshoring and those resulting from firm closure. While results are broadly in line with the main regression results, interpretation of the results presented in this table should be cautions because of the lower share of non-zero observations for the dependent variable.

Source: OECD calculations. 
Table C.4. Additional regression results

\begin{tabular}{|c|c|c|c|c|c|c|c|c|}
\hline Total ML & 1 - Tech & 2 - Robot & 3 - Unions & 4 - Med/Large & 5 - Tech & 6 - Robot & 7 - Unions & $8-$ Med/Large \\
\hline \multirow[t]{2}{*}{ ICT } & & -0.277 & -0.101 & -0.067 & & -0.609 & -0.407 & -0.354 \\
\hline & & $(0.39)$ & $(0.20)$ & $(0.21)$ & & $(0.51)$ & $(0.31)$ & $(0.30)$ \\
\hline \multirow[t]{2}{*}{ GLOBAL } & $0.017^{*}$ & -0.020 & $0.017^{\star *}$ & $0.017^{* *}$ & 0.003 & $-0.034^{* *}$ & 0.002 & 0.003 \\
\hline & $(0.01)$ & $(0.01)$ & $(0.01)$ & $(0.01)$ & $(0.01)$ & $(0.01)$ & $(0.01)$ & $(0.01)$ \\
\hline \multirow[t]{2}{*}{ GLOBAL_backward } & $0.038^{* * *}$ & 0.004 & $0.041^{* * *}$ & $0.044^{* * *}$ & 0.019 & -0.017 & 0.021 & $0.027^{\star}$ \\
\hline & $(0.01)$ & $(0.02)$ & $(0.01)$ & $(0.01)$ & $(0.02)$ & $(0.01)$ & $(0.01)$ & $(0.02)$ \\
\hline \multirow[t]{2}{*}{ EMP growth } & $-44.135^{\star \star \star}$ & $-35.235^{\star \star \star}$ & $-43.917^{\star \star \star}$ & $-44.386^{* \star *}$ & $-45.156^{\star \star \star}$ & $-33.067^{\star \star *}$ & $-40.212^{\star \star \star}$ & $-40.625^{\star \star *}$ \\
\hline & $(10.02)$ & $(10.45)$ & $(9.13)$ & $(8.98)$ & $(8.91)$ & $(9.26)$ & $(7.81)$ & $(7.71)$ \\
\hline \multirow[t]{2}{*}{ EPL_collective } & -0.080 & -0.269 & $-0.374^{\star \star *}$ & $-0.332^{\star \star *}$ & 0.101 & -0.198 & $-0.277^{\star *}$ & $-0.250^{*}$ \\
\hline & $(0.16)$ & $(0.20)$ & $(0.12)$ & $(0.12)$ & $(0.18)$ & $(0.21)$ & $(0.13)$ & $(0.13)$ \\
\hline \multirow[t]{2}{*}{ EPL_individual } & $-0.689^{\star \star \star}$ & -0.252 & $-0.629^{* *}$ & $-0.559^{\star *}$ & -0.269 & 0.123 & -0.157 & -0.122 \\
\hline & $(0.24)$ & $(0.34)$ & $(0.25)$ & $(0.24)$ & $(0.28)$ & $(0.35)$ & $(0.27)$ & $(0.27)$ \\
\hline \multirow[t]{2}{*}{$\%$ EMP by MNE } & $2.360^{\star \star \star}$ & $3.096^{\star \star \star}$ & $2.234^{\star * *}$ & $2.281^{\star \star \star}$ & $2.619^{* * *}$ & $3.193^{\star * \star}$ & $2.518^{\star \star \star}$ & $2.691^{\star \star *}$ \\
\hline & $(0.38)$ & $(0.59)$ & $(0.36)$ & $(0.37)$ & $(0.47)$ & $(0.66)$ & $(0.44)$ & $(0.44)$ \\
\hline \multirow[t]{2}{*}{ LUMPY } & $0.138^{\star \star *}$ & $0.086^{\star * \star}$ & $0.137^{\star \star \star}$ & $0.134^{\star \star *}$ & $0.142^{\star * *}$ & $0.074^{\star \star \star}$ & $0.136^{\star \star \star}$ & $0.130^{\star \star \star}$ \\
\hline & $(0.02)$ & $(0.02)$ & $(0.02)$ & $(0.02)$ & $(0.02)$ & $(0.03)$ & $(0.02)$ & $(0.02)$ \\
\hline \multirow[t]{2}{*}{ TFPva_I } & $0.021^{* *}$ & $0.023^{*}$ & $0.017^{\star *}$ & $0.018^{\star *}$ & $0.017^{*}$ & 0.015 & 0.012 & 0.013 \\
\hline & $(0.01)$ & $(0.01)$ & $(0.01)$ & $(0.01)$ & $(0.01)$ & $(0.01)$ & $(0.01)$ & $(0.01)$ \\
\hline \multirow[t]{2}{*}{ ICTcap } & -0.480 & & & & -0.511 & & & \\
\hline & $(0.32)$ & & & & $(0.47)$ & & & \\
\hline \multirow[t]{2}{*}{ Robot } & & $-0.555^{*}$ & & & & -0.667 & & \\
\hline & & $(0.30)$ & & & & $(0.53)$ & & \\
\hline \multirow[t]{2}{*}{ Robot (t-1) } & & -0.251 & & & & 0.073 & & \\
\hline & & $(0.26)$ & & & & $(0.47)$ & & \\
\hline \multirow[t]{2}{*}{ Robot (t-2) } & & $-0.391^{*}$ & & & & $-0.816^{\star \star}$ & & \\
\hline & & $(0.21)$ & & & & $(0.37)$ & & \\
\hline \multirow[t]{2}{*}{ TUD } & & & $-0.933^{*}$ & & & & $-1.330^{\star *}$ & \\
\hline & & & $(0.55)$ & & & & $(0.63)$ & \\
\hline \multirow[t]{2}{*}{$\%$ EMP Med/Large } & & & & -0.005 & & & & $-0.012^{* *}$ \\
\hline & & & & $(0.01)$ & & & & $(0.01)$ \\
\hline \multirow[t]{2}{*}{ Govt foreign } & & & & & $2.794^{*}$ & $3.042^{* *}$ & $3.122^{* *}$ & $3.013^{\star *}$ \\
\hline & & & & & $(1.48)$ & $(1.46)$ & (1.39) & $(1.38)$ \\
\hline \multirow[t]{2}{*}{ Govt domest } & & & & & 0.798 & -0.173 & 0.804 & 0.594 \\
\hline & & & & & $(0.94)$ & $(0.88)$ & $(0.88)$ & $(0.90)$ \\
\hline Country FE & No & No & No & No & No & No & No & No \\
\hline Industry FE & No & No & No & No & No & No & No & No \\
\hline Year FE & Yes & Yes & Yes & Yes & Yes & Yes & Yes & Yes \\
\hline Time periof & 2003-2014 & $2004-2014$ & 2003-2014 & 2003-2014 & $2009-2014$ & $2009-2014$ & $2009-2014$ & 2009-2014 \\
\hline No. Ctry & 11 & 12 & 12 & 12 & 11 & 12 & 12 & 12 \\
\hline No. Industry & 25 & 13 & 25 & 25 & 24 & 13 & 24 & 24 \\
\hline Observations & 2911 & 1156 & 3196 & 3196 & 1198 & 649 & 1313 & 1313 \\
\hline R-squared_a & 0.24 & 0.15 & 0.24 & 0.24 & 0.24 & 0.18 & 0.24 & 0.24 \\
\hline
\end{tabular}

Note: The dependent variable is $\log (\mathrm{ML}+1)$. Results are obtained using OLS regression, weighted by total employment. This table reports the results obtained from regressions that use different indicators. Columns 1 and 4 report the results of regressions replacing the contribution of ICT services to value-added by an indicator of ICT capital stock - the number of economies included in these regressions is reduced to 11 due to data availability. Columns 2 and 5 report the results of regressions that take into account the stock of robots - the robot stock variable is included in lagged values to check whether any effects would be delayed in time, but results do not differ from regressions with contemporaneous values. Robot data are only available for manufacturing services. Columns 3 and 6 report the results of regressions that further control for trade union density. Columns 4 and 8 report the results of regressions that control for the share of employment in companies with more than 100 employees.

Source: OECD calculations. 
Table C.5. Additional regression results (trade)

\begin{tabular}{|c|c|c|c|c|c|c|c|c|c|c|c|c|}
\hline Total ML & 1 - IM_intens & 2 - IM_intens & 3 - IM_intens & 4 - IM_intens & 5 - IM_intens & 6 - IM_intens & 7 - Inputs & 8 - Inputs & 9 - Inputs & 10 - Inputs & 11 - Inputs & 12 - Inputs \\
\hline \multirow[t]{2}{*}{ ICT } & -0.176 & -0.249 & $-0.277^{*}$ & -0.401 & $-0.469^{*}$ & -0.393 & -0.073 & -0.192 & -0.245 & -0.343 & -0.402 & -0.366 \\
\hline & $(0.20)$ & $(0.17)$ & $(0.16)$ & $(0.30)$ & $(0.26)$ & $(0.25)$ & $(0.21)$ & $(0.17)$ & $(0.16)$ & $(0.31)$ & $(0.27)$ & $(0.26)$ \\
\hline \multirow[t]{2}{*}{ EMP growth } & $-48.311^{\star \star \star}$ & $-22.266^{\star \star \star}$ & $-20.236^{\star \star \star}$ & $-47.749^{\star \star *}$ & $-24.528^{\star \star *}$ & $-24.244^{\star \star \star}$ & $-40.530^{\star \star \star}$ & $-20.708^{\star \star *}$ & $-19.519^{\star \star *}$ & $-37.471^{\star \star \star}$ & $-19.598^{\star \star *}$ & $-20.467^{\star \star \star}$ \\
\hline & $(10.23)$ & $(6.15)$ & $(5.25)$ & (7.64) & $(5.17)$ & $(4.98)$ & $(8.39)$ & $(6.05)$ & $(5.28)$ & $(7.86)$ & $(5.34)$ & $(5.15)$ \\
\hline \multirow[t]{2}{*}{ EPL_collective } & $-0.355^{\star \star \star}$ & $-0.325^{\star \star \star}$ & -0.124 & $-0.266^{* *}$ & $-0.249^{\star \star *}$ & -1.326 & $-0.353^{\star * *}$ & $-0.330^{* * *}$ & -0.318 & $-0.244^{*}$ & $-0.238^{* *}$ & -1.615 \\
\hline & $(0.12)$ & $(0.07)$ & $(0.66)$ & $(0.13)$ & $(0.09)$ & $(1.00)$ & $(0.12)$ & $(0.08)$ & $(0.67)$ & $(0.13)$ & $(0.10)$ & (1.01) \\
\hline \multirow[t]{2}{*}{ EPL_individual } & $-0.511^{* *}$ & $-0.756^{\star * *}$ & $-1.388^{*}$ & -0.158 & $-0.406^{\star *}$ & 1.444 & $-0.568^{* *}$ & $-0.699^{* * *}$ & $-1.315^{*}$ & -0.175 & $-0.339^{*}$ & 1.598 \\
\hline & $(0.24)$ & $(0.15)$ & $(0.74)$ & $(0.27)$ & $(0.18)$ & $(1.18)$ & $(0.25)$ & $(0.17)$ & $(0.77)$ & $(0.28)$ & $(0.19)$ & (1.23) \\
\hline$\%$ EMP by MNE & $(0.37)$ & $(0.30)$ & $(0.29)$ & $(0.43)$ & $(0.40)$ & $(0.39)$ & $(0.38)$ & $(0.33)$ & $(0.31)$ & $(0.48)$ & $(0.44)$ & $(0.42)$ \\
\hline \multirow[t]{2}{*}{ LUMPY } & $0.124^{* \star *}$ & 0.000 & 0.000 & $0.102^{* * *}$ & 0.000 & 0.000 & $0.143^{\star \star *}$ & 0.000 & 0.000 & $0.150^{\star \star *}$ & 0.000 & 0.000 \\
\hline & $(0.02)$ & (.) & (.) & $(0.02)$ & (.) & (.) & $(0.02)$ & (.) & (.) & $(0.02)$ & (.) & (.) \\
\hline \multirow[t]{2}{*}{ TFPva_I } & $0.021^{\star \star *}$ & -0.007 & -0.002 & $0.017^{*}$ & -0.006 & 0.001 & $0.014^{*}$ & -0.007 & -0.004 & 0.012 & -0.007 & -0.003 \\
\hline & $(0.01)$ & $(0.01)$ & $(0.01)$ & $(0.01)$ & $(0.01)$ & $(0.01)$ & $(0.01)$ & $(0.01)$ & $(0.01)$ & $(0.01)$ & $(0.01)$ & $(0.01)$ \\
\hline \multirow[t]{2}{*}{ Govt foreign } & & & & $4.844^{\star \star \star}$ & $3.497^{* *}$ & $3.459^{* *}$ & & & & 2.091 & $3.348^{* *}$ & $3.236^{* *}$ \\
\hline & & & & $(1.36)$ & $(1.43)$ & $(1.42)$ & & & & (1.46) & $(1.44)$ & $(1.43)$ \\
\hline \multirow[t]{2}{*}{ Govt domest } & & & & 0.845 & -0.365 & -0.254 & & & & 0.360 & -0.281 & -0.200 \\
\hline & & & & $(0.86)$ & $(0.88)$ & $(0.80)$ & & & & $(0.90)$ & $(0.90)$ & $(0.83)$ \\
\hline
\end{tabular}


70 | STRUCTURAL ADJUSTMENT, MASS LAY-OFFS AND EMPLOYMENT REALLOCATION

Table C.5. Additional regression results (trade) [continued]

\begin{tabular}{|c|c|c|c|c|c|c|c|c|c|c|c|c|}
\hline Total ML & 1-IM_intens & 2-IM_intens & 3 - IM_intens & 4 - IM_intens & 5 - IM_intens & 6 - IM_intens & 7 - Inputs & 8 - Inputs & 9 - Inputs & 10 - Inputs & 11 - Inputs & 12 - Inputs \\
\hline \multirow{2}{*}{ GLOBAL_backward } & $0.044^{* * *}$ & $0.055^{* * *}$ & $0.018^{* * *}$ & $0.041^{* * *}$ & $0.058^{* * *}$ & $0.016^{*}$ & $0.044^{\star * \star}$ & $0.049^{* * *}$ & $0.013^{*}$ & $0.029^{\star}$ & $0.046^{* \star *}$ & 0.007 \\
\hline & $(0.01)$ & $(0.01)$ & $(0.01)$ & $(0.01)$ & $(0.01)$ & $(0.01)$ & $(0.01)$ & $(0.01)$ & $(0.01)$ & $(0.01)$ & $(0.01)$ & $(0.01)$ \\
\hline \multirow[t]{2}{*}{ TRD-IM_intensity } & $-0.479^{\star \star}$ & $-1.333^{\star \star *}$ & $-1.171^{\star \star *}$ & $-1.040^{\star \star \star}$ & $-1.209^{\star \star \star}$ & $-1.115^{\star \star \star}$ & & & & & & \\
\hline & $(0.22)$ & $(0.23)$ & $(0.23)$ & $(0.23)$ & $(0.29)$ & $(0.24)$ & & & & & & \\
\hline \multirow[t]{2}{*}{ TRD-Interm_inputs } & & & & & & & $2.505^{\star \star \star}$ & $-2.506^{\star * *}$ & -0.496 & 1.218 & $-2.609^{\star \star \star}$ & -0.347 \\
\hline & & & & & & & $(0.71)$ & $(0.75)$ & $(0.94)$ & $(0.83)$ & $(0.92)$ & $(1.21)$ \\
\hline Country FE & No & No & Yes & No & No & Yes & No & No & Yes & No & No & Yes \\
\hline Industry FE & No & Yes & Yes & No & Yes & Yes & No & Yes & Yes & No & Yes & Yes \\
\hline Observations & 3196 & 3196 & 3196 & 1313 & 1313 & 1313 & 3072 & 3072 & 3072 & 1258 & 1258 & 1258 \\
\hline R-squared_a & 0.24 & 0.43 & 0.47 & 0.26 & 0.45 & 0.48 & 0.23 & 0.41 & 0.45 & 0.22 & 0.43 & 0.46 \\
\hline
\end{tabular}

Note: The dependent variable is $\log (\mathrm{ML}+1)$. Results are obtained using standard OLS regression, weighted by total employment. Columns 1-6 report the results of regressions replacing the foreign value-added share of exports (GLOBAL) by the import intensity measured as the share of gross imports on gross output (TRD-IM intensity). Columns 7-12 report the results of regressions replacing the foreign value-added share of exports (GLOBAL) by the share of imported intermediate inputs on total intermediate inputs (TRD-Interm_inputs). The year, country, industry coverage is the same as described in Table C.1 above. 
Table C.6. Analysis at regional (NUTS2) level

Ordinary least square (OLS) regressions

\begin{tabular}{|c|c|c|c|c|c|c|c|c|c|}
\hline & (1) & (2) & (3) & (4) & (5) & (6) & (7) & (8) & (9) \\
\hline VARIABLES & \multicolumn{9}{|c|}{ Total number of ML dismissals } \\
\hline \multirow{2}{*}{ Manuf. share } & $6.650^{\star \star *}$ & & & & $5.965^{\star \star *}$ & & & & $5.521^{\star \star *}$ \\
\hline & $(1.602)$ & & & & $(1.555)$ & & & & $(1.937)$ \\
\hline \multirow[t]{2}{*}{ Unemployment rate } & & -0.0271 & & & & -0.0327 & & & 0.00844 \\
\hline & & $(0.0381)$ & & & & $(0.0395)$ & & & $(0.0362)$ \\
\hline \multirow[t]{2}{*}{ Share pop. 50-64 } & & & $0.119^{* *}$ & & & & $0.117^{* *}$ & & $0.0758^{*}$ \\
\hline & & & $(0.0455)$ & & & & $(0.0501)$ & & $(0.0447)$ \\
\hline \multirow{2}{*}{$\begin{array}{l}\text { Share pop. w/o tertiary } \\
\text { educ. }\end{array}$} & & & & 0.0289 & & & & $0.0404^{*}$ & 0.00902 \\
\hline & & & & $(0.0202)$ & & & & $(0.0232)$ & $(0.0220)$ \\
\hline \multirow[t]{3}{*}{5 year change Manuf. share } & & & & & & & & & \\
\hline & & & & & $20.18^{\star \star *}$ & & & & $17.76^{\star \star *}$ \\
\hline & & & & & $(6.676)$ & & & & $(6.315)$ \\
\hline \multirow{2}{*}{$\begin{array}{l}5 \text { year change } \\
\text { Unemployment rate }\end{array}$} & & & & & & 0.0630 & & & 0.0691 \\
\hline & & & & & & $(0.0460)$ & & & $(0.0438)$ \\
\hline \multirow{2}{*}{$\begin{array}{l}5 \text { year change Share pop. } \\
50-64\end{array}$} & & & & & & & 0.0211 & & -0.0157 \\
\hline & & & & & & & $(0.136)$ & & $(0.136)$ \\
\hline \multirow{2}{*}{$\begin{array}{l}5 \text { year change Share pop. } \\
\text { w/o tertiary educ. }\end{array}$} & & & & & & & & -0.0810 & -0.0785 \\
\hline & & & & & & & & $(0.0549)$ & $(0.0534)$ \\
\hline \multirow[t]{2}{*}{ Log total employment } & $1.691^{* * *}$ & $1.748^{\star * *}$ & $1.760^{\star * \star}$ & $1.795^{\star \star *}$ & $1.642^{\star \star *}$ & $1.745^{\star * *}$ & $1.764^{* * *}$ & $1.796^{\star * \star}$ & $1.650^{\star * *}$ \\
\hline & $(0.129)$ & $(0.125)$ & $(0.125)$ & $(0.135)$ & $(0.127)$ & $(0.123)$ & $(0.134)$ & $(0.134)$ & $(0.128)$ \\
\hline Observations & 1,214 & 1,214 & 1,214 & 1,214 & 1,214 & 1,214 & 1,214 & 1,214 & 1,214 \\
\hline R-squared & 0.531 & 0.520 & 0.525 & 0.521 & 0.536 & 0.522 & 0.525 & 0.523 & 0.540 \\
\hline
\end{tabular}

Note: All regressions included country-year fixed effects. Standard errors clustered at region level. The economies included are Austria, Belgium, Czech Republic, Estonia, Finland, Greece, Hungary, Ireland, Italy, Lithuania, Luxembourg, Latvia, the Netherlands, Poland, Portugal, Spain, Sweden, Slovak Republic and the United Kingdom. 


\section{Annex notes}

33 Since 2011, the ERM also provides a database on national public support instruments for restructuring to assist companies and workers to anticipate and manage restructuring. To date, the database provides qualitative information on almost 350 national schemes.

${ }^{34}$ See http://www.oecd.org/els/emp/onlineoecdemploymentdatabase.htm.

35 The data are available at http://www.globaltradealert.org/data_extraction. See also (Hoekman, $\left.2015_{[51]}\right)$ for an application.

${ }^{36}$ Sectors are originally classified in GTA according to Common Product Classification (CPC, version 2.1) at the 3-digit level and then mapped into ISIC rev.4 industry codes at the 2-digit level. See https://unstats.un.org/unsd/cr/downloads/CPCv2.1_complete\%28PDF\%29_English.pdf.

${ }^{37}$ See http://www.oecd.org/sti/ind/stanstructuralanalysisdatabase.htm

${ }^{38}$ See https://www.oecd.org/sti/ind/STANi4_Industries_ENG.pdf

${ }^{39}$ See https://unstats.un.org/unsd/cr/downloads/CPCv2.1_complete\%28PDF\%29_English.pdf

40 The country variation in the measure of foreign government support results from the fact that for a given country, their domestic interventions are not included. This is particularly useful for econometric purposes as it allows including the domestic measure in the same regression equation.

${ }^{41}$ It is also possible to conduct interval censored survival analysis using non-parametric methods. Using these methods, the event time is imputed by either taking the midpoint of the censored interval or by taking the upper bound of the interval as the event date. For the purposes of our analysis, as the lower bound of each interval is fixed at 0 , this would imply that the hazard rate is dependent on the current tenure of the respondent. A Weibull distribution, with its assumption of a declining hazard rate over time, fits the economic theory of unemployment.

${ }^{42}$ In making an assumption about the distribution of events, the hazard rate is restricted to path defined by the distribution and the fit of the data to that distribution.

44 The exponential is a special case of the Weibull distribution where $\lambda=1$. 